\title{
Inhibitory mechanisms by which suramin \\ may attenuate neointimal formation after balloon angioplasty.
}

\author{
Timothy J. Gray \\ University of Toronto
}

A thesis submitted in conformity with the requirements for the degree of Master of Science, Graduate Department of Cellular and Molecular Pathology, University of Toronto

() Copyright by Timothy J. Gray (1997) 
National Library

of Canada

Acquisitions and

Bibliographic Services

395 Wellington Street

Ottawa ON K1A ON4

Canada
Bibliothèque nationale du Canada

Acquisitions et services bibliographiques

395, rue Wollington

Ottawa ON KIA ON4

Canada
The author has granted a nonexclusive licence allowing the National Library of Canada to reproduce, loan, distribute or sell copies of this thesis in microform, paper or electronic formats.

The author retains ownership of the copyright in this thesis. Neither the thesis nor substantial extracts from it may be printed or otherwise reproduced without the author's permission.
L'auteur a accordé une licence non exclusive permettant à la Bibliothèque nationale du Canada de reproduire, prêter, distribuer ou vendre des copies de cette thèse sous la forme de microfiche/film, de reproduction sur papier ou sur format électronique.

L'auteur conserve la propriété du droit d'auteur qui protège cette thèse. $\mathrm{Ni}$ la thèse ni des extraits substantiels de celle-ci ne doivent être imprimés ou autrement reproduits sans son autorisation. 


\section{ABSTRACT}

The post-procedural development of restenosis remains the major limitation of percutaneous transluminal coronary angioplasty. Neointimal lesion formation, an important characteristic of restenosis, is largely dependent on three properties of activated arterial smooth muscle cells (SMC): proliferation, migration, and abnormal production of extracellular matrix. Suramin, a polysulfonated naphthalurea, is a drug which may bind and sequester many cytokines and heparin-binding growth factors (PDGF, TGF- $B$, aFGF, bFGF, and IGF-1) and effectively inhibit their potential interactions with target cells. Since suramin alters proliferative, migratory, and secretory profiles of several types of cancer cells, we hypothesized that it may also inhibit a growth factor-dependent activation of coronary artery smooth muscle cells (CA SMC). Our pilot in vivo study, which used a single- and double-injury model of arterial restenosis in rabbits, indicated that suramin substantially decreased the rapid neointimal formation observed after experimental balloon injury. Therefore, a series of in vitro studies were aimed at dissecting mechanism(s) underlying this suramin-dependent effect. Results of these investigations demonstrates that suramin inhibits CA SMC proliferation. Suramin also inhibits deposition of fibronectin, a glycoprotein which is over-expressed by activated SMC and facilitates their migration from the media into the intima contributing to intimal thickening. Further in vitro assays showed that suramin inhibits CA SMC migration through pure elastin membranes and into scratch-gaps of monolayer cultures. Searching for the cellular mechanisms of these inhibitory effects we have established that suramin induces cell-surface aggregation of the 67-kD elastin binding protein (EBP), a protein which not only immobilizes cells to the extracellular matrix containing elastin, laminin and collagen type IV, but may also block the adjacent IL-1 type 1 receptors and inhibit the CA SMC response to this cytokine. Overall, the results of this study suggest that suramin acts as a multi-target inhibitor of SMC activation, thus it should be considered and further tested as a potential therapeutic agent that may attenuate intimal thickening and restenosis after angioplasty of atherosclerotic arteries. 


\section{ACKNOWLEDGMENTS}

First, I thank Dr. Aleksander Hinek for his supervision and support of this work and for the valuable experiences and insights into scientific research that I have gained from working with him.

I also wish to thank the many individuals at the Division of Cardiovascular Research at the Hospital for Sick Children who together create a stimulating environment that is ideal for learning and research. I would also like to thank Dr. Bradley Strauss and Dr. Ranga Robinson for their generosity and support during our animal studies and beyond.

I wish to extend many thanks and appreciation to the members of my Graduate Advisory Committee including Dr. Aleksander Hinek, Dr. Tony Cruz, Dr. Marlene Rabinovitch, and Dr. Bradley Strauss for their advice and encouragement throughout this research project. I would also like to thank Dr. Reinhold Vieth for graciously serving as an outside advisor for my thesis defense and also for being an important mentor who has helped uncover my keen interest in science.

I would also like to thank Bayer for their generous gift of suramin. 


\section{TABLE OF CONTENTS}

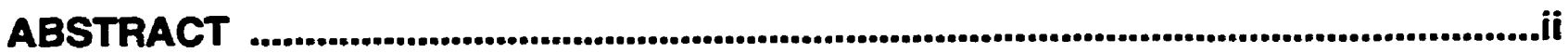

ACKNOWLEDGMENTS.....................................................................................................iii

TABLE OF CONTENTS......................................................................................................

LIST OF FIGURES........................................................................................................................vi

LIST OF ABBREVIATIONS.............................................................................................viii

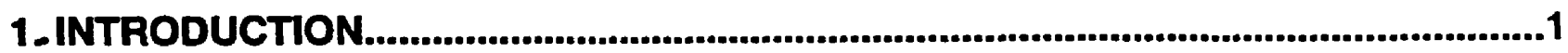

General Introduction.................................................................................................1

Percutaneous Transluminal Coronary Angioplasty.................................................1

Restenosis......................................................................................................................3

Pathogenesis of Restenosis........................................................................................4

Endothelium Denudation.....................................................................................4

Mural Thrombus Formation..............................................................................5

Inflammatory Response...............................................................................6

Smooth Muscle Cells.......................................................................................6

Regulators of Restenosis Pathogenesis...............................................................9

Fibronectin and Intimal Thickening....................................................................13

Elastin Binding Protein and Intimal Thickening......................................................14

Pharmacological Approaches to Restenosis...........................................................17

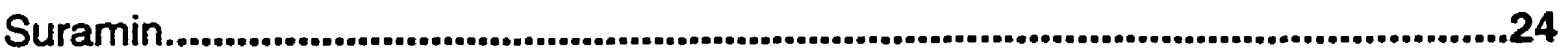

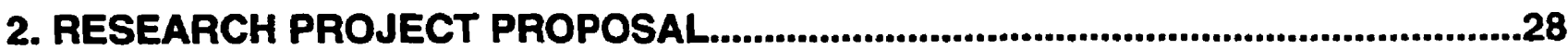

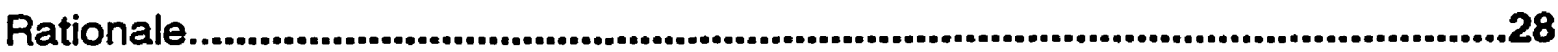

Hypotheses..............................................................................................................29

Specific Objectives...........................................................................................................29

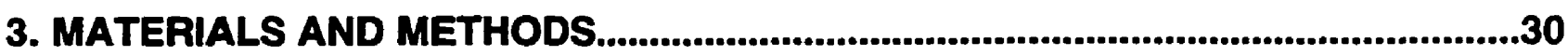

Rabbit Model of Restenosis.......................................................................30

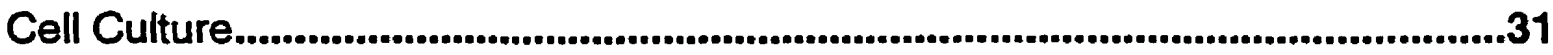

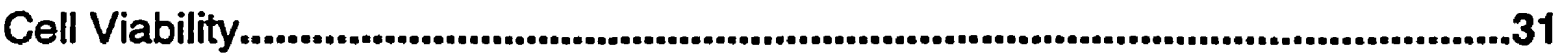

Total Protein Synthesis...................................................................................32

DNA Synthesis........................................................................................................32 


\section{MATERIALS AND METHODS (CONT.)}

Cellular Proliferation....................................................................................................32

CA SMC Migration through Elastin Membranes....................................................33

CA SMC Migration into Scratch Gaps.......................................................................33

CA SMC Migration on Fibronectin-Coated Surfaces................................................35

Immunocytochemistry................................................................................................35

RNA Isolation and Northem Blot Analysis............................................................37

Statistical Analysis......................................................................................................37

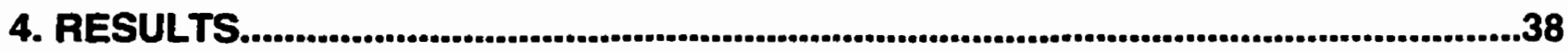

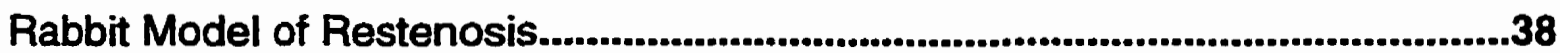

Cell Viability........................................................................................................................38

Total Protein Synthesis...............................................................................................39

DNA synthesis and Cell Proliferation.....................................................................39

CA SMC Migration into Scratch Gaps..................................................................40

CA SMC Migration through Elastin Membranes....................................................41

CA SMC Morphology................................................................................................41

Immunostaining for Fibronectin...............................................................................42

Northem Blot Analysis...................................................................................................42

CA SMC Migration on Fibronectin-Coated Surfaces.............................................43

Immunostaining for Elastin Binding Protein and Fibronectin.................................43 


\section{LIST OF FIGURES}

FIGURE 1. Model of the 67-kD elastin binding protein (EBP). (pp. 15).

FIGURE 2. EBP is a major component of the non-integrin cell surface receptor complex. (pp. 16).

FIGURE 3. Suramin: a polysulfonated naphthylamine derivative of urea. (pp. 25).

FIGURE 4. lliac arteries from control and suramin-treated rabbits after single injury. (pp. 45).

FIGURE 5. lliac arteries from control and suramin-treated rabbits after double injury. (pp. 46).

FIGURE 6. Trypan blue exclusion assay and total protein synthesis of control and suramin-treated CA SMC cultures. (pp. 47).

FIGURE 7. $\left[{ }^{3} \mathrm{H}\right]$-thymidine incorporation assay of control and suramin-treated $\mathrm{CA}$ SMC at different confluencies. (pp. 48).

FIGURE 8. Direct cell counting of control and suramin-treated subconfluent CA SMC after 48 hour and 96 hour incubations. (pp. 49).

FIGURE 9. Control and suramin-treated CA SMC migration after wounding injury. (pp. 50).

FIGURE 10. Migration assay of CA SMC exposed to control conditions or increasing concentrations of suramin for 48 hours after wounding injury. (pp. 51).

FIGURE 11. $\left[{ }^{3} \mathrm{H}\right]$-thymidine incorporation assay of control and hydroxyurea-treated $\mathrm{CA}$ SMC. (pp. 52).

FIGURE 12. $\left[{ }^{3} \mathrm{H}\right]$-thymidine incorporation assay of CA SMC after 24 hour hydroxyurea pre-treatment followed by 48 hour incubation with hydroxyurea and increasing concentrations of suramin. (pp. 53). 
FIGURE 13. Control and suramin-treated CA SMC migration after wounding injury following blockade of cell proliferation with hydroxyurea. (pp. 54).

FIGURE 14. Migration assay of control and suramin-treated CA SMC incubated in hydroxyurea for $\mathbf{4 8}$ hours after wounding injury. (pp. 55).

FIGURE 15. Migration into pure elastin membranes of CA SMC exposed to control conditions, chondroitin sulfate, or chondroitin sulfate and suramin for 7 days. (pp. 56).

FIGURE 16. Immunostaining for fibronectin in control and suramin-treated CA SMC cultures. (pp. 57).

FIGURE 17. Northem blot analysis of fibronectin from total RNA of control and suramintreated CA SMC cultures. (pp. 58).

FIGURE 18. Migration assay of control and suramin-treated CA SMC incubated on plastic or fibronectin-coated dishes. (pp. 59).

FIGURE 19. Immunostaining for focal adhesions in control and suramin-treated CA SMC cultures. (pp. 60).

FIGURE 20. Immunostaining for EBP of control, chondroitin sulfate-treated, and chondroitin sulfate and suramin-treated CA SMC cultures. (pp. 61).

FIGURE 21. Immunostaining for fibronectin in control, chondroitin sulfate-treated, and chondroitin sulfate and suramin-treated CA SMC cultures. (pp. 62). 


\section{LIST OF ABBREVIATIONS}

All

ACE

Atm

bFGF

BSA

CA SMC

Ci

CS

DS

EBP

ECM

EDTA

EGF

FBS

FITC

FN

GAM

GAR

H\&E

[3H]

IGF-1

$I L-1 B$

kD

M199

$\mathrm{NaOH}$

PBS angiotensin II

angiotensin converting enzyme

atmosphere

basic fibroblast growth factor

bovine serum albumin

coronary artery smooth muscle cell

Curie

chondroitin sulfate

dermatan sulfate

elastin binding protein

extracellular matrix

ethylenediaminetetraacetic acid

epidermal growth factor

fetal bovine serum

fluorescein isothiocyanate

fibronectin

goat anti-mouse

goat anti-rabbit

hematoxylin and eosin

tritium

insulin-like growth factor-1

interleukin-1 beta

kilodalton

medium 199

sodium hydroxide

phosphate buffered saline 
PDGF platelet derived growth factor

PTCA percutaneous transluminal coronary angioplasty

RNA ribonucleic acid

mRNA messenger ribonucleic acid

rRNA ribosomal ribonucleic acid

SEM standard error of the mean

SMC smooth muscle cell

TCA trichloroacetic acid

TGF-B transforming growth factor beta

VSMC vascular smooth muscle cells 


\section{INTRODUCTION}

Atherosclerosis develops in the artery wall in response to endothelial and medial smooth muscle injury and involves formation of fibrofatty and fibrous plaques, preceded and accompanied by inflammation (1). Atherosclerotic vascular disease is the principle contributor to the pathogenesis of myocardial and cerebral infarction, gangrene and loss of function of the extremities and is the most common cause of morbidity and mortality in North America, Europe, and Japan (2). Most sudden deaths from myocardial infarction result from rupture or fissure complicated atherosclerotic plaques and exposure of the sub-endothelium, thrombosis, and acute occlusion of the artery (3). The advent of percutaneous coronary balloon angioplasty (PTCA), allowed for more successful treatment of progressive atherosclerosis than medical therapy, without entailing the operative intervention and prolonged recovery required with bypass surgery (4). However, the tendency of arteries to restenose after an initially successful angioplasty limits the long term clinical success of this procedure. Whereas the development of primary atherosclerotic lesions typically occurs over many years and often requires decades before progression to a clinical manifestation such as myocardial infarction, the time course of vessel stenosis after angioplasty is much

more compressed, peaking within 6 months after intervention $(5,6)$. The rapid development of vessel occlusion following angioplasty offers a unique window of opportunity in which adjuvant medical intervention might be used to improve the efficacy of this procedure.

\section{PERCUTANEOUS TRANSLUMINAL CORONARY ANGIOPLASTY}

Coronary angioplasty has been widely used as a non-surgical revascularization procedure for patients with coronary artery disease since it was first introduced into the clinical setting by Andreas Gruentzig in 1979 (7). Percutaneous coronary balloon angioplasty involves the introduction and inflation of a balloon catheter within the 
compromised lumen of a diseased coronary artery. The physical force exerted by the inflated balloon on the artery wall causes distention of the vessel resulting in luminal diameter gain and improved vessel patency through the combination of arterial dissection and expansion (8). As a less invasive and purportedly lower cost alternative to coronary bypass surgery, PTCA enables the cardiologist to rapidly and directly alleviate coronary obstruction with remarkably low rates of mortality and morbidity (4). Although initially employed in patients with stable angina and single vessel disease, clinical use of PTCA has expanded to include treatment of unstable angina, multi-vessel disease, total vessel occlusion, and acute myocardial infarction $(5,6)$. Angioplasty is also employed as an adjuvant procedure following coronary atherectomy to allow for further increases in lumen area gain (9).

Currently, 300,000 PTCA procedures are performed annually in the United States with an overall in-hospital success rate in excess of $90 \%$ (4). The complications of balloon angioplasty most commonly responsible for unsuccessful clinical outcomes are rapid and chronic occlusion of the reopened arteries. Rapid closure of a distended coronary vessel is estimated to occur in 2 to $11 \%$ of patients and can often lead to myocardial infarction, the need for emergency bypass surgery, or even death (6). Acute closure is most often observed within six hours after intervention and results primarily as a consequence of vasospasm and the elastic properties of vascular walls reacting to the over-stretching induced by balloon inflation. Sub-endothelial hemorrhage and abundant thrombosis, also play a role in the majority of cases of acute lumen loss (4). Fortunately, progress in procedural techniques, peri-procedural pharmacological intervention, and the use of intravascular stents has allowed for effective reversal in an estimated half of these cases of acute occlusion $(10,11,12)$.

Despite reductions in the rates of acute complications, post-procedural development of chronic vessel occlusion, or restenosis, has been largely unaffected and remains the major limitation to PTCA $(13,14)$. Restenosis has been defined as a loss of at least $50 \%$ of the gain from PTCA, or as an increase of at least $30 \%$ in 
occlusive diameter from the immediate post-procedure stenosis upon follow-up angiography (15). Alternatively, restenosis has been characterized clinically by recurrent ischemic symptoms within 6 months after angioplasty (6). In addition to the repeat diagnostic and therapeutic catheterizations made necessary by restenosis, its marked prevalence, currently estimated to occur in 35 to $50 \%$ of angioplasty patients, and cost (estimated at $\$ 1.5$ billion per year in the United States alone), clearly compromise the long-term benefits of PTCA $(16,17)$. Accordingly, extensive research efforts, aimed at better understanding the pathophysiology of restenosis and devising effective adjuvant therapies that may increase the long-term efficacy of PTCA, have been put forth in recent years.

\section{RESTENOSIS}

Healthy arteries typically consist of three layers, the tunica intima, tunica media, and tunica adventia. The thin intimal layer (tunica intima), comprising endothelial cells resting on a basement membrane, contains little extracellular matrix and sparse smooth muscle cells (SMC) attached to the internal elastic lamina separating the intima and media. The tunica media, consists of several layers of contractile SMC attached to highly organized elastic laminae surrounded by proteoglycans, fibronectin, and thin collagen fibrils. The tunica adventitia, bordered by the external elastic laminae, contains mostly fibroblasts and few SMC which build a mostly fibrous extracellular matrix rich in collagen with only few elastic fibers (18). In restenosis, as a result of the trauma exerted by balloon inflation, profound structural changes occur in the vascular wall.

Observations from human pathologic and autopsy tissue after angioplasty and studies that examined healing responses after arterial injury in animal models of restenosis, have allowed a better understanding of the biology of restenosis. These investigations demonstrate that the neointimal thickening which develops in vessels after experimental balloon injury is also a major cause of restenosis after PTCA. This 
adaptive response of neointimal formation is characterized by extracellular matrix (ECM) degradation, fragmentation of the elastin framework, and deposition of new matrix molecules accompanied by medial SMC migration into the sub-endothelium and subsequent proliferation resulting in a thickened intima and a narrowed lumen $(5,19)$. Although primary atherosclerotic lesions appear hypocellular, consisting predominantly of well-organized ECM, restenotic lesions typically include a focus of hypercellularity consisting of proliferative SMCs and a surrounding extracellular matrix that is generally less well organized and compact (20). Multiple factors mediate neointimal thickening including endothelial cells, smooth muscle cells, inflammatory cells and platelet responses to several growth factors, hormonal factors, and mechanical forces.

\section{PATHOGENESIS OF RESTENOSIS}

\section{Endothelium Denudation}

In addition to its well established role in regulating vessel tone and platelet aggregation, the endothelium of intact vessels helps maintain SMC quiescence through the production of growth inhibitory mediators such as heparin sulfate and nitric oxide $(21,22)$. An invariable occurrence after balloon injury however, is denudation of the endothelium which results in exposure of the sub-endothelium to flowing blood. Re-endothelialization of the vessel, involving endothelial migration and proliferation, begins within 24 hours after experimental arterial injury and generally ceases 6 to 10 weeks later depending on the animal species (23). The success of this endothelial regeneration depends on the severity of the initial injury. While complete reendothelialization can be achieved after small denuding injuries, endothelial cells have been found to be incapable of sustained regrowth after extensive vessel damage $(24,25,26)$. Even if complete re-endothelialization occurs, the regenerated endothelium often displays abnormal morphological and functional characteristics. 
Endothelial loss and/or dysfunction compromises the regulation of vessel tone and may remove essential inhibitory signals to SMC proliferation. In animal models of minimal vascular injury, where rapid endothelial re-growth occurs, little or no intimal hyperplasia is observed (27). Conversely, in areas of extensive denudation, often left permanently uncovered by endothelium, significant intimal thickening occurs (28). Incomplete re-endothelialization remains a major contributing factor in restenosis. However, in chronically denuded areas, intimal hyperplasia peaks at 8 weeks and remains the same without increasing in cellularity or thickness for up to 1 year after injury (29). This suggests that endothelial cells are not the sole modulators of neointimal formation.

\section{Mural Thrombus Formation}

With the highly thrombotic subendothelium exposed and a lack of functional endothelium and its anti-thrombotic functions, marked and rapid platelet adhesion and aggregation occur followed by the release of their alpha granules within a few minutes after injury (30). Constituents of alpha granules include serotonin, and thromboxane A2, both potent stimuli for vasoconstriction and further platelet aggregation (31) in addition, fibrinogen, and the extracellular matrix glycoprotein fibronectin are also released (32). Numerous mitogenic substances including platelet-derived growth factor (PDGF), released at the site of injury, may also be involved in the process of SMC activation (33). Additionally, platelets secrete endoglycosidase and other heparin-neutralizing factors which may release SMCs from growth inhibition and render them susceptible to further stimulation by PDGF (19). Moreover, platelet degranulation may result in chronically generated thrombin at the site of injury where it becomes tightly bound to the arterial ECM and remains actively thrombotic (34).

The extent of vascular injury and hemorheologic factors such as elevated shear stress are thought to facilitate platelet adherence and thrombus formation (35). Autopsy studies and hypercholesterolemic rabbit injury models indicate that 
atheromatous plaques that are high in lipid content also stimulate thrombus formation during restenosis $(36,37)$. The importance of platelets and thrombus formation in neointimal formation can be illustrated in thrombocytopenic rabbits subjected to balloon injury which show significantly less intimal thickening compared to control animals with normal platelet counts (38).

\section{Inflammatory Response}

Within hours after balloon injury, circulating leukocytes and mononuclear cells, particularly macrophages, respond to the induction of pro-inflammatory signals from damaged endothelial cells at the areas of injury, and undergo direct adhesion and chemotaxis into the damaged vasculature $(39,40)$. Their numbers increase over the first few days after injury and they secrete, growth factors, and cytokines capable of further stimulating platelet aggregation, as well as SMC proliferation, migration, and matrix production (6). The ability to inhibit neointimal formation in animals by blocking monocyte chemotactic proteins in addition to observations from atherectomy tissue obtained after PTCA describing a prevalence of macrophages, suggests an important role for inflammation in restenosis (41).

\section{Smooth Muscle Cells}

Normal vessels are predominantly comprised of contractile SMCs. These quiescent medial SMCs with numerous myofilaments provide both vasomotion and structural support to the vessel and are generally unresponsive to growth factors (42). Immediately following arterial injury with a balloon catheter however, multiple factors lead to the activation of these cells. Early markers of SMC activation such as expression of nuclear oncogenes, are detectable as soon as 30 minutes after injury $(43,44)$. Recent success in using antisense oligonucleotides to the nuclear oncogenes c-myb and c-myc to inhibit neointimal thickening in animal models of 
vascular injury, suggests that this early phase of SMC activation is an integral component in the development of neointimal hyperplasia $(45,46)$.

Upon activation, medial SMCs begin to proliferate and migrate to the subendothelial space where they undergo further cycles of cell proliferation. Analysis of restenotic lesions retrieved by atherectomy suggests that SMC proliferation, detected in $15 \%$ to $20 \%$ of cells, is higher than in primary atherosclerotic lesions (47). Proliferation of medial SMCs is evident within 24 hours after experimental balloon injury, observed predominantly around the circumference of the lumen and in the tears created by balloon injury, reaches a peak at 1 week and then declines markedly by 2 weeks (48). Occurring in nearly $100 \%$ of patients following PTCA, SMC proliferation is believed to play an integral role in the development of restenosis (49). However, reports suggest that proliferation is not a prominent feature of restenosis and that SMC migration is responsible for much of the cellular accumulation observed in the neointimal lesion (50). Activated SMCs migrate through breaks in the intemal elastic lamina into the intima which is normally devoid of SMC. Electron microscopy of human pathological restenotic lesions reveals that SMC stretching and migration through fenestrations in the internal elastic lamina occur within 1 to 6 days after PTCA (51). Regulation of SMC migration during restenosis, although incompletely understood, is believed to be complex and multi-factorial.

As SMCs proliferate and migrate from the media into the intima they assume a synthetic phenotype closely resembling fibroblasts with abundant synthetic organelles including Golgi, free ribosomes, and rough endoplasmic reticulum $(42,52)$. Once in the intima these SMC begin to produce large amounts of collagen, elastin, and several types of glycoproteins including fibronectin, vitronectin, as well as several proteoglycans including chondroitin sulfate, hyaluronic acid, dermatan sulfate, heparin sulfate, biglycan, and decorin (40). Fibrous bundles of type I collagen and elastin ultimately comprise nearly $90 \%$ of the volume of the neointimal lesion (53). These ECM proteins can affect the fate of neointimal lesions by modulating cell migration, 
and the activity of growth factors (54). Adventitial fibroblasts may also proliferate and migrate to the intima where they synthesize collagen (55).

Experimental balloon injury is followed by a marked increase in expression of genes that encode matrix proteins such as collagens and elastin in the arterial wall (56). In a double injury model of restenosis in the rabbit iliac artery Strauss et al (57) demonstrated significant increases in synthesis of ECM proteins, collagen, elastin, and sulfated GAGs peaking at 1 to 2 weeks that remained at this level by 4 weeks and decreased towards baseline by 12 weeks. Also evident in this model was a delayed accumulation of collagen and elastin, suggesting that degradation of newly synthesized proteins is particularly prominent in the first few weeks following injury and that turnover of matrix proteins may significantly impact the subsequent development of the neointimal lesion.

In animal models, the degree of intimal thickening is maximal after 3 months (58). Angioscopic and angiographic observations, as well as pathological evidence obtained at autopsy or after atherectomy, indicate that restenosis in humans also peaks between 1 and 3 months after angioplasty depending on the magnitude of the initial injury $(14,55)$. These studies also demonstrate that nearly all vessels deteriorate to some extent after angioplasty suggesting restenosis is not simply an undesirable side effect that occurs in a minority of cases but rather a process of healing and remodeling that results from balloon injury and occurs to some extent in virtually all patients. Upon re-endothelialization at approximately ten days after injury, cells begin to secrete heparin proteoglycan and other inhibitory mediators of SMC proliferation (19). Additional increases in vessel wall thickness that occur after the initial SMC proliferative phase, appear to reflect the adjunctive synthesis of ECM by synthetic SMC. After 2 to 3 months, SMCs retum to a contractile phenotype and no further significant increase in intimal thickening occurs (59). Generally after 2 years, evidence of angioplasty is unidentifiable, and lesions are almost indistinguishable from conventional atherosclerotic plaques (49). 


\section{REgULATORS OF RESTENOSIS PATHOGENESIS}

As evident from extensive investigation into vessel responses after angioplasty in humans or experimental balloon injury in animals, restenosis is clearly a multifactorial process.

The degree of mechanical force exerted and medial injury caused by balloon inflation appears to play a role in determining the extent of restenotic lesion development. Instances of endothelial denudation without significant vessel damage result in a mild neointimal thickening even when there is delayed endothelial regeneration (260). In contrast, focal endothelial denudation with substantial medial trauma, often involving rupture of the internal elastic lamina, is associated with marked neointimal formation despite rapid endothelial regeneration (61). These observations suggest that endothelial dysfunction alone is not sufficient to cause extensive intimal thickening. Direct trauma to medial SMCs may induce a greater response by increasing local release of growth factors from damaged cells and by direct induction of proliferative pathways in the remaining viable cells (40).

Coagulative factors are also thought to regulate cellular responses during intimal thickening. Thrombin is mitogenic towards SMCs and is capable of inducing multiple growth-related signals in SMCs including the expression of c-fos protooncogene (62). The platelet product serotonin, in addition to its stimulatory effect on platelet activation and vasoconstriction, has also been shown to have direct mitogenic effects on SMCs during restenosis (63). The extent of thrombus formation at the site of injury may also play a role in the subsequent restenotic process by serving as a scaffold that ultimately determines the volume of the neointima (64).

Growth factors play a major role in the response of SMCs to balloon injury. Although platelets are a major source of PDGF, endothelial cells, macrophages, and SMCs themselves also secrete PDGF after arterial injury (65-68). Platelet derived growth factor-AA, initially released from alpha granules of platelets, and PDGF-BB, 
produced later by a variety of cells present in the vessel wall, are potent stimulators of SMC proliferation (69). Along with synergistic effects with other mitogens, PDGF is thought to induce SMC entry into the cell cycle, after which SMCs begin to secret de novo PDGF and other mitogens further perpetuating proliferation beyond the phase of platelet deposition (70). Intimal SMCs from injured rat arteries secrete 5-fold greater amounts of PDGF activity (42) and increased PDGF expression after balloon injury of pre-existing vascular lesions in baboons corresponds to the extent of SMC proliferation (71). Although implicated in SMC mitogenesis, many studies suggest PDGF may be a more critical mediator of SMC migration. For instance, in experimental injury models of restenosis, neointimal thickening and SMC migration can be significantly increased upon PDGF administration while antibodies to PDGF reduce neointimal SMC accumulation without affecting mitogenic activity (72).

Basic fibroblast growth factor (bFGF), a growth factor that is generated at site of injury, is thought to be mitogenic for SMCs as well as endothelial cells and may also play a role in restenosis (73). Vessel stretching after balloon inflation, is thought to liberate bFGF from cells resulting in local increases of this growth factor that stimulate the initial waves of cellular proliferation. Serum leaking through damaged endothelium at the site of injury might also allow for elastase-mediated release of bFGF from the ECM (74). In animal models of restenosis, infusion of bFGF accelerates endothelial regrowth but also enhances SMC proliferation $(75,76)$. Conversely, infusion of antibodies to bFGF can reduce initial instances of SMC proliferation by $80 \%$ in the arterial media after balloon denudation but demonstrates no effect on the resulting neointimal formation (77).

Additional growth factors that have been implicated in the development of restenosis include transforming growth factor beta (TGF-B), insulin-like growth factor type 1 (IGF-1), and tumor necrosis factor alpha (TNF- $\alpha$ ). Transforming growth factor- $\beta$ has been demonstrated to modulate fibronectin expression and may be important in the control of ECM protein synthesis $(78,79,80)$. TGF- $B$ is produced by SMCs, 
platelets, and endothelial cells and its mRNA is increased in SMCs after arterial wall injury and reaches a maximum immediately prior to the phase of ECM synthesis $(81,82)$. Infusion of TGF-B after experimental injury, stimulates a 20 -fold increase in synthesis of chondroitin sulfate; a predominant ECM proteoglycan of early intimal hyperplasia (83). Furthermore, transfection of TGF-B in the arterial wall is associated with an increase in neointimal pro-collagen synthesis (84). Insulin -like growth factor-1 is also implicated in the stimulation of ECM by activated SMCs. The main source of IGF-1 is SMCs, and its mRNA expression undergoes a 10-fold increase after experimental balloon injury (85). Increased TNF- $\alpha$ expression after injury in the rabbit aorta is believed to facilitate SMC proliferation (86).

The ability of angiotensin II (AII) to modulate SMC proliferation in vitro (87) and the increased All activity observed after vascular injury, suggest a role for All in the pathogenesis of restenosis (88). In a rat model of restenosis, infusion of All prior to vascular injury markedly enhances SMC proliferation in the intima (89). Additionally, angiotensin converting enzyme inhibitors suppress neointimal proliferation after vascular injury (90). Angiotensin II may also enhance the expression endogenous growth factor such as TGF-B and PDGF by SMCs (91). Serotonin and other vasoactive hormones, including catecholamines and vasopressin, released at the site of injury may also induce SMC proliferation $(92,93)$. Endothelin, a vasoconstrictor peptide produced by vascular endothelial cells, is another potent mitogen for SMC that may induce cellular proliferation in the damaged vessel as suggested by the ability of endothelin antagonists to reduce neointimal thickening after experimental vascular injury $(94,95)$.

An essential requirement for SMC migration is extensive upregulation of matrixdegrading protease activity after balloon injury. Activated proteases degrade ECM and basement membrane components including elastin, collagen types I, III, and IV, laminin, and fibronectin and release SMC from surrounding matrix proteins, thereby facilitating their migration (96). Increased protease activity also releases matrix-bound 
growth factors which further stimulate cellular migration and proliferation (97). In balloon injury models of restenosis, elevated levels of plasminogen activators (urokinase PA (u-PA), tissue type PA (t-PA)), plasmin, and matrix metalloproteinases (MMPs) have been demonstrated to coincide with SMC migration $(97,98)$. Plasminogen activators catalyze the conversion of plasminogen to plasmin which can degrade a variety of ECM proteins and may also trigger the early phase of activation of TGF-B, and IGF-1 further facilitating ECM production by SMCs (40). Plasmin is also capable of activating MMPs, which are a group of zinc-dependent enzymes involved in ECM degradation during normal processes of embryogenesis, wound healing, and tumor invasion (99). An increased activity of the gelatinases MMP-2 and MMP-9 observed after experimental balloon injury, correlates with SMC migration to the intima (96) while inhibitors of PA, plasmin, or MMPs markedly decrease SMC migration after vascular injury $(100,101)$. Serine elastases secreted by SMC and infiltrating leukocytes, including human leukocyte elastase (HLE) and endogenous vascular elastase (EVE) which degrade elastin matrix and release or activate stored growth factors and modulate cytokine activity through elastin derived peptides may also contribute to the development of arterial thickening $(102,103)$. Inhibitors to elastases can reduce experimental neointimal formation in animals $(104,105)$.

Arterial remodelling describes the adaptive enlargement that human coronary arteries undergo in response to the progressive expansion of primary atherosclerotic plaques, in order to prevent lumen narrowing (106). Such a compensatory enlargement also appears to occur during neointimal formation after balloon injury $(107,108,109)$. Although mechanisms responsible for arterial remodeling after balloon injury are not known, hemorological factors such as shear stress and luminal flow rates are believed to modulate vessel remodelling in primary atherosclerotic lesions (106). Decreased wall shear stress resulting from improved patency after angioplasty may induce a compensatory decrease in luminal radius accomplished by neointimal formation to normalize velocity of blood flow and wall shear stress. If blood flow after 
the procedure is not sufficiently increase to raise wall sheer stress above a baseline, vessel radius may decrease resulting in restenosis (5). Additionally, increased shear stress and flow velocity following balloon inflation may impair recovery of the endothelium and exacerbate restenosis development (110).

\section{FIBRONECTIN AND INTIMAL THICKENING}

Fibronectin is a $220 \mathrm{kD}$ extracellular matrix glycoprotein involved in cell differentiation, cell-substratum adhesion, and cell migration (111). Modified expression of fibronectin has been identified as a major factor facilitating SMC migration as well as trafficking of leukocytes across the vessel wall (112-116). Fibronectin, as well as other matrix constituents characterized by the presence of an Arg-Gly-Asp amino acid sequence such as osteopontin and vitronectin, are likely to facilitate SMC migration by interactions with specific integrins expressed by activated SMCs $(117,118)$. In 3-dimensional collagen gels, migrating SMCs from the ductus arteriosus show increased rates of migration relative to aortic SMCs which is dependent on increased fibronectin production and cellular binding to fibronectin (119).

In the normal developmental process of intimal thickening such as during late gestational closure of the ductus arteriosus, SMC migration is related to increased expression of fibronectin, chondroitin sulfate, hyaluronate, and the receptor for hyaluronan mediated motility (RHAMM) $(119,120)$. As well, neointimal formation in piglet coronary arteries after cardiac transplantation is associated with increased endothelial and smooth muscle cell fibronectin synthesis induced by TNF alpha and IL-1B after an immune inflammatory reaction (112,114,115). Moreover, accumulation of fibronectin is evident in early atherosclerotic lesion development (121). After experimental balloon injury in rabbit arteries, re-expression of embryonic forms of fibronectin occurs in the media and adventitia within 24 to 48 hours while fibronectin mRNA and protein levels continue to accumulate in the luminal layers of the 
developing neointima for 2 weeks (122). Additionally, restenotic lesions taken at coronary atherectomy demonstrate increased in fibronectin expression compared with primary lesions (123), further suggesting that fibronectin, as an important mediator of SMC migration, may be an integral ECM component influencing restenotic lesion development.

\section{ELASTIN BINDING PROTEIN AND INTIMAL THICKENING}

Studies from our laboratory suggest that functional deficiency in the SMC elastin binding protein (EBP) may also play a role in the pathogenesis of neointimal thickening. The $67-\mathrm{kD}$ protein, identical to the enzymatically inactive spliced variant of B-galactosidase, is a major component of the non-integrin cell surface receptor expressed on vascular SMC which normally mediates their firm anchorage to the extracellular matrix $(124,125,126)$. The EBP recognizes several non-identical hydrophobic domains on elastin (VGVAPG), laminin (LGTIPG), and type IV collagen (PGAIPG), provided they form a similar secondary conformation. The 67-kD protein is not a transmembrane molecule, but immobilizes on the cell surface by an association with two other proteins, the 61-kD and the 55-kD receptor sub-units. The 67-kD protein binds to matrix ligands in a calcium-independent manner, but only in the absence of galactosugars, which may also bind to a separate "lectin-like" domain of this protein (figure 1). Binding of the carbohydrate-bearing moieties causes such conformational changes of the $67-\mathrm{kD}$ protein that it loses the ability to bind its principal matrix ligands and separates from the cell surface (127). Thus, galactosugars may inactivate this unique cell surface receptor and modulate cell-matrix interactions.

In vitro studies have demonstrated that free galactosugars or galactosugarbearing GAGs such as CS or DS induces shedding of EBP from the cell surface of SMC and stimulates their detachment from the surrounding matrix and the consecutive migration (127). Additional observations that rapidly migrating SMC from intimal cushions of the late gestation ductus arteriosus, as well as from atherosclerotic lesions, express significantly lower levels of EBP as compared to healthy aortic SMC 
Elastin/Laminin

Binding Domain

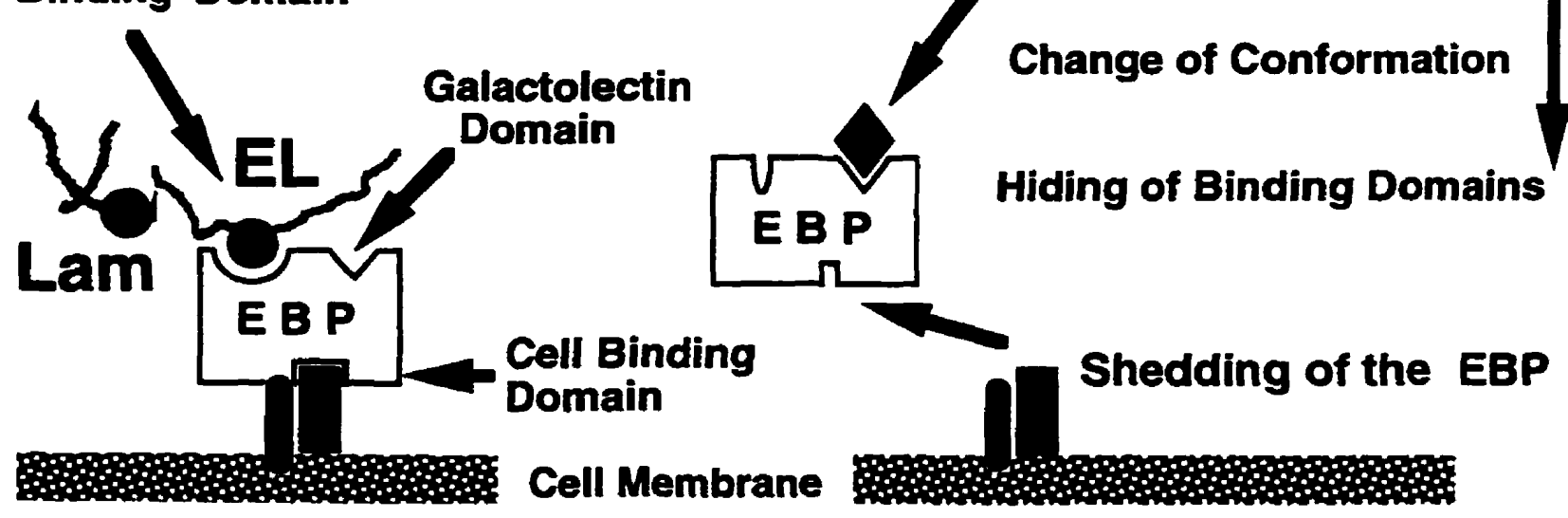

Figure 1. The cell surface Elastin Receptor consists of three protein subunits. The major subunit of this receptor, the 67-kD Elastin Binding Protein (EBP), has three distinct binding domains through which it binds to: 1) several similar but nonidentical hydrophobic sequences in elastin, laminin, and collagen type IV, 2) two other cell membrane associated subunits, and 3 ) galactosugars. Binding of galactosugar-containing moieties to the lectin domain of the EBP triggers a change in its molecular conformation and hiding of two other binding domains. This causes dissociation from bound ECM ligands and release of EBP from its association with the $55-\mathrm{kD}$ and $61-\mathrm{kD}$ subunits of the receptor. 


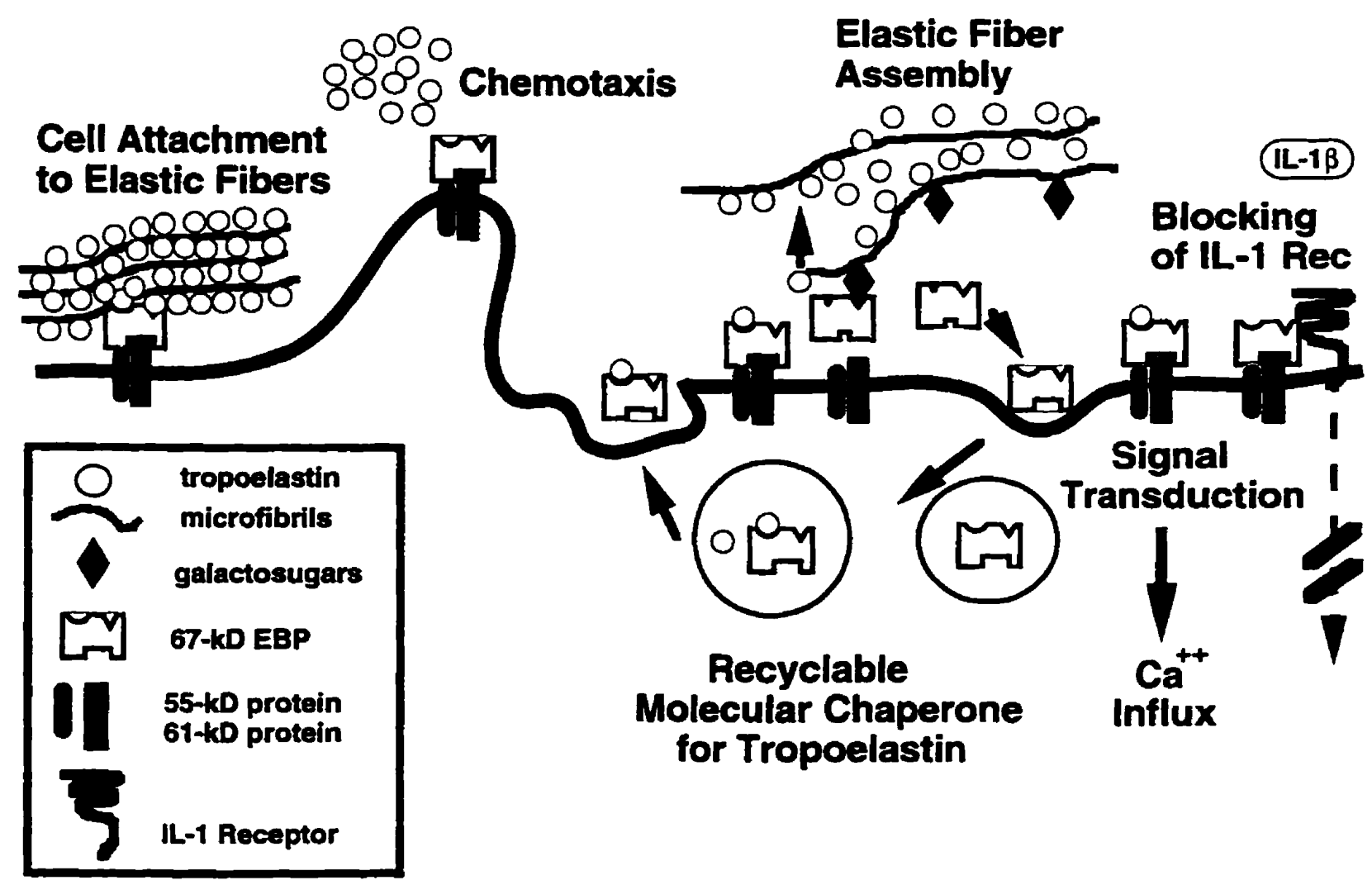

Figure 2. The multi-functional elastin/laminin binding protein.

The EBP is a major component of the non-integrin cell surface receptor complex expressed on fibroblasts, SMC, chondroblasts, leukocytes, and certain cancer cell types.

1. In healthy vascular walls, the EBP provides a solid contact between SMC and elastic membranes.

2. EBP acts as a chemotactic receptor towards elastin, laminin, and collagen type IV degradation products.

3. In elastin producing cells the EBP acts as a recyclable molecular chaperone facilitating tropoelastin secretion and elastic fiber assembly.

4. Binding of elastin, laminin, and collagen type IV derived-peptides to cell surface EBP induces rapid $\mathrm{Ca}++$ influx which may be an initial step in a signal transduction pathway.

5. The EBP localizes in close proximity to the IL- 1 type 1 receptor on surface of vascular SMC, greatly reducing the binding of its corresponding cytokine. 
further suggest that deficiency in EBP may facilitate SMC detachment from elastin matrix and their migration and may represent an important phenotypical alteration of SMC during vascular diseases such as restenosis (128).

Since the 67-kD protein has been identified as an important factor facilitating intracellular transport and extracellular assembly of tropoelastin in normal elastogenic cells (fibroblasts, chondroblasts and vascular SMCs), its deficiency in rapidly migrating SMC from ductus arteriosus leads to impaired elastic fiber production (128). Furthermore, EBP deficiency has also been demonstrated to lead to an upregulation of fibronectin (FN) synthesis by SMCs implicating it in a possible mechanism controlling fibronectin production $(116,127)$. Studies by Hinek et al $(116)$ have demonstrated that EBP normally localizes in close proximity to the IL-1 type 1 receptor and functionally limits the ability of IL-1B to bind to its receptor and stimulate FN synthesis in vascular SMC. Chondroitin sulfate-induced shedding of the EBP allows for efficient binding of IL-IB to its receptor which is associated with an upregulation of fibronectin production by SMCs. Together these observations suggest that deficiency in EBP may facilitate SMC migration during intimal thickening by directly compromising cellular attachment to extracellular elastin as well as by allowing for an increase in IL-1B stimulated increasing in FN production. Moreover, recent data from our laboratory indicated that transfection of EBP-deficient DA SMC with the CDNA clone encoding EBP, improved elastic fiber production, decreased production of fibronectin and increased cellular ability to attach to elastin (129). Figure 2 summarizes the functions of the EBP.

\section{PHARMACOLOGICAL APPROACHES TO RESTENOSIS}

A wide range of pharmacological approaches, aimed at inhibiting the development of restenosis after PTCA and reflecting the numerous factors involved in its pathogenesis, have been explored. To date these approaches include the use of anti-platelet agents, anti-thrombotics, anticoagulants, thrombolytics, antiproliferatives, anti-inflammatory drugs, vasodilators, antioxidants, lipid-lowering agents, chimeric 
toxins, antisense oligonucleotides, and gene therapy. Although numerous clinical trials for the prevention of restenosis have been conducted most have demonstrated little or conflicting benefit.

Because platelets and thrombus formation probably play an extensive role in inducing SMC migration and proliferation, anti-platelet therapy has been at the forefront of restenosis pharmacology. Specifically, the well established interaction between thromboxane A2 (TXA2) and platelets, leading to formation of thrombus, vasospasm, and ultimately SMC proliferation, suggests points in the arachidonic acid pathway as potential sites for directed therapy. Aspirin, an irreversible blocker of cyclooxygenase, clinically reduces upregulated TXA2 synthesis that normally stimulates platelet activation after vascular injury (130). Together with the vasodilatory and anti-platelet agent dipyrimadole, aspirin reduces acute complications associated with PTCA but, despite very positive results in animals, has been unsuccessful in reducing rates of restenosis in humans $(131,132,133)$. Solutroban a more specific inhibitor of TXA2, and the thromboxane receptor antagonists vapiprost and S-1452 also failed to alleviate clinical restenosis after PTCA $(134,135,136)$. Similar negative or inconclusive clinical results were obtained from inhibitors of thromboxane synthetase (137). Clinical trials using omega-3 fatty acids from salt water fish oils appear to lower platelet thromboxane production and leukotriene formation following PTCA by competitively interfering with arachidonic acid metabolism but are unable to inhibit neointimal formation in patients $(138,139)$. The anti-platelet agent dextran, used to prevent acute complications of PTCA, reduces platelet adhesion and deposition in a dog model of balloon injury but has no effect on restenosis after PTCA in humans (140). Similarly, ticlopidine, an anti-thrombotic agent of unknown mechanism, did not reduce clinical instances of restenosis (141).

Heparin is routinely used to prevent acute complications associated with PTCA particularly coronary thrombosis and abrupt vessel closure. Heparin is a well know inhibitor of VSMC proliferation in vitro however, long-term heparin administration 
results in bleeding complications after PTCA and has no effect on restenosis $(142,143)$. Heparin consists of an assortment of glycosaminoglycans (GAGs) ranging in weight from 2 to $50 \mathrm{kD}$. Low molecular weight heparins ( 2 to $5 \mathrm{kD}$ ) can effectively inhibit SMC proliferation in vitro as well as restenosis in animal studies $(144,145)$. Unfortunately, clinical trials with these low molecular weight heparins were unsuccessful in inhibiting restenosis after PTCA (146).

The specific thrombin inhibitor, hirudin, effectively prevents coronary thrombosus formation after PTCA in humans and inhibits neointimal formation after vascular injury in animals $(147,148)$. Hirudin is, however, unable to inhibit clinical instances of restenosis (149). Administration of prostacyclin, a vasodilator and antiplatelet mediator produced from endothelial cells that is deficient in restenosis, has also been investigated as a potential inhibitor of restenosis (150). Randomized clinical trials with prostacyclin, however, failed to reduce angiographic restenosis or platelet aggregation after PTCA (151).

Some promising anti-platelet therapy has been reported. The use of monoclonal antibody directed against platelet membrane GP IIb/lila receptor complex, that essentially blocks platelet aggregation, is effective in reducing acute complications and restenosis in a canine model of vascular injury as well as in a group of patients following PTCA $(152,153)$. Additionally, the GP Ilb/llla antagonists from snake venom which are peptides that include the sequences Arg-Gly-Asp (RGD) or Lys-Gly-Asp (KGD) have been shown to antagonize the GP Ilb/lla receptor and can reduce neointimal hyperplasia when locally delivered to injured rat carotid arteries (154). Moreover, the stable analogue of prostacyclin, ciprostene, has shown clinical promise by demonstrating an ability to reduce various complications associated with angioplasty including myocardial infarct, death, and the need for repeat catheterizations or coronary bypass surgery (155).

The importance of SMC proliferation in the pathogenesis of restenosis is well understood. The presence of multiple growth stimuli at the sites of vascular injury 
following PTCA and the many steps involved in this proliferative process offer potential targets for pharmacological intervention. These approaches, which have met with generally limited success, include the use of growth factor antagonists, inhibitors of growth factor receptors, and anti-proliferatives and anti-neoplastic agents used in cancer chemotherapy.

The PDGF antagonist, trapidil, significantly reduces SMC proliferation in vitro and in a rabbit model of restenosis (156). Moreover, in clinical studies trapidil has shown significant reductions in angiographic restenosis $(157,158)$. Serotonin, released from platelet granules after vascular injury and thought to contribute to the process of restenosis by direct mitogenic effects on SMC and by stimulating platelet activation and vasoconsriction has been another target for restenosis inhibition. Despite an ability to reduce SMC proliferation in an animal model of vascular injury, the serotonin S2-receptor antagonist ketanserin does not inhibit restenosis after PTCA (159). Stimulation of natural inhibitors of SMC proliferation, such as nitric oxide, is another potential avenue for reducing neointimal formation. However, in a clinical study the nitric oxide donors, linsidomine, molsidomine, or diltiazem demonstrated only moderate reductions in restenosis rates (160).

Mycophenolate Mofetil, an anti-proliferative and immunosuppressive agent which inhibits SMC proliferation in vitro, suppresses neointimal thickening after vascular injury in the rat (161). Colchicine is a plant alkaloid that interrupts mitotic spindle formation and arrests cell division in metaphase that may inhibit SMC and leukocyte migration and proliferation (162). Although colchicine treatment has shown promising results in preventing restenosis in animals, clinical studies reveal no beneficial effect $(163,164)$. Antimitotics such as vincristine and dactinomycin have also demonstrated an ability to reduce SMC proliferation after experimental vascular injury, while others such as triaslyclosporin, azathioprine, and methotrexate failed to inhibit restenosis in different animal models $(165,166,167)$. The severe toxicity observed with most anti-mitogenic and anti-neoplastic is clearly a limiting factor of 
these preventative approaches. For instance, although heparin inhibits SMC proliferation in vitro and in vivo, the continuously high dose of intravenous heparin would significantly suppress smooth muscle cell growth proves impractical in the clinical setting (168).

Angiotensin converting enzyme (ACE) inhibitors are considered for restenosis prophylaxis since local neointimal ACE and angiotensin II activities increase in balloon injured arteries (169) and in addition to its vasodilatory efficacy, locally produced angiotensin II stimulates migration and proliferation of arterial SMC (170). The angiotensin-converting enzyme inhibitors cilazapril and captopril strongly reduce SMC proliferation and neointimal formation after vascular injury in the rat angioplasty model but not in other animal models $(171,172,173)$. Furthermore, in clinical studies cilazapril and the additional ACE inhibitors, fosinopril and enalapril, were unable to prevent restenosis in humans $(174,175)$.

Potential contributions of recoil, lack of compensatory vessel enlargement, and flow-stress considerations have prompted investigation into the role for vasodilators in the prevention of restenosis. Calcium antagonists, used routinely during PTCA to reduce acute complications including vasospasms, have also been suggested to reduce growth-factor-dependent proliferation and migration of SMC after angioplasty (176). Unfortunately, clinical studies involving the calcium antagonists diltiazem or nifedipine demonstrated no benefit in reducing long-term restenosis $(177,178)$.

The potential role of inflammatory cells and the mitogens and chemoattractants that they secrete during neointimal formation has prompted the use of antiinflammatory drugs, in particular corticosteroids, as potential inhibitors of restenosis development. Some success in reducing neoinitmal formation in animal models has been met with the use of steroids and nonsteroidal anti-inflammatory drugs (NSAIDS) $(179,180)$. Cyclosporin $A$, an inhibitor of T-cell activation, inhibits SMC proliferation and ECM production in denuded rat endothelium (181). Other approaches which antagonize leukocyte and endothelium adhesion molecules necessary for leukocyte 
adhesion and accumulation have demonstrated positive as well as negative results of reducing restenosis in animals $(182,183)$. Clinical trials involving the seleniumcontaining heterocyclic NSAID ebselen which reduces activation of leukocytes and peroxidation of lipids has shown promise at reducing restenosis in a small study of 80 patients undergoing PTCA (184). Additionally, tanilast, which reduces keloid formation by suppression of macrophages and fibroblasts demonstrated a significant reduction in restenosis rates at 3 months following PTCA (185).

Additional inhibitory strategies include photochemotherapy which uses a drug such as 8-methoxypsoralen that is activated by light and locally cross-links DNA thereby blocking cell replication and has been demonstrated to effectively attenuate neointimal and medial cellular proliferation in a pig model of balloon angioplasty (186). Molecular strategies have also been employed to inhibit restenosis in experimental models. Lethal chimeric toxins that have demonstrated an ability to selectively kill SMC in vitro are also capable of inhibiting neointimal proliferation after balloon injury without effecting uninjured arteries $(187,188,189)$.

Blocking the expression of genes essential for nuclear transcription and nonmuscle myosin necessary for SMC proliferation and migration and proliferation using antisense oligodeoxynucleotides, which introduces short DNA sequences that hybridization with target mRNA molecules, has also been attempted. After successful in vitro results, in vivo studies against proliferating cell nuclear antigen (PCNA), c-myc, and c-myb have demonstrated reductions in neointimal thickening after experimental injury $(190,191)$. The success of these techniques will depend on the development of safe and effective local delivery devices (192).

Local delivery of pharmacological agents with restenosis limiting qualities has also been attempted in the clinic. Such methods could have the combined advantages of delivering effective drug concentrations at site of injury while reducing risks of potential systemic side-effects that may result from prolonged administration. Experimental percutaneous delivery systems which create a micro-environment to 
distribute therapeutic agents include, porous and infusion balloon catheters, polymeric or coated stents, coated microspheres, and polymeric drug delivery systems placed at the adventitial surface of the artery (40). Any potential benefit local delivery of any drug, however, must be weighed against the potential exaggerated endothelial injury or inflammatory response that might result from any additional mechanical injury caused by the delivery system.

Although there are a number of avenues that show some promise, especially in in vitro and experimental animal models, the vast majority of pharmacological approaches aimed at preventing restenosis have failed in clinical trials. No systemic agent has been conclusively shown to reduce restenosis. Clearly, lack of a highly effective pharmacological therapy that prevents restenosis across the board is due to the difficulty of attenuating the multiple and diverse biochemical signals which regulate its pathogenesis. As well, the success in animal models that has alluded investigators in clinical trials raises serious questions regarding the overall validity of many animal models in restenosis research. What is clear however, is that most pharmacological approaches, targeting specific factors or aimed at the inhibition of a single step in the development of restenosis, have been largely disappointing. Thus, perhaps a multifaceted approach, using of panel of drugs or a single compound capable of attenuating multiple processes involved in the development of intimal thickening, may prove to be more effective in inhibiting restenosis after PTCA. For example, the multiple actions of halofuginone which inhibits SMC proteoglycan and collagen type I synthesis and gene expression as well as cellular proliferation, may account for the $50 \%$ reduction in intimal thickening after rabbit ear model of crush injury (193). Suramin is another potential drug which may be considered in a multi-targeted approach to restenosis inhibition after PTCA. 


\section{SURAMIN}

Suramin is a symmetrical polysulfonated naphthylamine derivative or urea (figure 3). Suramin was originally synthesized in 1916 by the Bayer Company and since then has been routinely used as an effective treatment for trypanosomiasis and onchocerciasis (194). More recently, the ability of suramin to inhibit reverse transcriptase, the DNA polymerase of retroviruses, and block the infection and cytopathic effect of HIV in vitro prompted its use in clinical AIDS trials $(195,196)$. Although limited success was realized in these studies, the appearance of adrenal toxicity in AIDS patients prompted clinical investigation into the potential of suramin as an anti-cancer drug $(197,198)$. To date, suramin has demonstrated effective antitumor activity toward several metastatic cancers refractory to conventional chemotherapy, including renal-cell carcinoma, prostate cancer, ovarian cancer, adrenocortical carcinoma, and certain lymphomas (199).

Suramin is clinically administered by slow intravenous injections as it is not absorbed orally and intramuscular and subcutaneous injections are irritating and painful. Suramin has a plasma half-life of $\mathbf{4 4}$ to 54 days with relatively uniform tissue concentrations throughout the body with the exceptions of the brain, where there is little if any present, and the kidney where concentrations are usually double. AIDS trials demonstrated that suramin has a narrow therapeutic window and frequent drug monitoring is necessary to avoid systemic toxic effects. Although suramin induces complication such as fever, rash, and vomiting, clinical evidence demonstrates that complete resolution of side effects occurs upon cessation of treatment (200).

Suramin has many well established biological effects including the ability to inhibit the binding of various growth factors to their receptors and to dissociate receptor bound growth factors (200). Suramin also directly binds and causes microaggregation of several growth factors, including PDGF, epidermal growth factor (EGF), bFGF, TGF-B, IGF-1 (201). Since the growth factors inhibited by suramin are primarily heparin-binding proteins and suramin itself is a polyanion, it seems likely that 


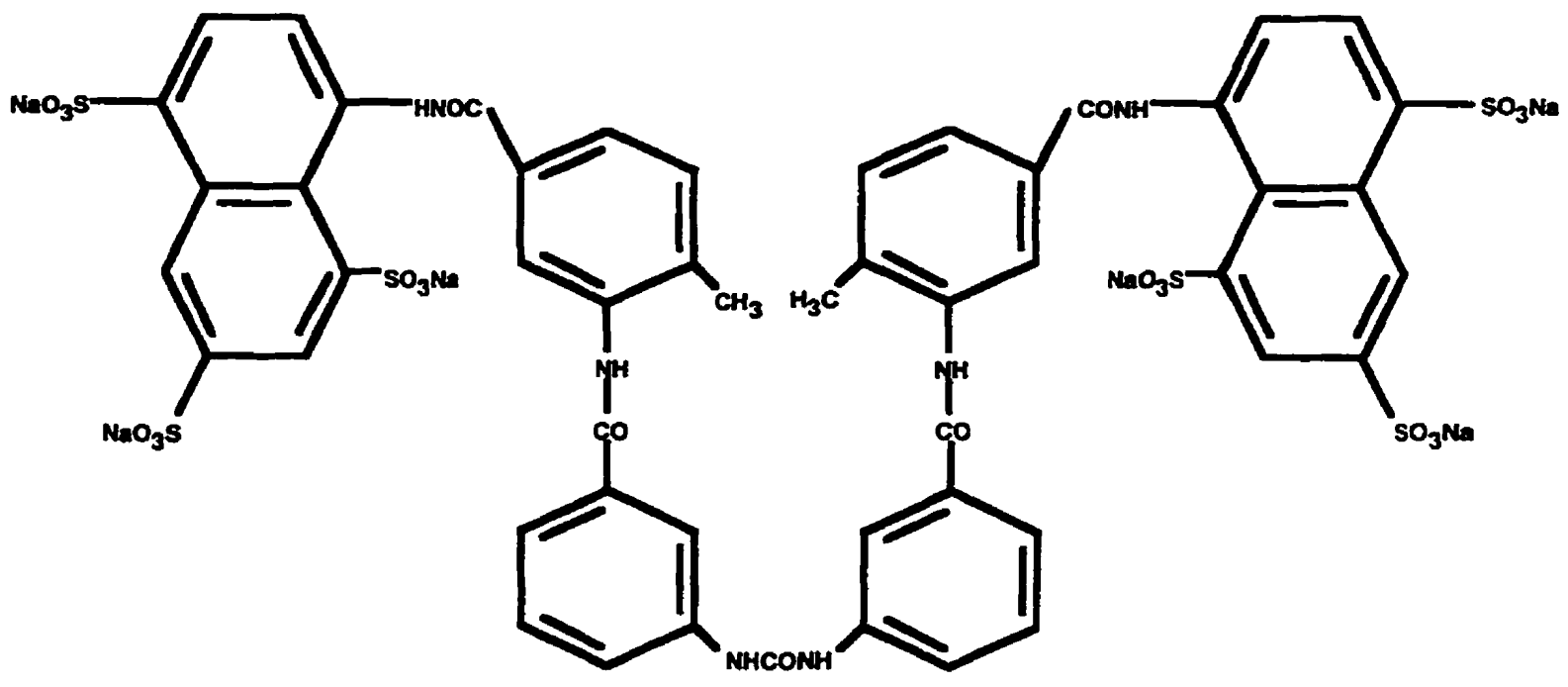

Figure 3. The chemical structure of suramin. 
suramin binds to the positively charged amino acids by which growth factors interact with their receptors or induces conformational changes, thus inhibiting receptor binding.

Specifically, suramin dissociates PDGF from its receptor and inhibits PDGFinduced DNA synthesis and cell proliferation in quiescent Swiss 3T3 cells (202). Suramin also inhibits the binding of several cytokines including IL-1 beta, IL-2, and 6 to their respective receptors (203) and can cause upregulation of cell surface expression of several receptors including those for PDGF and bFGF while inhibiting their intracellular intemalization and degradation $(204,205)$.

Suramin is also capable of inhibiting several cellular responses integral to neointimal formation during restenosis including cell proliferation, migration, and ECM degradation. It is a potent inhibitor of several nuclear enzymes in vitro, including DNA primase, DNA polymerase alpha, RNA polymerase, DNA topoisomerase II, and reverse transcriptase and can inhibit growth factor stimulated tumor cell growth in vitro by arresting cells in G1-phase of the cell cycle (206). Suramin has also been reported to inhibit glycosaminoglycan catabolism which may lead to the accumulation of heparan sulfate, which is known to inhibit SMC proliferation (207). Suramin also appears to influence cell adhesion and migration. It causes altered actin staining and reduced lamellipodia extrusions in endothelial cells and inhibits their migration in vitro $(208,209)$. Additionally, suramin inhibits the migration of human fetal lung fibroblasts in vitro as well as fibroblast and macrophage migration from the ends of sciatic nerves $(210,211)$. Suramin has also demonstrated potential as a protease inhibitor that can inhibit u-PA induction while increasing PAl-1 (PA inhibitor-1) production in endothelial cells $(212,213)$. Moreover, suramin inhibits melanoma cell invasion through its inhibitory effects on heparanases activity and basement membrane degradation (214). It is also capable of inducing differentiation in several human cancer cell lines in vitro and can induce apoptosis in malignant rat prostate cancer cells that have defective apoptotic pathways $(215,216)$. 
Various studies, employing suramin as a non-specific growth factor antagonist, have demonstrated its potential to inhibit SMC proliferation. Suramin inhibits All-, and conditioned media-stimulated SMC proliferation in vitro. $(217,218)$. Sjolund et al $(219)$ demonstrated that suramin inhibits PDGF- and serum-stimulated SMC proliferation. This latter study further demonstrated that suramin inhibits PDGF binding to SMC, displaces PDGF bound to the cell surface, and reduces lysosomal enzyme activity thereby slowing down the degradation of internalized PDGF.

The potential of suramin to inhibit intimal thickening after arterial injury in vivo has also been investigated. Ishikawa et al (unpublished data) have shown that suramin inhibits SMC proliferation in vitro as well as neointimal formation after balloon injury in the rat carotid artery. Similarly, Asada et al (220) have demonstrated that suramin inhibits neointimal thickening and smooth muscle cell proliferation after intimal injury in the rabbit aorta. 


\title{
2. PROJECT PROPOSAL
}

\begin{abstract}
The overall objective of this Master's of Science project was to assess the potential of suramin to inhibit neointimal formation after balloon injury in a rabbit model of restenosis, and provide an insight into the inhibitory mechanisms in which suramin may attenuate arterial smooth muscle cell activation.
\end{abstract}

\section{RATIONALE}

Two previous studies have examined suramin as a potential inhibitor of neointimal thickening. In vivo studies by Asada et al (220) and Ishikawa et al (unpublished data) demonstrated that suramin does indeed inhibit neointimal formation after vascular injury in animals. These studies were however incomplete. The authors suggested that suramin may inhibit SMC proliferation, but disregarded any potential effect of this drug on SMC migration or accumulation of ECM proteins which are both prominent factors contributing to the intimal thickening after PTCA.

Since suramin induced radical inhibitory alterations in secretory, migratory, and proliferative profiles of cancer cells, we anticipated that, in addition to inhibiting SMC proliferation, suramin may also inhibit SMC migration and ECM deposition, thereby demonstrating potential as a multi-target inhibitor of restenosis. Moreover, our preliminary results demonstrate that suramin caused an unusual accumulation of EBP on the cell-surface of SMC, therefore we speculate that this suramin-dependent immobilization of EBP may induce increased anchorage of vascular SMC to elastin fibers of the ECM and delineate a novel mechanism in which this drug may inhibit their migration. 
In this his project we first examined whether the short-term delivery of suramin may inhibit neointimal formation after balloon injury in normal and previously injured rabbit iliac arteries. Following this, in a series of in vitro studies, we examined whether suramin may affect CA SMC proliferation, migration, and fibronectin production. We paid special attention to the fact that suramin-mediated effects may be linked to the induced accumulation of EBP on the cell-surface on CA SMC.

\section{HYPOTHESES}

Suramin inhibits intimal thickening after experimental balloon injury of arterial walls in an animal model. This beneficial effect is due to inhibition of vascular smooth muscle cells proliferation, migration and extracellular matrix production and not to overall toxicity of this multi-potent compound.

\section{SPECIFIC OBJECTIVES}

To test the above hypotheses, a set of experiments were developed with the following specific objectives:

1. Assess the ability of suramin to inhibit intimal thickening after balloon injury in the rabbit iliac artery; a model of restenosis

2. Assess morphological alterations of CA SMC and possible cytotoxic effects of the concentrations of suramin used in the in vitro studies.

3. Assess the ability of suramin to inhibit CA SMC proliferation in vitro.

4. Assess the ability of suramin to inhibit CA SMC migration in vitro.

5. Assess the ability of suramin to inhibit CA SMC fibronectin deposition in vitro.

6. Assess the functional involvement of EBP in the suramin-induced effects on CA SMC migration and fibronectin deposition. 


\section{MATERIALS AND METHODS}

\section{RABBIT MODEL OF RESTENOSIS}

A double-balloon normolipemic injury model using New Zealand White rabbits weighing 3.6 to $3.8 \mathrm{~kg}$ was used as previously described (221). In this model, a fibrocellular intimal thickening occurs in response to the first balloon injury and serves as the diseased substrate for the second balloon angioplasty injury. Xylazine and ketamine were administered by intramuscular injection at a dose of $0.3 \mathrm{~mL} / \mathrm{kg}$ prior to the procedure. Under general anaesthesia, the animals underwent surgical cutdown, after which a 4F sheath (Cordis Corp) was placed in the right carotid artery. Heparin sulfate (1000 IU) and acetylsalicylic acid $(50 \mathrm{mg})$ were injected intra-arterially to prevent early vessel occlusion. A 3F angioplasty balloon catheter with a balloon length of $\mathbf{4 0 ~} \mathrm{mm}$ was then passed under fluoroscopic guidance using an over-thewire system into the right and then the left iliac arteries. The initial $4 \mathrm{~cm}$ of the iliac vessels immediately distal to the aortic bifurcation (a reproducible landmark for removal of the vessels) underwent dilation. The injuries consisted of four 1-minute inflations of the 3.0-mm-diameter balloon catheter serially inflated to $6,8,4$, and 10 Atm with 45 seconds between inflations. Gentle traction of the balloon catheter at 4 Atm was performed to ensure complete endothelial denudation. At the end of the procedure, angiographic patency was confirmed, the balloon catheter was withdrawn, and the arteriotomy was repaired. After recovery, the rabbits were fed regular rabbit chow and water ad libitum. Angioplasty of the right iliac artery was repeated 21 days later through a left carotid arteriotomy using a similar inflation protocol without balloon traction.

While the control rabbits received daily intravenous injection of $2 \mathrm{~mL}$ saline, the drug testing animals received similar daily treatment with $15 \mathrm{mg} / \mathrm{kg}$ of suramin (Germanin, Bayer) dissolved in $2 \mathrm{ml}$ of saline. The dose of suramin (15 mg/kg/day) used in these experiments was calculated according to the directions for clinical use 
of suramin in children. In both experimental models, saline and suramin injections started one day prior to the first injury and one day prior to the second injury, then daily administration continued until the respective sacrifice of the animals 21 days later. Two control and two suramin-treated animals were sacrificed in both experimental models. Iliac arteries were harvested from each animal, fixed in $10 \%$ formaldehyde, embedded in paraffin, and serial transverse sections of the arteries were stained by hematoxylin and eosin.

\section{CELL CUlture}

Porcine coronary artery SMC were isolated for primary cultures as previously described (222). Briefly, segments of the interventricular artery were dissected from porcine hearts and rinsed in Dulbecco's phosphate buffered saline (PBS) containing 3\% antibiotics/antimycotics and gentamycin (GIBCO-BRL). The endothelium and adventitia were removed by gently scraping with a scalpel blade (No. 11) and the remaining medial layer was minced into $x$-plants (approximately $1 \mathrm{~mm}^{2}$ ) which were allowed to adhere to the culture dish. The explants were then incubated in medium 199 (M199) (GIBCO-BRL) supplemented with 10\% FBS (Intergen), 1\% antibiotic/antimycotic, and gentamycin until confluent. Cells were passaged by trypsinization using $0.05 \%$ trypsin/EDTA (GIBCO-BRL) and plated at a density of $10 \mathrm{x}$ $10^{5}$ cells $/ \mathrm{cm}^{2}$. All experiments, using only first or second passage CA SMC, were performed in triplicate and repeated at least two times.

\section{CELL VIABILITY}

Cell morphology of CA SMC was assessed using phase-contrast microscopy after exposure to migration assay test conditions. Trypan blue exclusion assay was assessed in confluent cultures of CA SMC incubated in M199 supplemented with $5 \%$ FBS $\pm 200 \mu \mathrm{M}$ suramin for $24,48,96$ hours. Briefly, cells were gently rinsed with PBS and exposed to $0.1 \%$ trypan blue in PBS for 5 minutes. Cells were trypsinized with 
$0.05 \%$ trypsin/EDTA and loaded on to a hemocytometer. The percentage of blue stained cells was determined in four fields for each sample.

\section{TOTAL PROTEIN SYNTHESIS}

To assess the effect of suramin exposure on total protein synthesis quadruplicate confluent cultures of CA SMC (10 × $\left.10^{6} \mathrm{cells} / \mathrm{dish}\right)$ maintained in M199 with $5 \%$ FBS were exposed to increasing concentrations of suramin $(0-200 \mu \mathrm{M})$, and $\left[{ }^{3} \mathrm{H}\right]$-valine $(1 \mu \mathrm{Ci} /$ well) for 6 hours. Following the incubation, medium were removed and cells were extensively washed with PBS, then precipitated in $5 \%$ TCA at $4^{\circ} \mathrm{C}$, and solubilized in $0.3 \mathrm{M} \mathrm{NaOH}$. Duplicate aliquots from each culture were counted by scintillation counter.

\section{DNA SYNTHESIS}

DNA synthesis in CA SMC was assayed by measurement of the incorporation of $\left[{ }^{3} \mathrm{H}\right]$-thymidine (Amersham) into the cells as previously described (223). CA SMC were plated in 24-well culture dishes and incubated in M199 supplemented with $10 \%$ FBS for 24,48 , or 72 hours achieving $40-50 \%, 60-70 \%$, and $80-90 \%$ confluency respectively. Cells were made quiescent by incubation with serum-free M199 supplemented with $0.1 \%$ BSA for 48 hours. Cells were then incubated in fresh M199 supplemented with 5\% FBS and increasing concentrations of suramin for 24 hours. $\left[{ }^{3} \mathrm{H}\right]$-thymidine $(1 \mu \mathrm{Ci} /$ well $)$ was added for the final 6 hours of incubation. Media was removed and cells were washed with PBS, precipitated in $5 \%$ TCA at $4^{\circ} \mathrm{C}$, and then solubilized in $0.3 \mathrm{M} \mathrm{NaOH}$. Duplicate aliquots from each experimental sample were analyzed by scintillation counting and averaged.

\section{CELLULAR PROLIFERATION}

A direct assessment of cell proliferation was made by counting cells exposed to $5 \%$ FBS in the presence or absence of suramin. Briefly, CA SMC were plated in 
12-well culture dishes and incubated in M199 supplemented with 10\% FBS for 48 hours achieving 50-60\% confluency. Cells were made quiescent by incubation with serum-free M199 supplemented with $0.1 \%$ BSA for 48 hours. Cells were then incubated in fresh M199 supplemented with 5\% FBS and increasing concentrations of suramin $(0-200 \mu \mathrm{M})$ for 48 and 96 hours. After incubation cells were washed twice with PBS, trypsinized with $0.05 \%$ trypsin/EDTA, and then counted by hemocytometer. Experimental conditions were performed in triplicate and each condition sample was measured in quadruplicate.

\section{CA SMC MIGRATION THROUGH ELASTIN MEMBRANES}

CA SMC migration through elastin membranes was assessed as previously reported (127). Briefly, CA SMC (40,000 cells/well) were plated on top of pure elastin membranes placed in 24 well dishes and maintained with regular media (M199 +5\% FBS) alone, with $200 \mu \mathrm{g} / \mathrm{mL}$ CS, or with $200 \mu \mathrm{g} / \mathrm{mL} \mathrm{CS}$ and $100 \mu \mathrm{M}$ suramin for 7 days. After incubation elastin membranes were washed twice in PBS, fixed in $10 \%$ paraformaldehyde, and embedded in paraffin. Transverse sections (10 $\mu \mathrm{m}$ thickness) were then stained with hematoxylin and eosin and reviewed under a Vanox $\mathrm{AH}-3$ Olympus light microscope to assess the depth of SMC migration.

\section{CA SMC MIIGRATION INTO SCRATCH-GAPS}

CA SMC migration was assessed using a modified razor blade wounding injury assay of confluent cultured cells as previously reported $(224,225)$. CA SMC were plated on $100 \mathrm{~mm}$ culture dishes and incubated in M199 supplemented with 10\% FBS for 6 days until fully confluent. Media was then replaced with M199 supplemented with 5\% FBS for 24 hours. Cell cultures were then scraped with a single-edged razor blade ( 4 wounds/dish) leaving behind a discernible scratch line that could be identified upon later examination. Cells were washed twice with PBS and placed in M199 supplemented with 5\% FBS and increasing concentrations of 
suramin for 48 hours (fresh media containing experimental conditions was replenished after 24 hours). Forty eight hours after the initial wounding, four microscopic fields (2-mm diameter) were evaluated for each wounding injury. The number of migrating cells across the wound edge and the maximal distance migrated (wound edge to nucleus of farthest cell) were determined in each field and averaged for each wounding injury.

To assess the migration of quiescent cell cultures, CA SMC were plated on $100 \mathrm{~mm}$ culture dishes and incubated in M199 supplemented with 10\% FBS for 6 days until fully confluent. Media was replaced with M199 supplemented with 5\% FBS and $5 \mathrm{mM}$ hydroxyurea for 24 hours prior to wound injury. Cell cultures were then scraped and washed twice with PBS as above. Wounded cultures were then incubated in M199 supplemented with 5\% FBS, 5 mM hydroxyurea, and increasing concentrations of suramin for 48 hours (fresh medium containing experimental conditions was replenished after 24 hours) and assessed as above. Hydroxyurea was added to eliminate confounding effects of suramin on cell proliferation because suramin inhibits CA SMC proliferation and proliferation contributes to the number of migrating cells in scratch injury models of migration (224). Previous studies have shown that 24 hour treatment with $5 \mathrm{mM}$ hydroxyurea results in complete inhibition of confluent vascular smooth muscle cell proliferation without affecting SMC migration compared with irradiated cells (225).

To assess the effect of hydroxyurea on proliferation, CA SMC were plated in 24-well dishes and incubated in M199 supplemented with 10\% FBS for 6 days until fully confluent. Media was replaced with M199 supplemented with $5 \%$ FBS $\pm 5 \mathrm{mM}$ hydroxyurea for 30 hours. $\left[{ }^{3} \mathrm{H}\right]$-thymidine $(1 \mu \mathrm{Ci} /$ well $)$ was added for the final 6 hours of incubation and the cells were washed, TCA precipitated, and counted to determine DNA synthesis as described above. To assess any compounding effects of suramin and hydroxyurea on proliferation inhibition, CA SMC were plated in 24-well dishes and subject to identical conditions as in quiescent migration assay. $\left[{ }^{3} \mathrm{H}\right]$-thymidine (1 
$\mu \mathrm{Ci} /$ well) was added for the final 6 hours, the cells were washed, TCA precipitated, and counted as in DNA synthesis.

\section{CA SMC MIGRATION ON FIBRONECTIN-COATED SURFACES}

The effect of exogenous fibronectin on CA SMC migration in the presence or absence of $100 \mu \mathrm{M}$ suramin was assessed in the following manner. CA SMC were plated $(60,000$ cells/dish) in 6 well culture dishes that were either uncoated or coated with fibronectin (Becton Dickinson). During cell plating, the culture dishes were tilted at an angle of $45^{\circ}$ to only allow cellular attachment to the lower portion of each well. Cells were incubated in $2 \mathrm{~mL}$ of M199 supplemented with 10\% FBS for 3 days during which time the dishes remained at the $45^{\circ}$ angle. SMC cultures were then incubated in M199 supplemented with 5\% FBS and $5 \mathrm{mM}$ hydroxyurea for 24 hours at the same $45^{\circ}$ angle. The starting line of cellular migration was determined by averaging 5 measurements of the distance of the furthest cell from serial demarcations on the underside of the culture dish in $\mathbf{5}$ microscopic fields for each condition. Microscopic fields were indicated by a red marker on the bottom of the culture dish so that they could be found upon later examination. CA SMC cultures were then incubated in a flat position $\left(0^{\circ}\right)$ for 48 hours in $M 199$ supplemented with $5 \%$ FBS, $5 \mathrm{mM}$ hydroxyurea, with or without $100 \mu \mathrm{M}$ suramin; a concentration that was previously observed to significantly inhibit CA SMC migration. After 48 hours the migration distance of CA SMC in each field was determined as described above, and the migration distance was calculated by subtracting the initial pre-migration distance from the final 48 hour migration distance. The conditions were performed in triplicate and the experiment was performed twice.

\section{IMMUNOCYTOCHEMISTRY}

To visualize cellular fibronectin, CA SMC were removed of media, washed twice with PBS, and fixed in methanol for 30 minutes at $-20^{\circ} \mathrm{C}$. Nonspecific binding 
sites were blocked with blocking solution (filtered PBS containing $0.1 \%$ normal goat serum and $0.1 \% \mathrm{BSA}$ ) at room temperature for 1 hour. Cells were then incubated with primary antibody to fibronectin (mouse anti-human cellular fibronectin (Chemicon) diluted 1:400 in blocking solution) for 1 hour, washed twice with blocking solution, and incubated with fluorescein-conjugated goat anti-mouse antisera (diluted 1:100 in blocking solution) for 1 hour, all at room temperature. Nuclei were counterstained with propidium iodide $(5 \mu \mathrm{g} / \mathrm{ml})$ for 15 minutes. Cells were then washed 3 times in PBS and mounted in elvanol.

To visualize cell-surface EBP, CA SMC cultures were washed twice with PBS, fixed in $2 \%$ paraformaldehyde, and blocked as above. At room temperature, cells were incubated with the primary antibody which recognizes elastin binding protein (diluted 1:400) for 1 hour, washed twice with blocking solution, and incubated with fluorescein-conjugated goat anti-rabbit antisera (diluted 1:100) for 1 hour. Nuclear staining and mounting was performed as described above. Immunofluorescence was observed by epifluorescence Vanox AH-3 Olympus microscope using standard fluorescein excitation and emission filters.

To assess the effect of suramin on fibronectin deposition, confluent cultures of CA SMC were incubated in M199 supplemented with 5\% FBS and increasing concentrations of suramin for $0,1,4$ or 7 days. Cultures were then fixed and routinely immunostained with a monoclonal antibody to fibronectin as described above. Multiple images of the immunostained cultures were then captured using a microscope-mounted TV camera, stored in memory of Macintosh 9500 computer and quantified using Image Pro Plus software.

To assess the effects of chondroitin sulfate and suramin on cell-surface EBP expression, confluent CA SMC were incubated for 30 minutes in M199 supplemented with $5 \%$ FBS alone, with $200 \mu \mathrm{g} / \mathrm{mL}$ CS, or $100 \mu \mathrm{M}$ suramin which was followed by an another 30 minute incubation after the addition of $200 \mu \mathrm{g} / \mathrm{mL}$ CS. Cells were prepared for EBP immunostaining as described above. 
To assess the effects of chondroitin sulfate (CS) and suramin on fibronectin deposition, confluent CA SMC were incubated in M199 supplemented with 5\% FBS alone, with $200 \mu \mathrm{g} / \mathrm{mL}$ CS, or with $100 \mu \mathrm{M}$ suramin and $200 \mu \mathrm{g} / \mathrm{mL}$ CS for 48 hours. Cells were analyzed for fibronectin expression by immunostaining as described above.

To assess the effect of suramin exposure on CA SMC focal adhesion complexes, sub-confluent cultures of CA SMC were incubated in M199 supplemented with $5 \%$ FBS with or without $100 \mu \mathrm{M}$ suramin for a time course of 0,15 , 30,45 minutes and $1,2,4,8,24$, and 48 hours, fixed in methanol, and blocked as described above. Cells were then incubated with the primary monoclonal antibody to vinculin (diluted 1:400 in blocking solution) followed by secondary fluoresceinconjugated goat anti-mouse antisera (diluted 1:100 in blocking solution).

\section{RNA ISOLATION AND NORTHERN BLOT ANALYSIS}

To assess the effect of suramin on CA SMC fibronectin mRNA levels, total RNA was isolated by Trizol method (Gibco) from confluent cultures of CA SMC incubated in M199 supplemented with $5 \%$ FBS $\pm 200 \mu \mathrm{M}$ suramin for $0,24,48$, and 72 hours. $15 \mu \mathrm{g} /$ lane of total RNA was electrophoresed through $1 \%$ agarose/formaldehyde gel, transferred to a charged nylon membrane, and cross-linked in a Stratalinker. Membranes were probed with [32P]-labeled random-primed probe prepared from human fibronectin CDNA (Gibco BRL), washed and subjected to autoradiography. Fibronectin mRNA levels were normalized to corresponding 18s and 28s rRNA levels from ethidium bromide stained gels.

\section{STATISTICAL ANALYSIS}

Differences between groups were analyzed with one-way analysis of variance (ANOVA). If analysis of variance demonstrated significant differences between groups, individual differences were analyzed with a two-tailed unpaired $t$ test. 


\section{RESULTS}

\section{SURAMIN REDUCES INTIMAL THICKENING AFTER BALLOON INJURY}

Our pilot experiments examined a possible inhibitory effect of suramin on neointimal formation using a single- and double-injury rabbit model of restenosis as described by Strauss (57). Histological sections of the iliac arteries taken from control rabbits $(n=2)$ (sacrificed 21 days after the single balloon catheter injury) displayed the development of a fibromuscular neointima (Figure 4 A). Similar, yet more extensive, neointimal thickening was characteristic of the iliac arteries of control rabbits examined 21 days after the second injury $(n=2)$ (Figure 5 A). In sharp contrast to the clearly developed intimal thickening observed in control arteries, the progressive changes in the injured arteries of the suramin-treated rabbits were almost completely inhibited in all single injured arteries $(n=2)$ (Figure 4 B), and largely decreased in double injured arteries $(n=2)$ (Figure 5 B). In suramin-treated and single injured rabbits the neointima was limited only to few layers of SMC (1-5) separated by a small amount of extracellular matrix (Figure 4 B), whereas the thick neointima that developed in control animals consisted of multiple cellular layers (15-28) and large amounts of fibrotic matrix (Figure $4 \mathrm{~A}$ ). After double-injury, a very thick, protruding neointima (25-36 cell layers) was visible in the iliac arteries of control rabbits (Figure $5 \mathrm{~A}$ ) while the hyperplastic intimal lesions (20-27 cell layers) were less extensive in the suramintreated animals. (Figure $5 \mathrm{~B}$ ).

\section{SURAMIN MODULATES VITAL FUNCTIONS OF ARTERIAL SMC}

Our in vitro studies indicated that $25 \mu \mathrm{M}-200 \mu \mathrm{M}$ concentrations of suramin added to cultured arterial smooth muscle cells were not cytotoxic but inhibited migration, proliferation and matrix production of these "builders" of intimal thickening.

\section{SURAMIN DID NOT AFFECTED CELL VIABILITY}

Phase-contrast microscopy of confluent cultures of CA SMC showed that exposure to $200 \mu \mathrm{M}$ suramin did not changed their overall morphology and cells 
continued to display "hill-and-valley" characteristics of untreated-control cells (data not shown). Moreover, approximately $99 \%$ cells exposed to $200 \mu \mathrm{M}$ suramin for 1,2 , and 4 days consistently demonstrated exclusion of trypan blue, similar to control cells (Figure 6 A).

\section{SURAMIN CAUSED A DECREASE IN TOTAL PROTEIN SYNTHESIS}

Total protein synthesis measured after 6 hours of $\left[{ }^{3} \mathrm{H}\right]$-valine incorporation showed, however, that this sensitive indicator of overall SMC metabolic activity began to decrease significantly at a suramin concentration of $200 \mu \mathrm{M}(p<0.05)$. Cells exposed for 6 hours to $200 \mu \mathrm{M}$ decreased their total protein synthesis by approximately $25 \%$ as compared to control (Figure 6 B).

\section{SURAMIN INHIBITS CA SMC DNA SYNTHESIS AND CELL PROLIFERATION}

To establish suramin effect on SMC mitogenesis, we assessed whether suramin could modulate serum-stimulated DNA synthesis and cellular proliferation of quiescent CA SMC. Suramin inhibited $\left[{ }^{3} \mathrm{H}\right]$-thymidine incorporation by CA SMC, at $40-50 \%, 60-70 \%$, and $80-90 \%$ confluency, in a dose-dependent manner (Figure $7 \mathrm{~A}$, $B$, and $C$ respectively). At each confluency, inhibition was statistically significant beginning at a concentration of $50 \mu \mathrm{M}(\mathrm{p}<0.05)$ while treatment with $100 \mu \mathrm{M}$ suramin resulted in an approximate $90 \%$ decrease in DNA synthesis $(p<0.001)$. Further significant decreases in DNA synthesis were not realized with higher suramin concentrations. Suramin also inhibited CA SMC proliferation in a dose-dependent manner as measured by direct cell counting. Exposure of sub-confluent CA SMC to increasing concentrations of suramin for 48 and 96 hours (Figure 8 A \& B respectively) resulted in a significant reduction in cellular proliferation beginning at a concentration of $25 \mu \mathrm{M}$ (p<0.05). At each time point, treatment with $100 \mu \mathrm{M}$ suramin resulted in an approximate $50 \%$ reduction in cellular proliferation $(p<0.001)$ while, similar to the DNA 
synthesis assessment, increased concentrations above this level did not provide additional significant inhibition (Figure 8 A \& B).

\section{SURAMIN INHIBITS CA SMC MIGRATION}

CA SMC migration was assessed using a razor blade wounding injury of confluent CA SMC (Figure 9 A) exposed to suramin (Figure 9 C) or regular medium (Figure 9 B) for 48 hours. Suramin inhibited both the number of CA SMC migrating across the wound edge (Figure $10 \mathrm{~A}$ ) as well as the distance traveled by the furthest cell (Figure $10 \mathrm{~B}$ ). Migration of control CA SMC for $48 \mathrm{~h}$ resulted in $77 \pm 3$ cells crossing the wound edge with a maximal distance migrated of $731 \pm 3 \mu \mathrm{M}$ (mean $\pm S E M$, $\mathrm{n}=12$ woundings). Inhibition of migrating cell number and the farthest distance traveled was statistically significant beginning at a suramin concentration of $25 \mu \mathrm{M}$ $(p<0.05)$. At a concentration of $100 \mu \mathrm{M}$ suramin, an approximate $80 \%$ decrease in both the number of migrating cells and the migration distance was observed.

As suramin inhibits CA SMC proliferation and proliferation influences cell migration in wounding assays, a modified razor blade wounding injury of quiescent CA SMC was used to assess any direct effects of suramin on cellular migration. In this assay, confluent CA SMC cultures were pre-treated with $5 \mathrm{mM}$ hydroxyurea for 24 hours and exposed to increasing concentrations of suramin and $5 \mathrm{mM}$ hydroxyurea, or regular media with $5 \mathrm{mM}$ hydroxyurea, for 48 hours after wounding injury (Figure 13). Similar to previous studies $(224,225), 24$ hour pre-treatment with $5 \mathrm{mM}$ hydroxyurea resulted in a significant inhibition of CA SMC proliferation. CA SMC exposed to $5 \mathrm{mM}$ hydroxyurea demonstrated a decrease of approximately $82 \%$ in $\left[{ }^{3} \mathrm{H}\right]$-thymidine incorporation compared to untreated controls (Figure 11). Additionally, suramin did not confound the inhibitory effects of hydroxyurea on CA SMC DNA synthesis during the migration assay as assessed by $\left[{ }^{3} \mathrm{H}\right]$-thymidine incorporation (Figure 12). The results from these migration assays of non-proliferative CA SMC indicate that suramin exposure inhibits the number of CA SMC migrating over the wound edge (Figure $14 \mathrm{~A}$ ) 
as well as the distance traveled by the farthest cell concentration-dependent manner (Figure $14 \mathrm{~B}$ ). Treatment of control CA SMC with $5 \mathrm{mM}$ hydroxyurea resulted in $54 \pm 5$ cells crossing the wound edge and a maximal distance of $775 \pm 4 \mu \mathrm{M}$ at 48 hours (mean \pm SEM, $n=12$ woundings). Inhibition of migrating cell number was statistically significant beginning at $10 \mu \mathrm{M}(\mathrm{p}<0.05)$. Inhibition of the farthest distance traveled was observed to be significant beginning at a concentration of $25 \mu \mathrm{M}(\mathrm{p}<0.05)$. At $100 \mu \mathrm{M}$, suramin inhibited the distance of migration by approximately $70 \%$ and the number of migrating cells by approximately $85 \%$. Further significant inhibition on CA SMC migration was observed at a suramin concentrations of $200 \mu \mathrm{M}$.

\section{SURAMIN INHIBITS CS-STIMULATED MIGRATION OF CA SMC THROUGH ELASTIC MEMBRANES}

Coronary artery SMC plated on top of the three-dimensional scaffolds of pure elastic membranes usually attach to the top membranes and do not migrate as depicted in transversal sections of 7 day old cultures (Figure 15 A). Addition of 200 $\mu \mathrm{g} / \mathrm{ml}$ of CS to the culture medium significantly stimulated SMC migration (Figure 15 B). Interestingly, CA SMC exposed simultaneously to $200 \mu \mathrm{g} / \mathrm{ml}$ of CS and $100 \mu \mathrm{M}$ of suramin (Figure $15 \mathrm{C}$ ) remained attached to the top membranes and were unable to migrate into the three-dimensional scaffolds, in contrast to the cells exposed to CS alone (Figure $15 \mathrm{~B}$ ).

\section{SURAMIN AFFECTS CA SMC MORPHOLOGY}

The fact that suramin inhibit CA SMC migration prompted an assessment of the effects of this drug on cellular shape, rearrangements of cytoskeleton and distribution of focal adhesions of cultured cells. The suramin-treated CA SMC were more rounded and demonstrated a lack of distinguishable leading and trailing edges characteristic of a migratory SMC. Moreover, immunostaining for vinculin revealed a substantial increase in number of focal adhesions in CA SMC treated for 24 hours with $100 \mu \mathrm{M}$ suramin as compared to control cells (Figure 19). This increase in focal adhesions 
coincided with the decreased migratory capabilities of CA SMC as assessed in the migration assay. In suramin-treated CA SMC, focal adhesions were concentrically distributed around the cell periphery in contrast to their eccentric and sparse distribution in control cells.

\section{SURAMIN INHIBITS FIBRONECTIN DEPOSITION BY CA SMC}

Immunostaining was employed to assess whether suramin exposure inhibited fibronectin deposition by CA SMC. The immuno-detected fibronectin levels of confluent CA SMC cultures after 24 hour exposure to $100 \mu \mathrm{M}$ suramin (Figure $16 \mathrm{~B}$ ) were barely detectable compared to untreated controls (Figure $16 \mathrm{~A}$ ). Analysis of fluorescence intensity reveals that fibronectin levels are inhibited by suramin in a concentration dependent manner (Figure $16 \mathrm{C}$ ). Inhibition was statistically significant at a concentration of $50 \mu \mathrm{M}$ and is maximal at $100 \mu \mathrm{M}$ at which concentration fibronectin staining is decreased by approximately $85 \%(p<0.001)$ compared to untreated controls.

\section{SURAMIN INHIBITS FIBRONECTIN MRNA LEVELS}

Northern blot analysis was employed to evaluate whether suramin exposure inhibited fibronectin mRNA levels which may explain the decrease in fibronectin immunostaining. Fibronectin mRNA levels in CA SMC exposed to $200 \mu \mathrm{M}$ suramin for 24,48 , and 72 hours were markedly reduced compared to untreated controls (Figure 17 A). Densitometry analysis of the autoradiograph further illustrates that fibronectin mRNA levels remain diminished upon continued suramin exposure (Figure $17 \mathrm{~B}$ ). Additional time-course experiments demonstrated that fibronectin mRNA levels begin to decrease within 24 hours of suramin exposure (data not shown). 
FIBRONECTIN DOES NOT OVERCOME SURAMIN-INDUCED INHIBITION OF CA SMC MIGRATION

To assess whether exogenous fibronectin covering the migratory paths may overcome the suramin-induced inhibition of CA SMC migration, cells were also plated on dishes coated with exogenous fibronectin. These cells were then allowed to migrate in the presence or absence of $100 \mu \mathrm{M}$ suramin for 48 hours. Our results indicate that while CA SMC plated on exogenous fibronectin coated surfaces demonstrated a significant increase in migration distance as compared to cells migrating on plastic, the presence of fibronectin coating did not overcome the inhibitory effects of suramin on their migration (Figure 18). Suramin-treated CA SMC, either plated on fibronectin or plastic surfaces, demonstrated significant decrease in their migratory capabilities as compared to respective untreated controls. Furthermore, the percentage decrease in migration of suramin-treated versus untreated CA SMC on fibronectin was larger than the degree of migration inhibition of suramin-treated versus control CA SMC plated on plastic.

\section{SURAMIN INDUCES CELL-SURFACE ACCUMULATION OF EBP}

As previously reported, incubation with $200 \mu \mathrm{g} / \mathrm{mL}$ CS causes shedding of the EBP from the cell-surface of CA SMC and this coincides with an upregulation in fibronectin deposition and cellular migration through scaffolds of pure elastin membranes $(94,97,98)$. Immunostaining with the anti-S-gal antibody, which recognizes EBP, was employed to assess the effect of suramin on the cell-surface distribution of EBP in nonpermeablized CA SMC. We have found that cells exposed to 30 minute treatment with $100 \mu \mathrm{M}$ suramin demonstrated cell-surface aggregation of EBP (data not shown). Since cells treated simultaneously with $200 \mu \mathrm{g} / \mathrm{ml}$ of CS and with $100 \mu \mathrm{M}$ of suramin also demonstrated an increased concentration of immunodetectable EBP on their surfaces, we conclude that suramin treatment (Figure $20 \mathrm{C}$ ) also rendered this receptor unresponsive to CS-induced shedding (Figure 20 B). The immunostaining for fibronectin performed on parallel 48 hour cultures 
indicated that suramin-induced cell-surface accumulation of EBP coincided with a substantial decrease of fibronectin deposition by CA SMC, despite their exposure to CS (Figure 21). The functional significance of the suramin-dependent increased EBP accumulation on the cell surfaces seems to be also confirmed by the above mentioned results indicating that CA SMC exposed to suramin did not migrate through elastic membranes and did not respond to simultaneous treatment with CS which induces EBP shedding and stimulates cellular migration (Figure 15). 
Figure 4. Suramin inhibits intimal thickening in the injured rabbit iliac artery. Representative H\&E stained cross sections from control $(n=2)(A)$ and suramin-treated $(n=2)(B)$ animals show that 21 days after single injury inflicted by the balloon catheter, the thick neointima of the control arteries (A) consists of multiple cellular layers (15-28) and large amounts of fibrotic matrix. The neointima in the suramin-treated rabbits (B) was largely limited to single layers of SMC (1-5) separated by a small amount of extracellular matrix. Arrows indicate internal elastic lamina. Magnification $\times 100$. 


\section{$\begin{array}{ll}\text { A. control } & \text { B. suramin }\end{array}$}

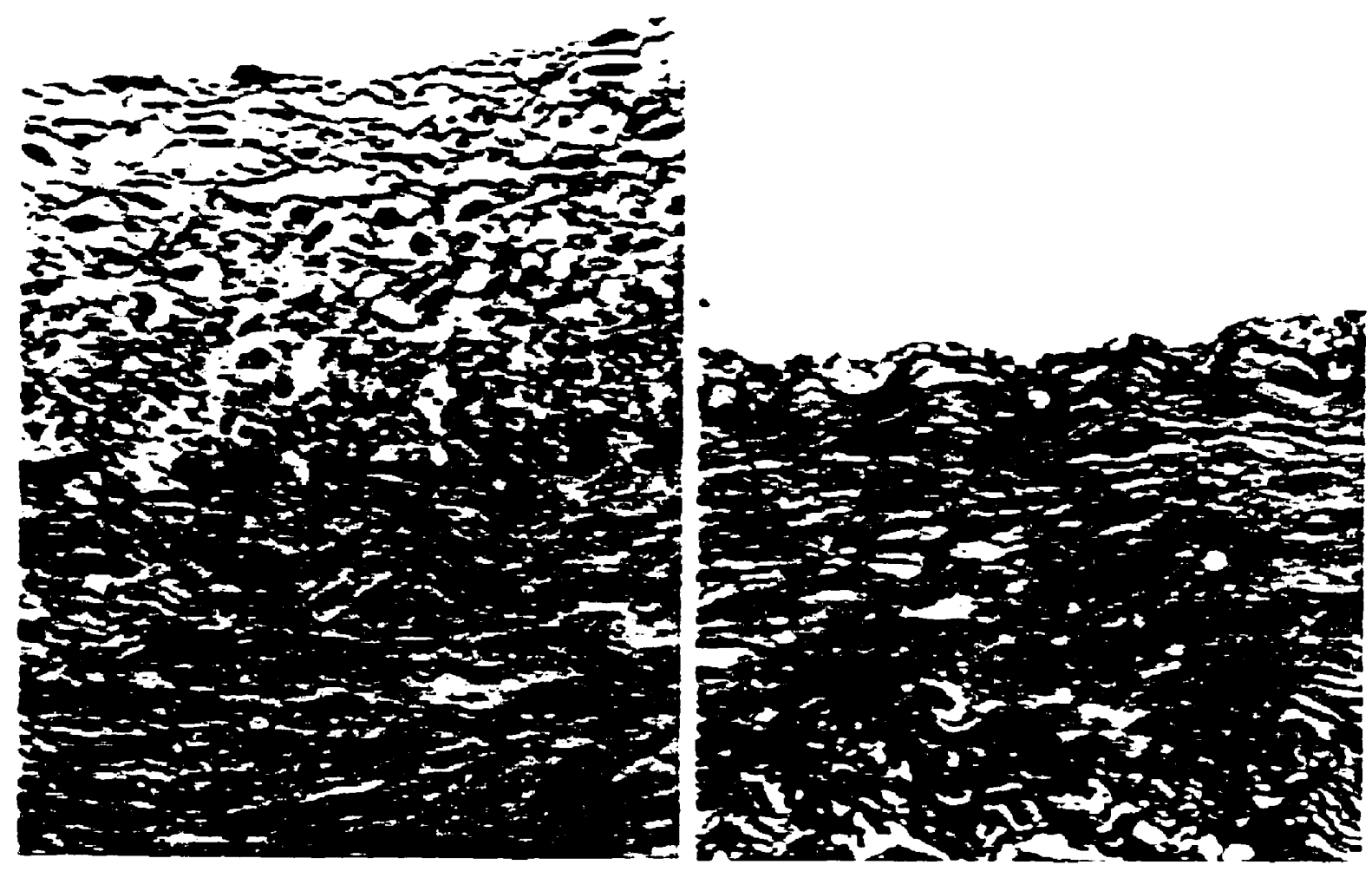


Figure 5. Suramin decreases intimal thickening in double injured rabbit arteries. Representative H\&E stained cross sections from iliac arteries of control $(n=2)(A)$ and suramin-treated $(n=2)(B)$ rabbits show that 21 days after second balloon catheter injury, thick protruding neointima (25-36 layers) is visible in the arteries of control rabbits (A). Hyperplastic intimal lesions were less (20-27 layers) developed in suramin-treated rabbits (B). These results indicate however, that suramin administered 3 weeks after primary injury did not reverse existing plaques induced by the first injury. Arrows indicate internal elastic lamina. Magnification x100. 


\section{A. control $\quad$ B. suramin}

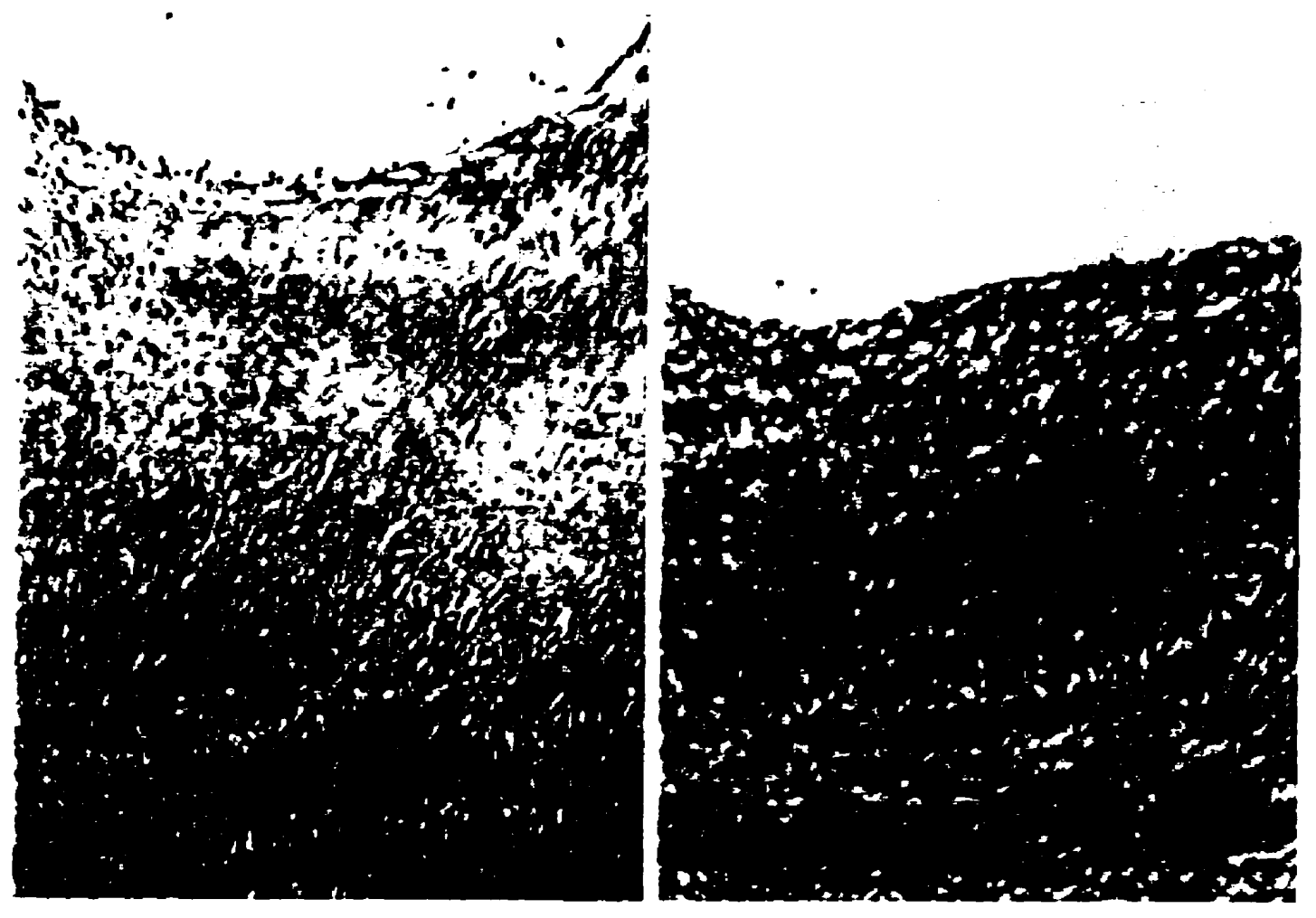


Figure 6. Cell viability and total protein synthesis. Upper graph (A) shows cell viability assessed by trypan blue exclusion test in control CA SMC cultures (hashed bars) and in cultures treated with $200 \mu \mathrm{M}$ suramin (solid bars) for 1, 2, and 4 days. The percentage of trypan blue stained cells was determined at each time point in four fields of triplicate cultures. Lower graph (B) illustrates total protein synthesis after 6 hour incorporation of $\left[{ }^{3} \mathrm{H}\right]$-valine to quadruplicate control (hashed bar) and suramin treated cultures (solid bars). The results are expressed as percentage of untreated control (mean \pm SEM), ${ }^{*} p<0.05$. 
A.

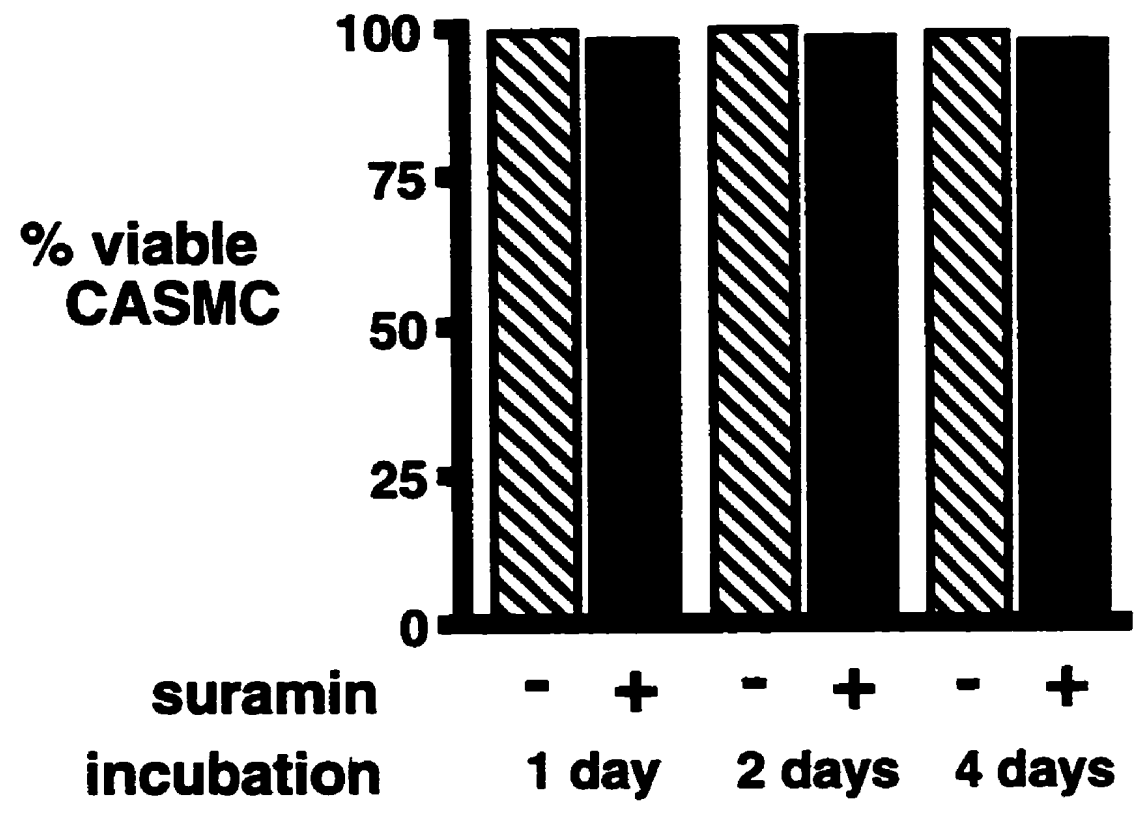

B.

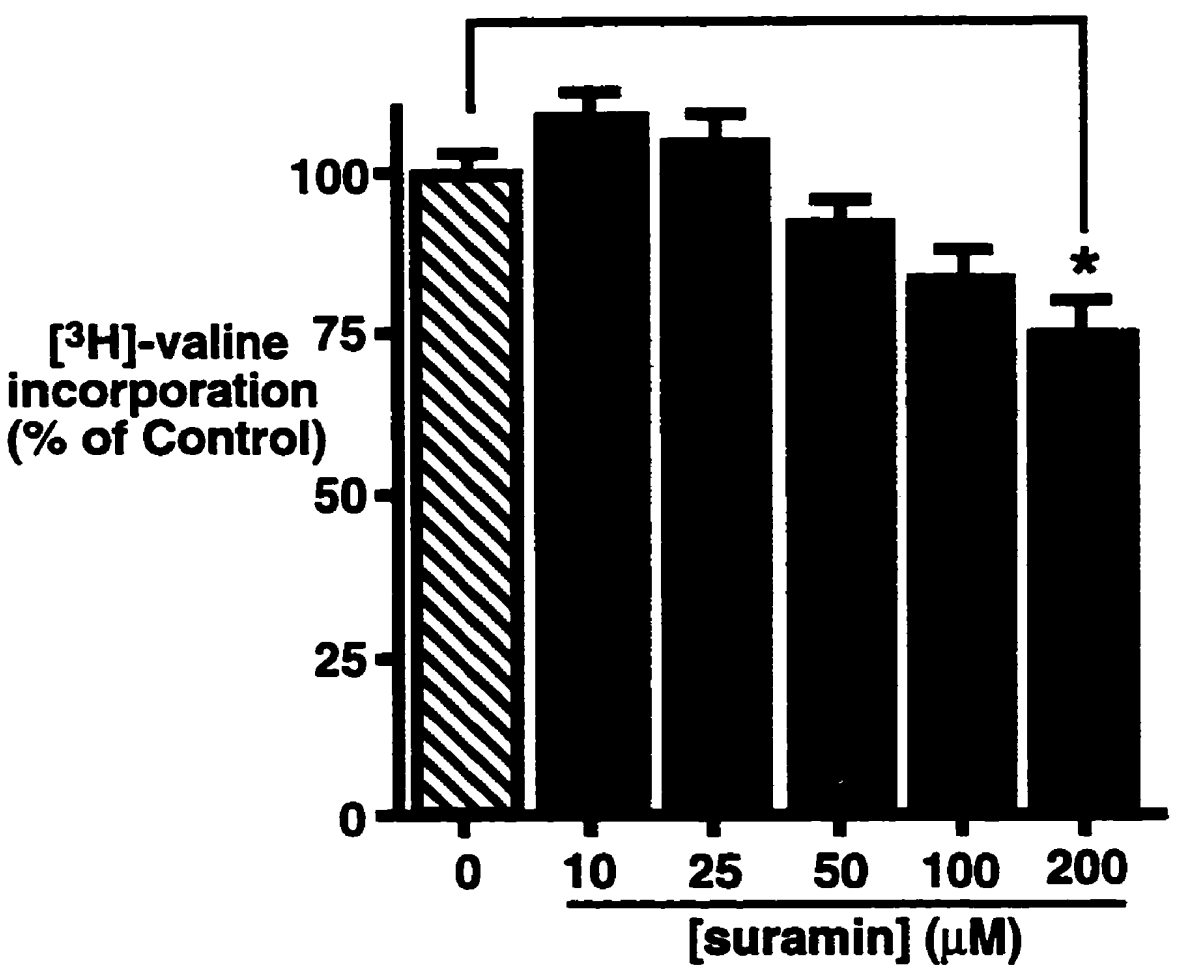


Figure 7. Suramin inhibits $\left[{ }^{3} \mathrm{H}\right]$-thymidine incorporation into CA SMC cultures in dose-dependent manner. The magnitude of such inhibition is not affected by the state of culture confluency, as depicted in graphs: (A) 40-50\%, (B) 60$70 \%$, and (C) $80-90 \%$ confluency. Quadruplicate cultures of different confluency CA SMC were serum-starved for $\mathbf{4 8}$ hours and then transferred to medium containing $5 \%$ FBS and maintained in the absence (hashed bars) or presence (solid bars) of increasing concentrations of suramin for 24 hours. $\left[{ }^{3} \mathrm{H}\right]$-thymidine was added for the final 6 hours of incubation. Results from three separate experiments were averaged and expressed as percentage of control (mean \pm SEM), ${ }^{*} p<0.001$ indicates significant difference between particular experimental group and untreated control. 

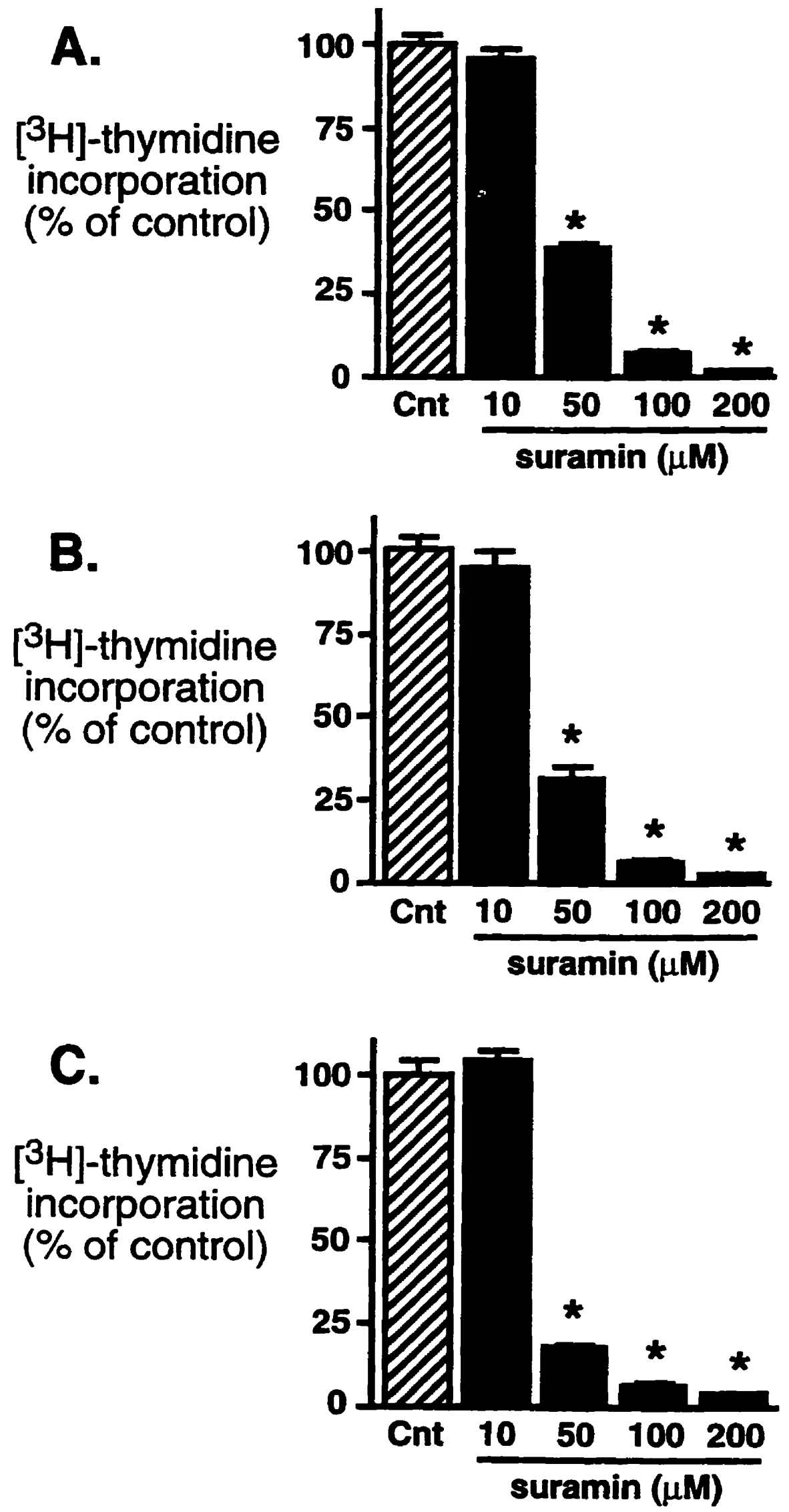
Figure 8. Direct cell counting of control and suramin-treated cultures reveals that suramin inhibits serum-induced proliferation of CA SMC in dose-dependent manner. Quadruplicate subconfluent cultures of CA SMC were serum-starved for 48 hours and then exposed to medium with 5\% FBS and maintained for 48 hours (A) and 96 hours (B) in the absence (hashed bars) or presence (solid bars) of increasing concentrations of suramin. After incubation cells were washed with PBS, trypsinized, and counted by hemocytometer. Results expressed as real cell number/culture (mean $\pm S E M$ ) from one of two independent experiments. Significant differences between control and suramin-treated cultures were as indicated, ${ }^{*} p<0.05$, $\# p<0.001$. 

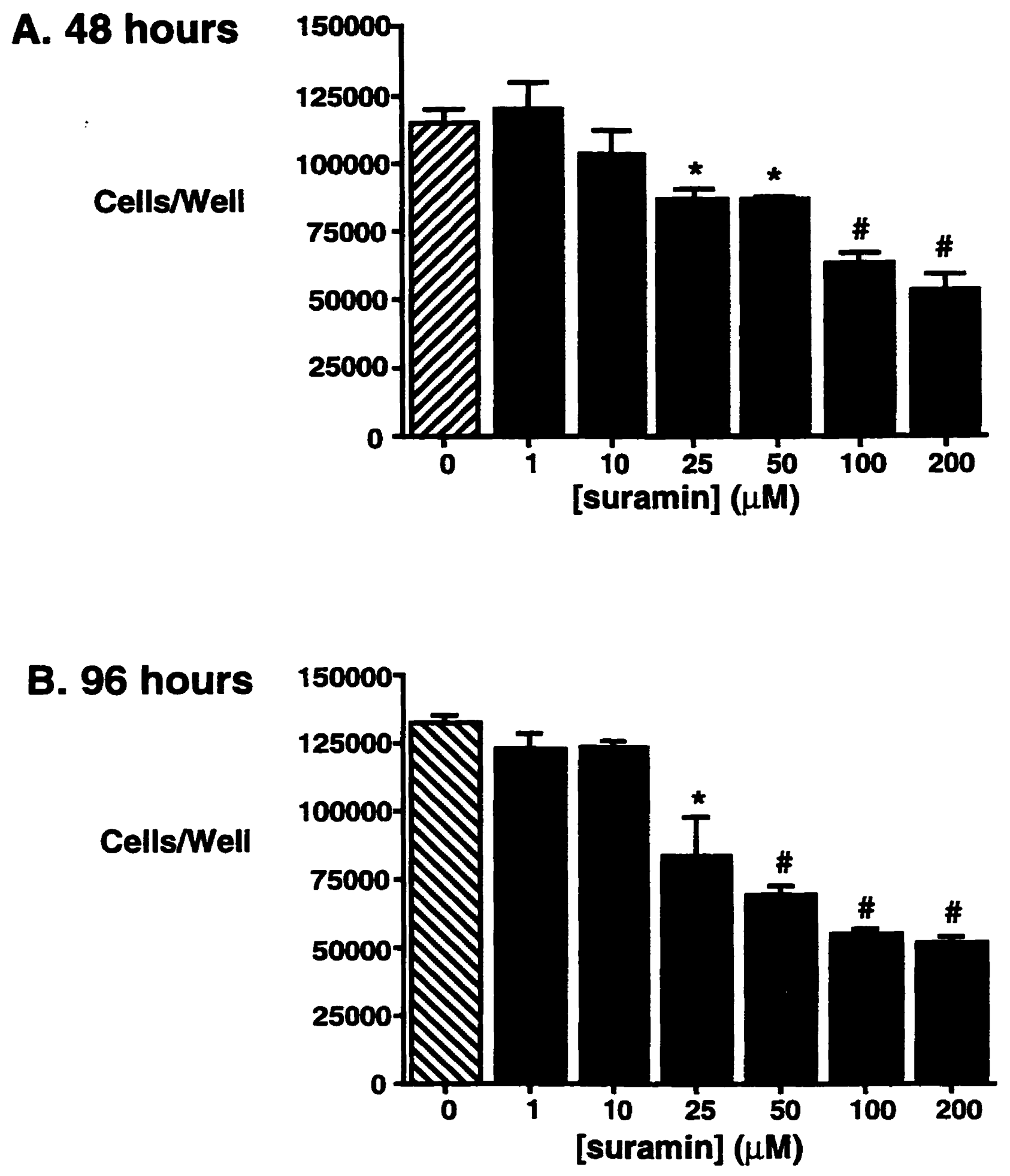
Figure 9. Suramin inhibits CA SMC migration into scratch gaps of confluent cultures maintained in media with 5\% FBS. Representative photomicrographs illustrating CA SMC cultures immediately after wounding (A), as well as control (B) and $100 \mu \mathrm{M}$ suramin-treated (C) cultures, 48 hours after wounding. Magnification $\times 100$. Arrow indicates the edge of wounded culture from which the migration starts. 


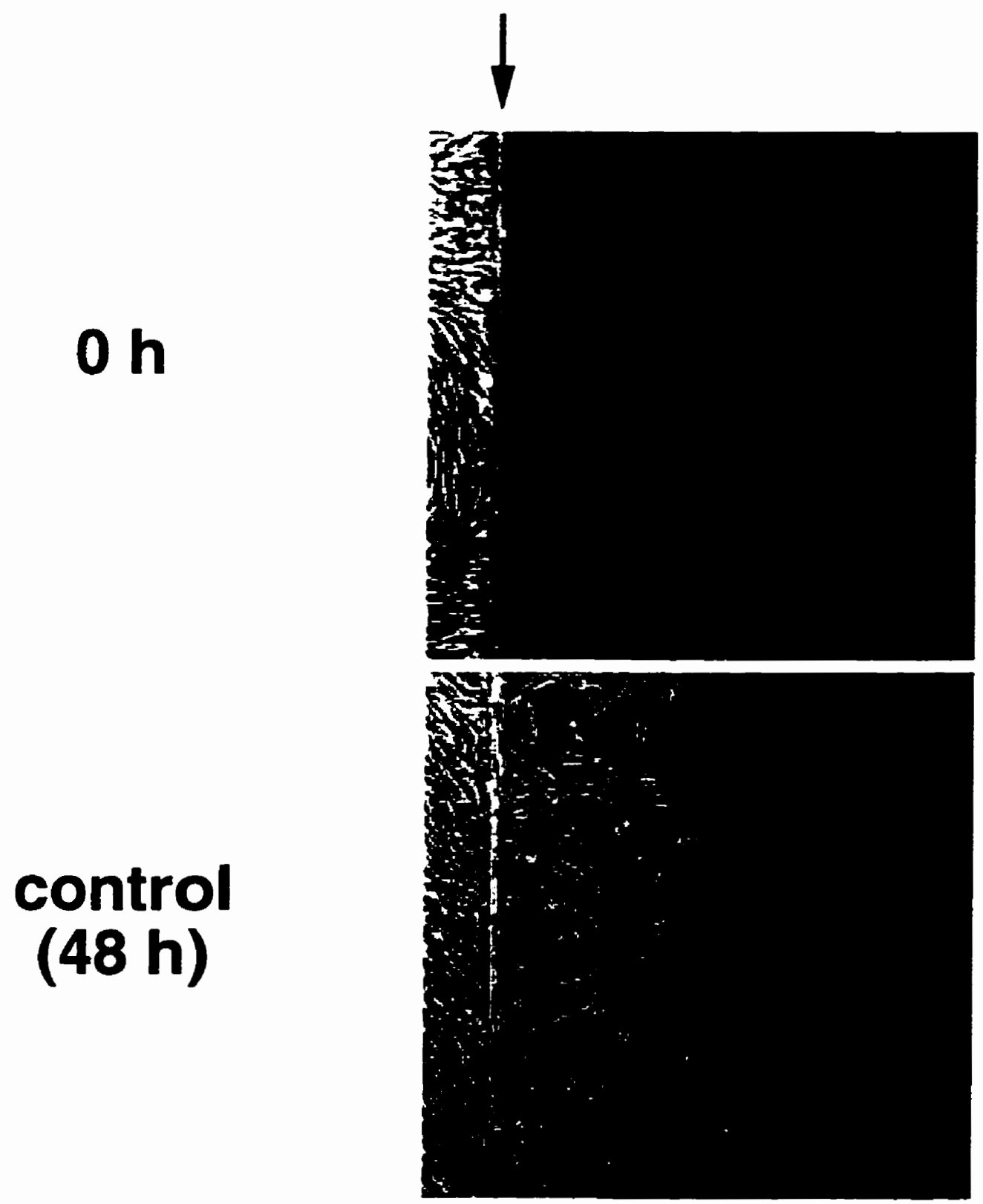

\section{$100 \mu \mathrm{M}$ suramin (48 h)}

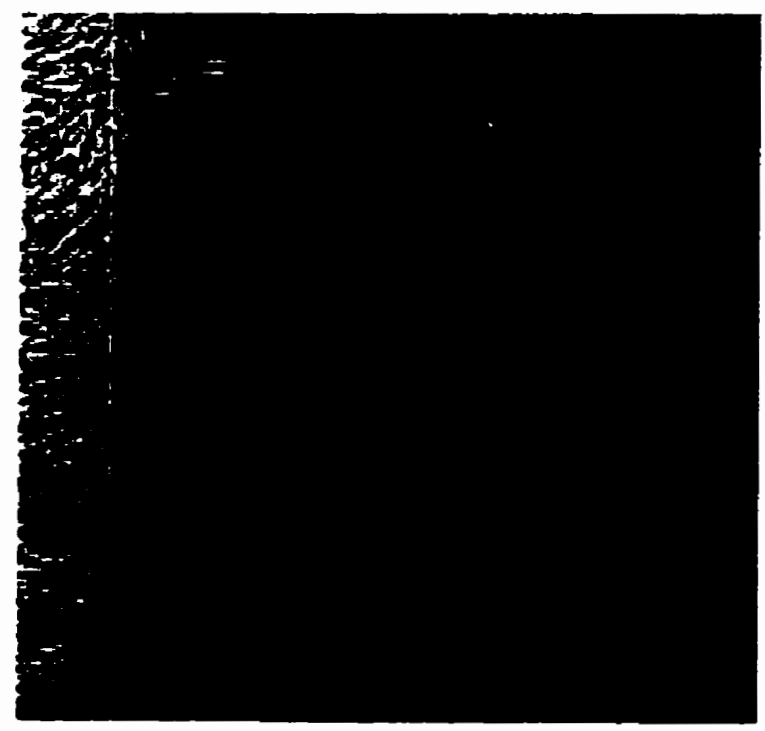


Figure 10. Suramin inhibits CA SMC migration in dose-dependent manner. The upper graph (A) indicates the number of migrating CA SMC (observed in the scratch gap) and the lower graph (B) shows the maximum distance between the wounded edge and the leading migrating cells. Confluent CA SMC cultures maintained in medium with $5 \%$ FBS, were wounded, and then maintained in the absence (hashed bars) or presence (solid bars) of the indicated concentrations of suramin for 48 hours. Results from four microscopic fields (2-mm diameter) were evaluated and averaged for each wound and expressed as percentage of control. Each bar represents the mean $\pm S E M$ of 12 individual culture woundings from three separate experiments, ${ }^{*} p<0.001$ compared to control. 
A.

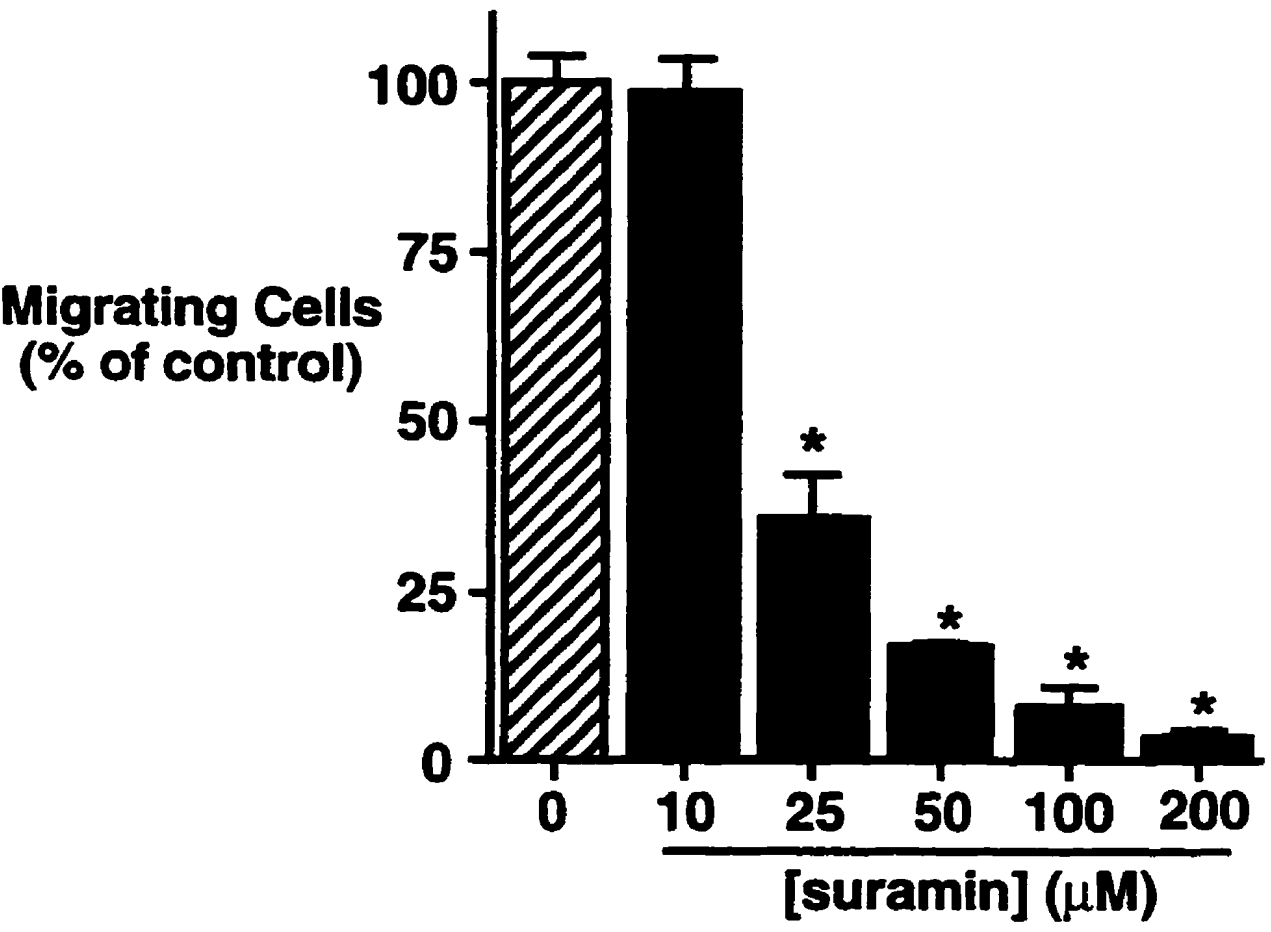

B.

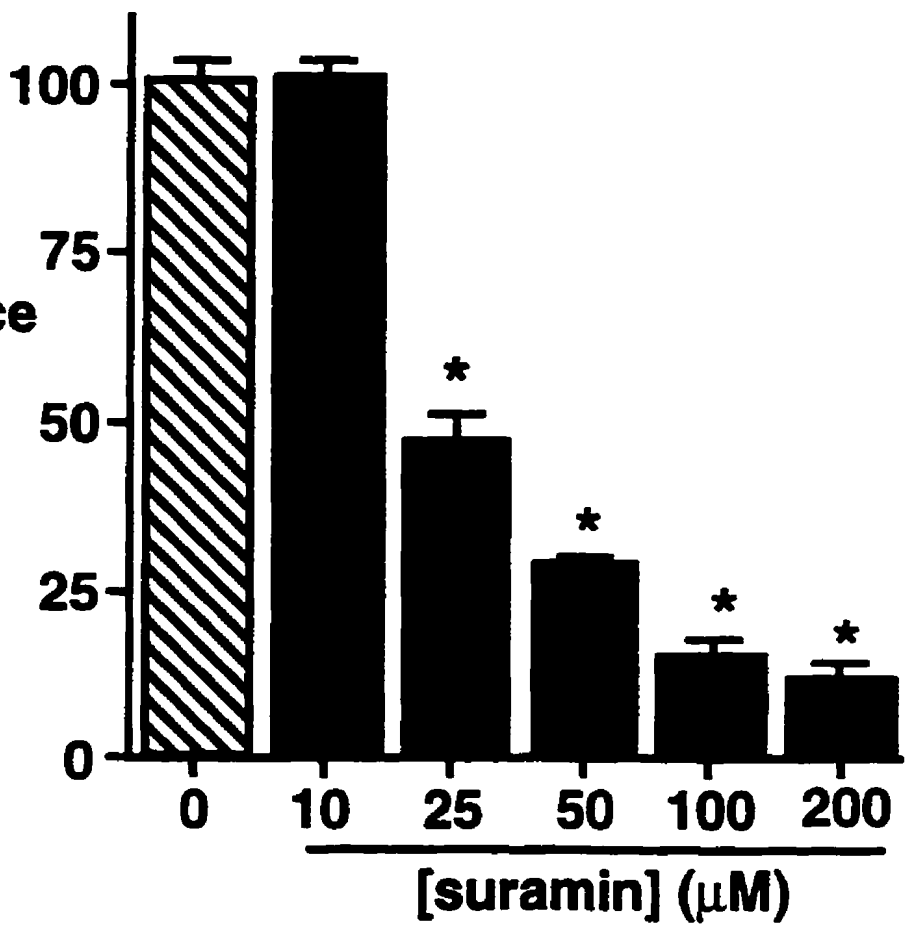


Figure 11. 24 hour exposure to $5 \mathrm{mM}$ hydroxyurea significantly inhibits [ ${ }^{3} \mathrm{H}$ ]-thymidine incorporation into confluent cultures of CA SMC maintained with 5\% FBS. Quadruplicate control (hashed bar) and hydroxyureatreated (solid bar) CA SMC cultures were incubated for 24 hours after which time [ $\left.{ }^{3} \mathrm{H}\right]$ thymidine was added for an additional 6 hours. The results are expressed as percentage of control (mean \pm SEM), ${ }^{*} p<0.05$ compared to control. 
[3H]-thymidine incorporation (\% of control)

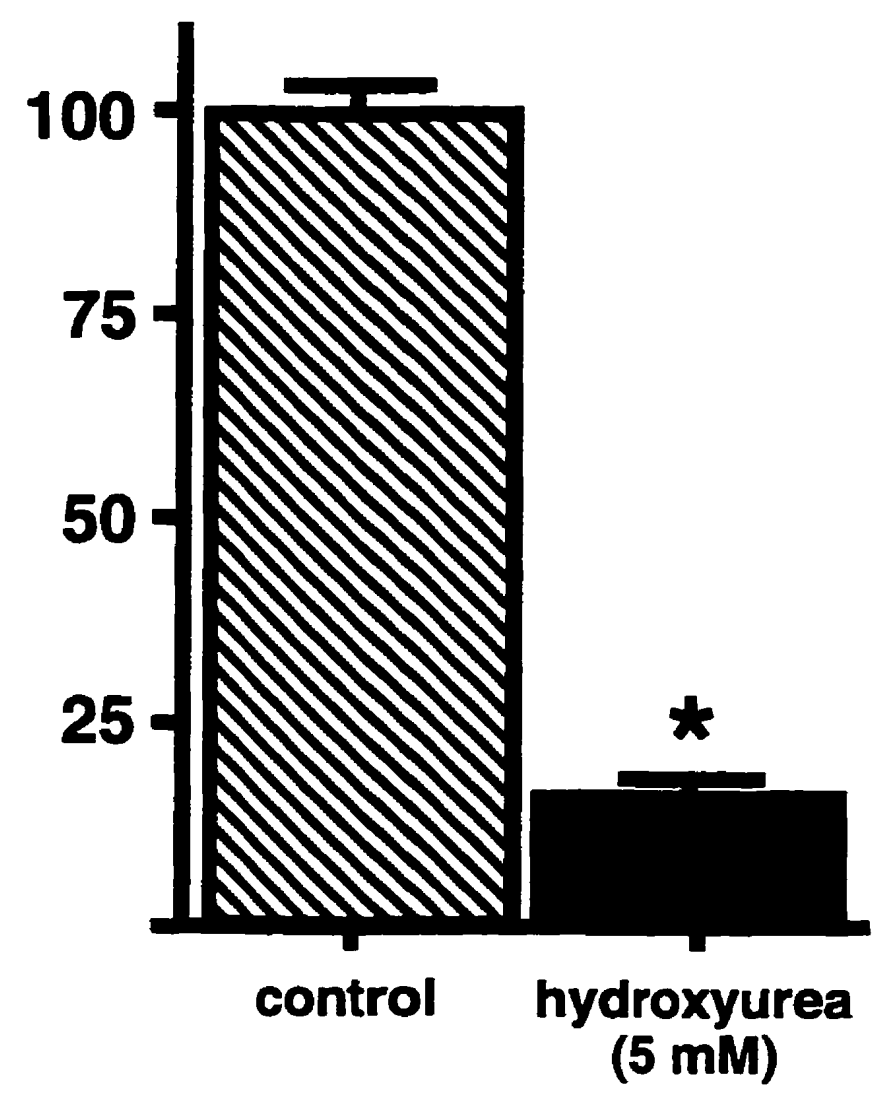


Figure 12. The graph illustrates that 24 hour pre-treatment of confluent CA SMC with $5 \mathrm{mM}$ hydroxyurea inhibits their DNA synthesis to the level which can not be further inhibit by the consecutive 48 hour treatment with increased concentrations of suramin. Quadruplicate cultures of CA SMC were maintained for an initial 24 hours in medium with 5\% FBS in the absence (hashed bar) or presence of $5 \mathrm{mM}$ hydroxyurea, and then additionally incubated in the presence or absence of indicated concentrations of suramin and hydroxyurea for 48 hours. [ ${ }^{3} \mathrm{H}$ ]thymidine was added for the final 6 hours of incubation. The results are expressed as percentage of untreated control (mean \pm SEM). 
[3H]-thymidine

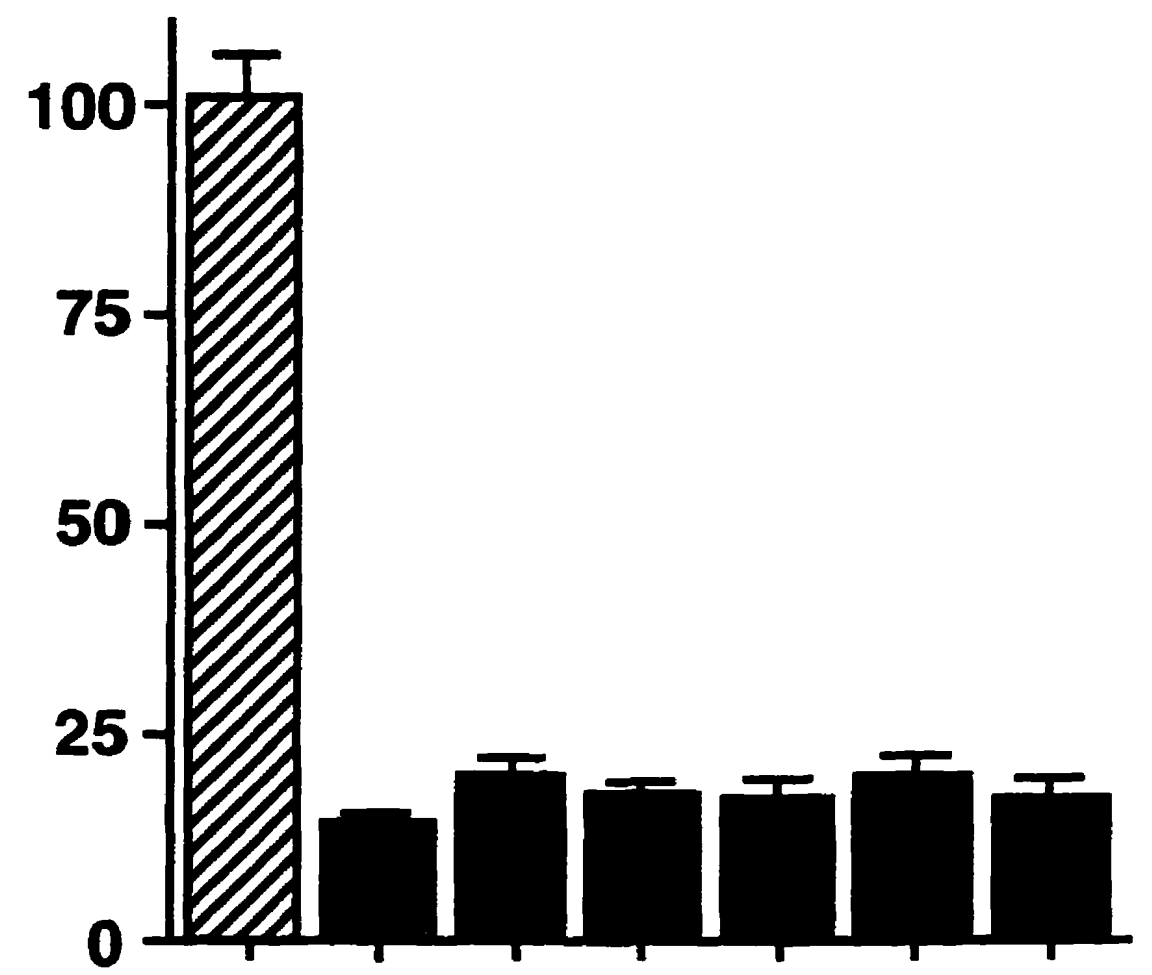

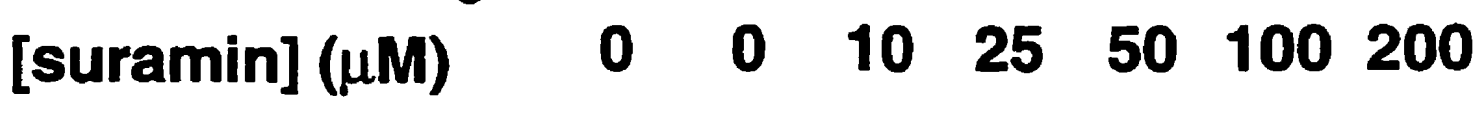

$5 \mathrm{mM}$ hydroxyurea -++++++ 
Figure 13. CA SMC pre-exposed to hydroxyurea (which blocks their proliferation) are still able to migrate into the scratch gaps of wounded cultures. Exposure to suramin inhibits their migratory capabilities. Representative photomicrographs illustrating control (A) and $100 \mu \mathrm{M}$ suramin-treated (B) CA SMC cultures 48 hours after wounding. In both groups, cells were pre-treated with $5 \mathrm{mM}$ hydroxyurea 24 hours prior to the wounding and the same concentration of hydroxyurea was maintained during the subsequent 48 hour migration period. Magnification $\times 100$. Arrow indicates the edge of wounded culture from which the migration starts. 


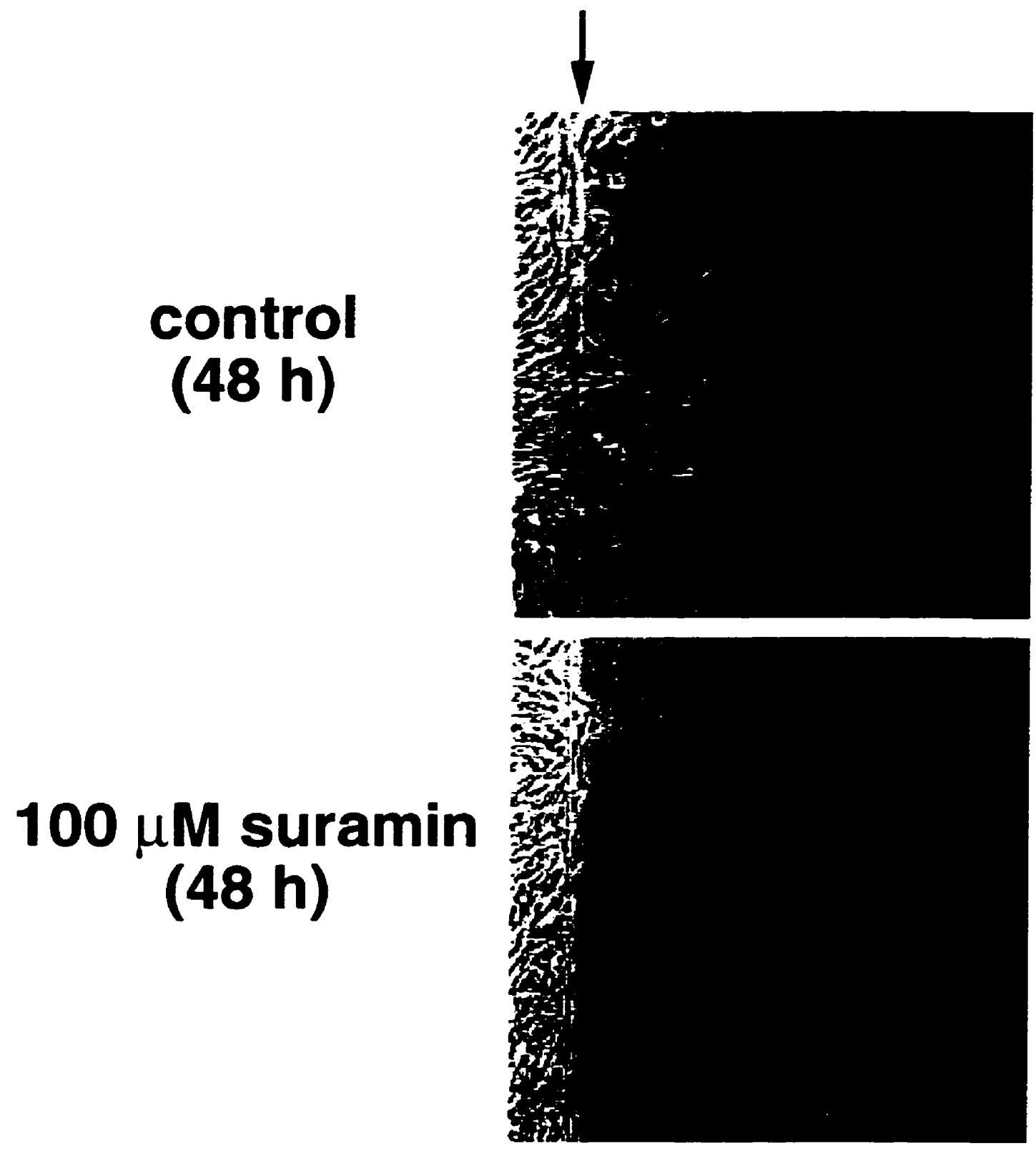


Figure 14. CA SMC are able to migrate and fill the scratch gaps of wounded cultures even in the presence of hydroxyurea which largely blocks their proliferation. Suramin can however inhibit their migration in dose-dependent manner. The upper graph (A) indicates the number of migrating CA SMC (observed in the scratch gap) and the lower graph (B) shows the maximum distance between the wounded edge and the leading migrating cells. Confluent $C A$ SMC cultures, pre-treated with $5 \mathrm{mM}$ hydroxyurea 24 hours prior to the wounding, were wounded and then maintained in medium containing $5 \mathrm{mM}$ hydroxyurea in the absence (hashed bars) or presence (solid bars) of the indicated concentrations of suramin for 48 hours. Results from four microscopic fields (2-mm diameter) were evaluated and averaged for each wound and expressed as percentage of control. Each bar represents the mean $\pm S E M$ of 12 individual culture woundings from three separate experiments, ${ }^{*} p<0.001$ compared to control. 
A.
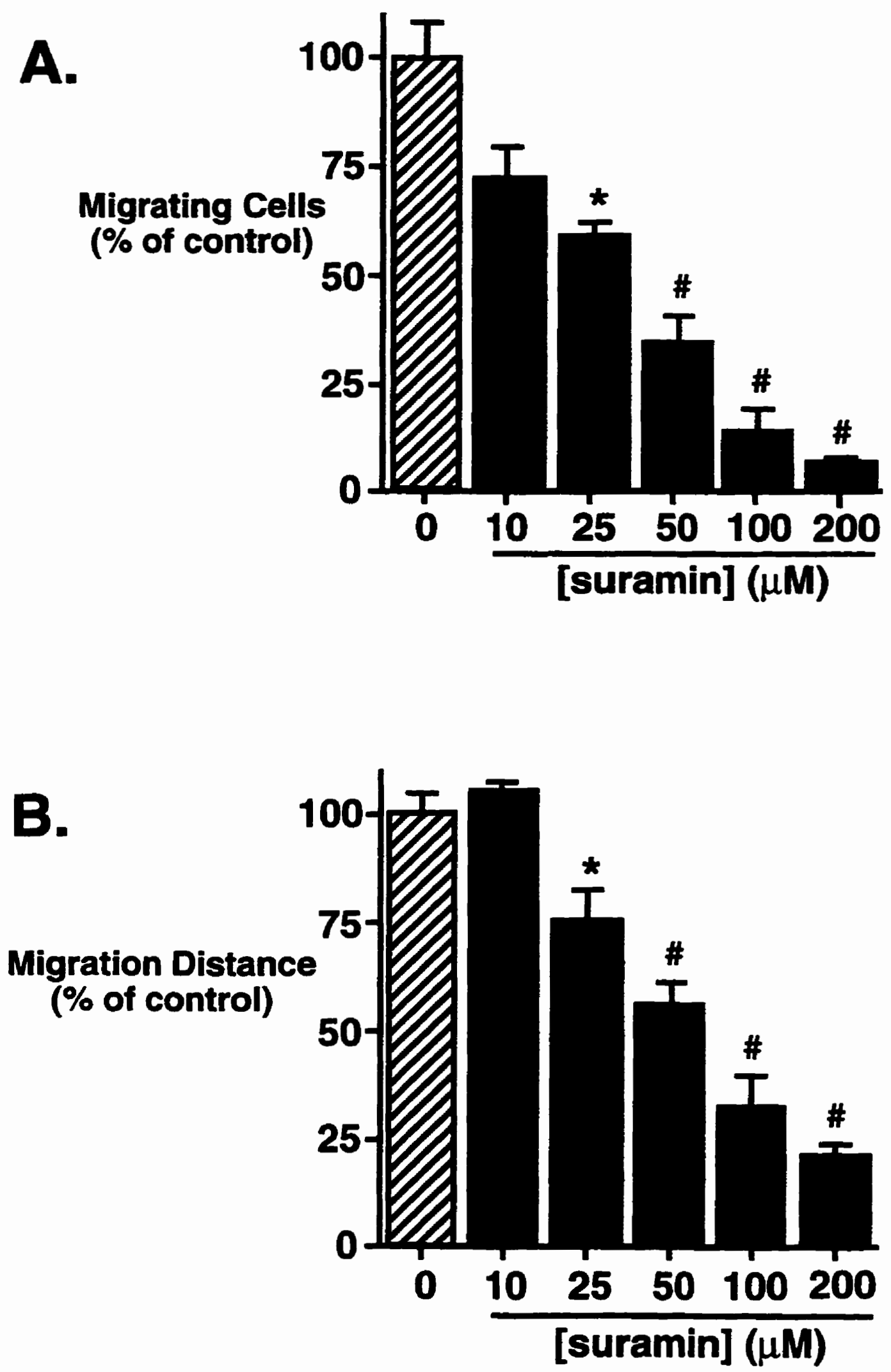
Figure 15. Suramin inhibits chondroitin sulfate-induced CA SMC migration through elastin membranes. Representative photomicrographs of transversal sections of three-dimensional scaffolds of pure elastin, 7 days after CA SMC were plated on top. Cultures were incubated in: (A) regular medium (control), (B) medium with $200 \mu \mathrm{g} / \mathrm{mL}$ CS, (C) medium with $200 \mu \mathrm{g} / \mathrm{mL}$ CS and $100 \mu \mathrm{M}$ suramin. H\&E staining, magnification $\times 100$. 
control

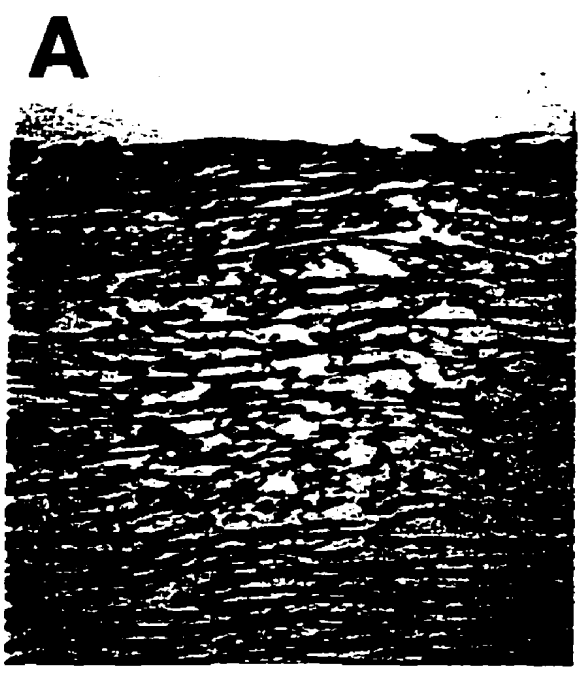

\section{CS}
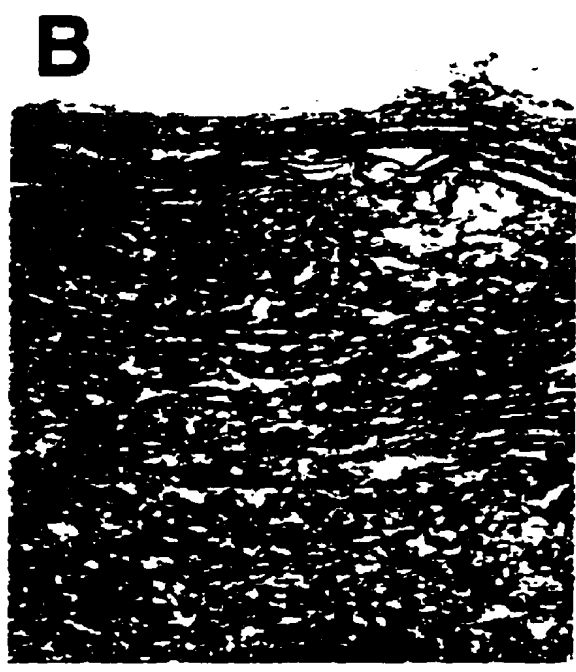

CS + suramin

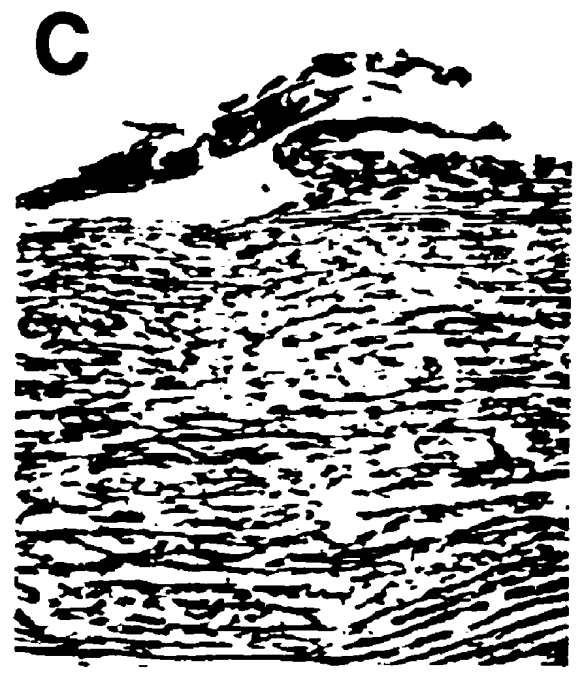


Figure 16. Suramin inhibits fibronectin deposition by CA SMC. Representative photomicrographs showing immunolocalization of fibronectin (FN) in CA SMC cultures incubated for 24 hours in normal media (A) and normal media with $100 \mu \mathrm{M}$ suramin (B). Cultures were stained with a monoclonal antibody to $\mathrm{FN}$ and GAM-FITC as well as with propidium iodide to distinguish cell nuclei. The amounts of the immunodetectable fibronectin (green fluorescence) were also quantitatively assessed (using Image Pro program) in cultures of confluent CA SMC incubated for 24 hours in the absence (hashed bar) or presence (solid bars) of indicated concentrations of suramin (C). Results from 20 separate assessments were averaged for each experimental sample and expressed as percentage of control (mean $\pm S E M),{ }^{*} p<0.001$. 


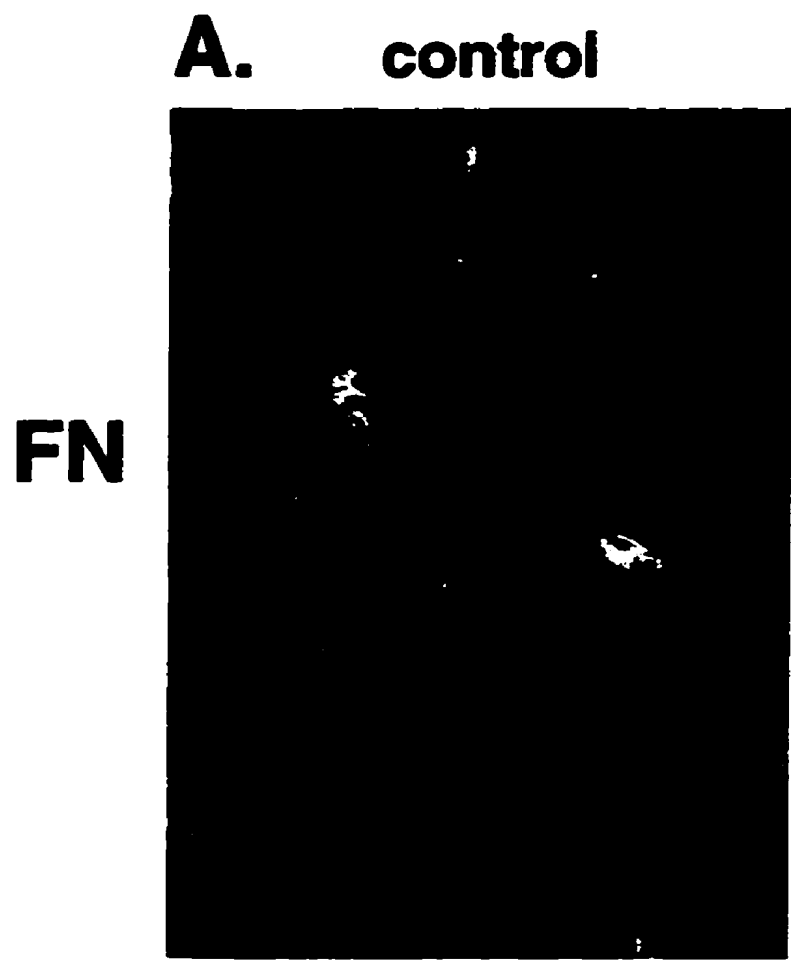

B. suramin $(100 \mu \mathrm{M})$

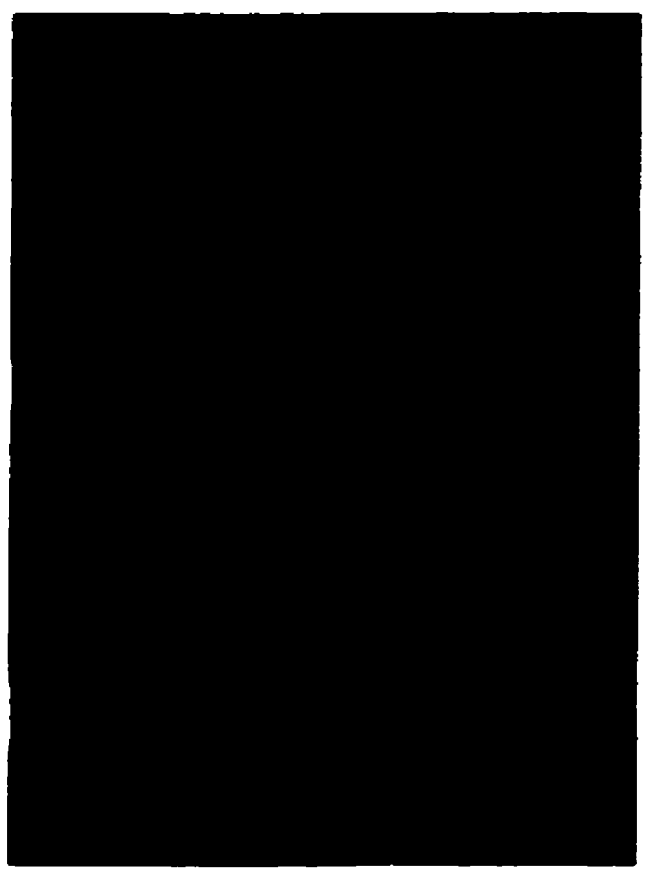

C.

Fluorescence Intensity

(\% of control)

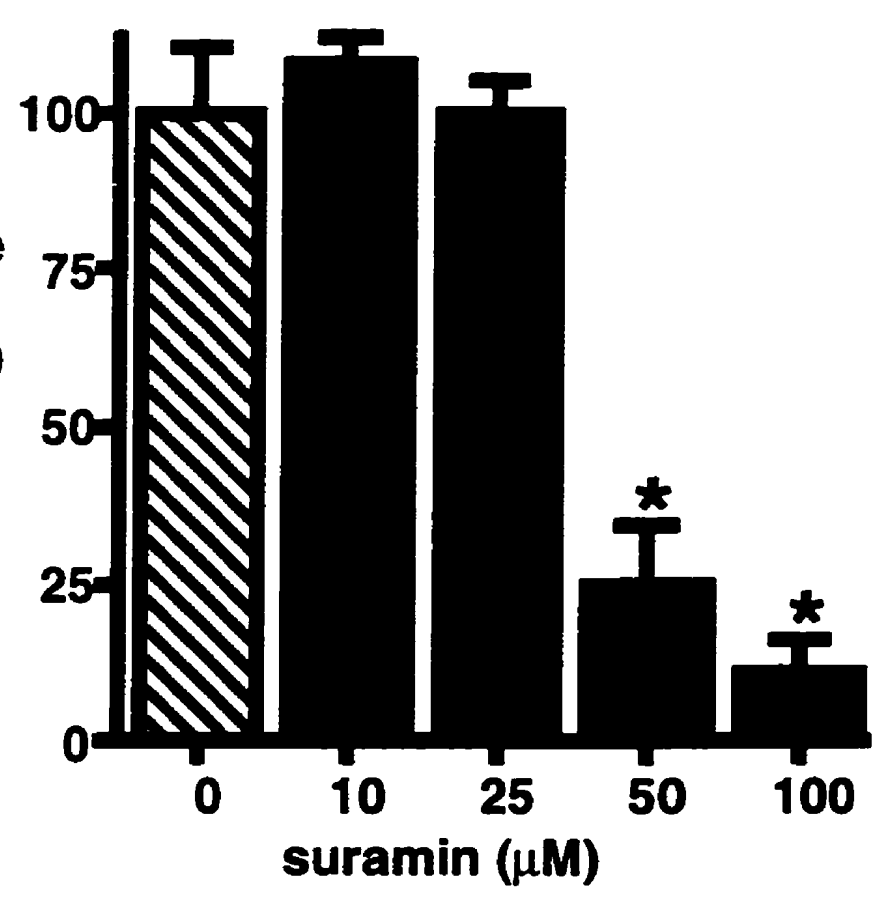


Figure 17. Suramin inhibits fibronectin mRNA levels of confluent CA SMC cultures. Northern blot analysis (A) demonstrates that confluent CA SMC cultures incubated with $200 \mu \mathrm{M}$ suramin for 24,48 , and 72 hours have reduced $F N$ mRNA levels compared to untreated controls at each time point. FN levels from autoradiograph were normalization to $28 \mathrm{~s}$ and 18s rRNA loading controls from ethidium bromide stained gels. The bar graph (B) represents densitometric analysis of the above autoradiograph. 
A.
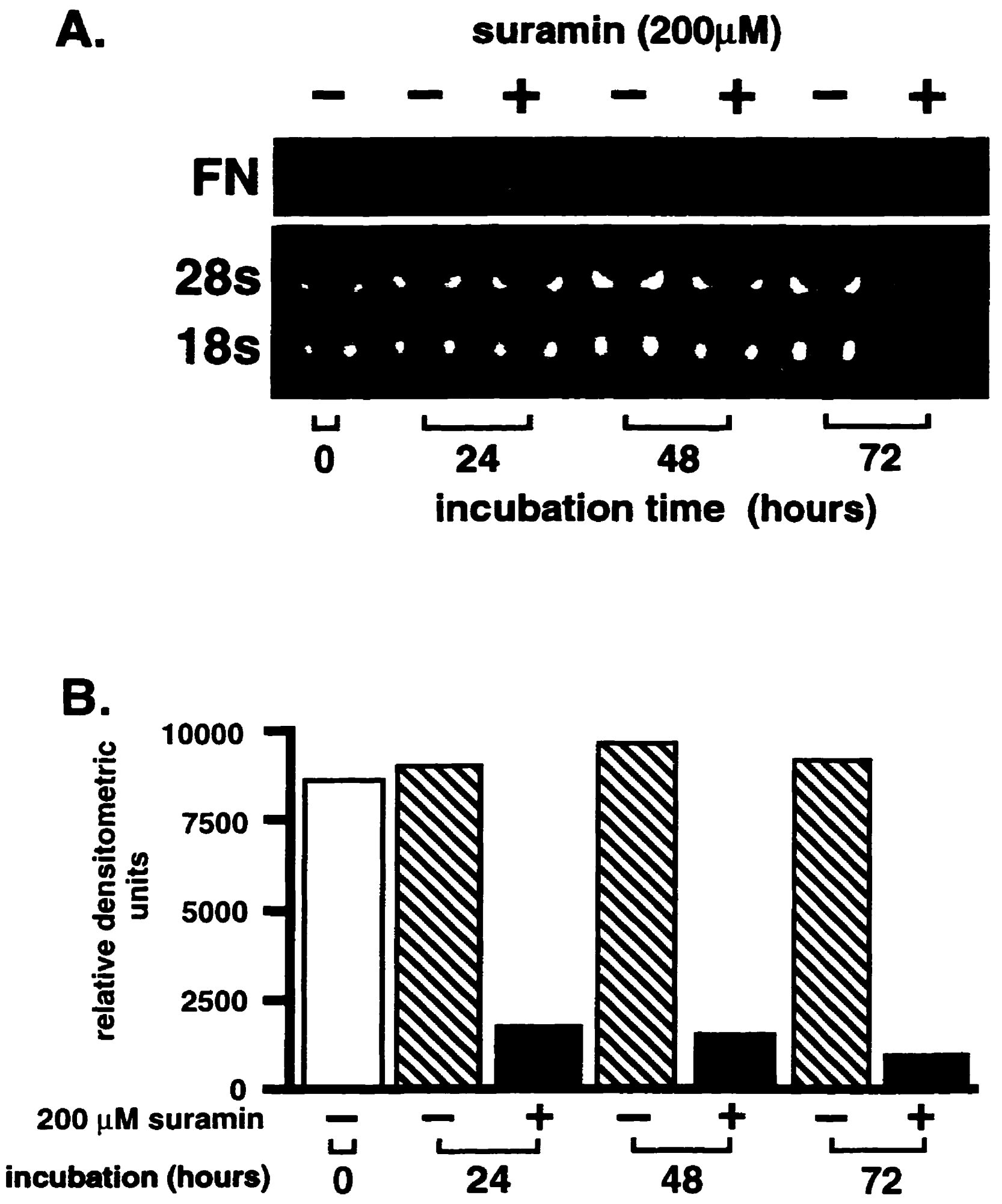
Figure 18. The Presence of exogenous fibronectin does not overcome suramin-induced inhibition of CA SMC migration. The bar graph indicates the distance of CA SMC migration on plastic (hashed bars) and on fibronectin coated surfaces (solid bars) in the absence or presence of suramin. CA SMC were densely plated only on one half of culture dishes, pre-treated with $5 \mathrm{mM}$ hydroxyurea for 24 hours, and then incubated in the presence or absence of $100 \mu \mathrm{M}$ suramin and allowed to migrated into areas devoid of cells for $\mathbf{4 8}$ hours. Five individual assessments of migration distance in 5 microscopic fields (2- $\mathrm{mm}$ diameter) were evaluated and averaged for each sample and results were expressed as percentage of control (mean \pm SEM), ${ }^{*} p<0.001$. 


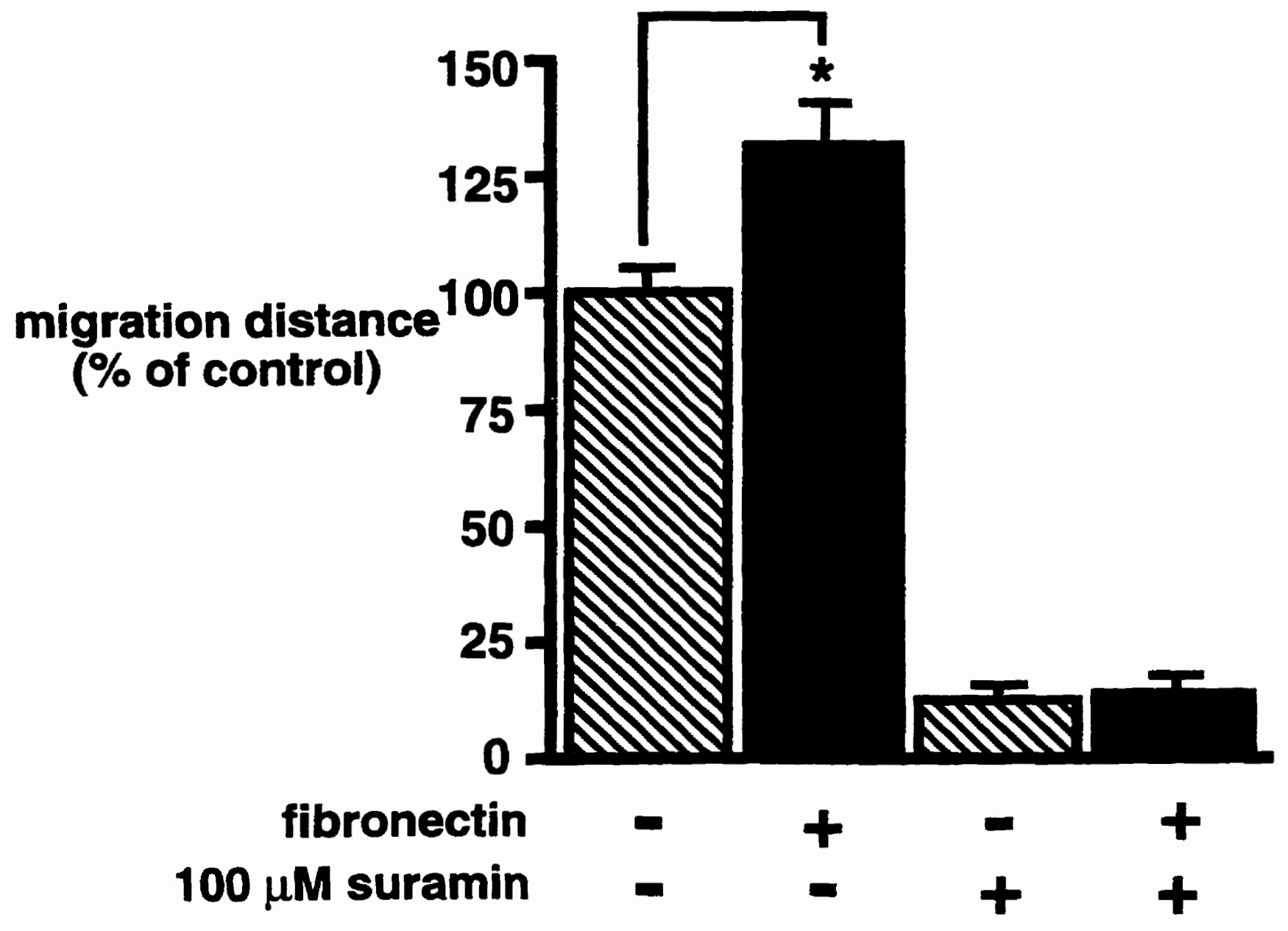


Figure 19. Suramin alters focal adhesion distribution in CA SMC. Representative photomicrographs showing immunolocalization of vinculin which marks distribution of focal adhesions in CA SMC incubated in the absence (A) or presence of $100 \mu \mathrm{M}$ suramin (B) for 24 hours. Suramin-treated CA SMC demonstrated reduced cellular protrusions and increased vinculin-positive focal adhesions compared to controls. Subconfluent cultures were stained with a monoclonal antibody to vinculin and GAM-FITC. Magnification x400. 


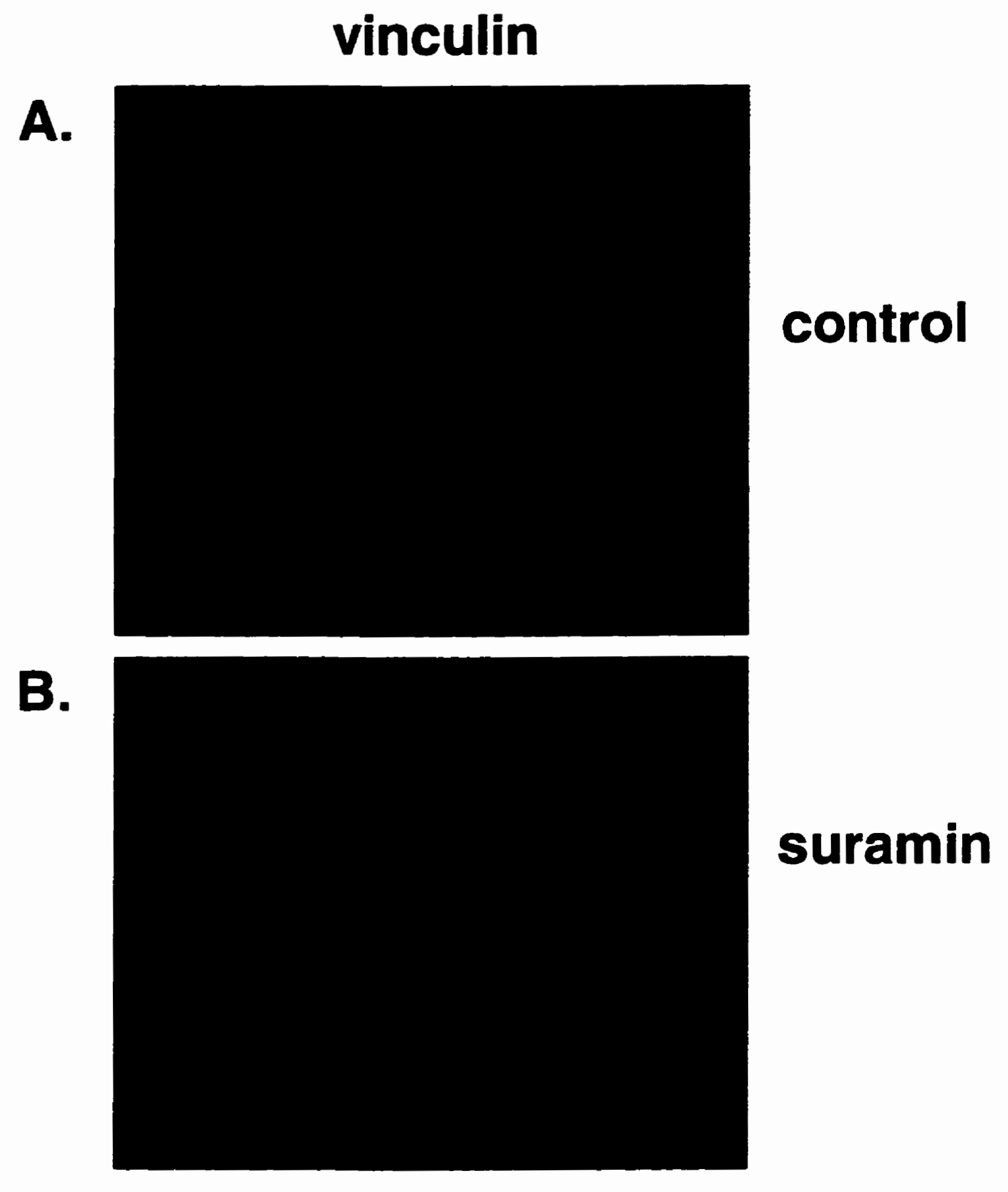


Figure 20. Suramin induces accumulation of EBP on the cell surface of CA SMC and inhibits chondroitin sulfate-induced shedding of this receptor. Representative photomicrographs showing immunolocalization of EBP on surfaces of nonpermeabilized CA SMC after 30 minute incubation in: normal medium (A), medium with $200 \mu \mathrm{g} / \mathrm{mL}$ CS (B), or medium containing $100 \mu \mathrm{M}$ suramin which was followed by the addition of $200 \mu \mathrm{g} . / \mathrm{mL}$ CS for another 30 minutes (C). Magnification $\times 400$. 


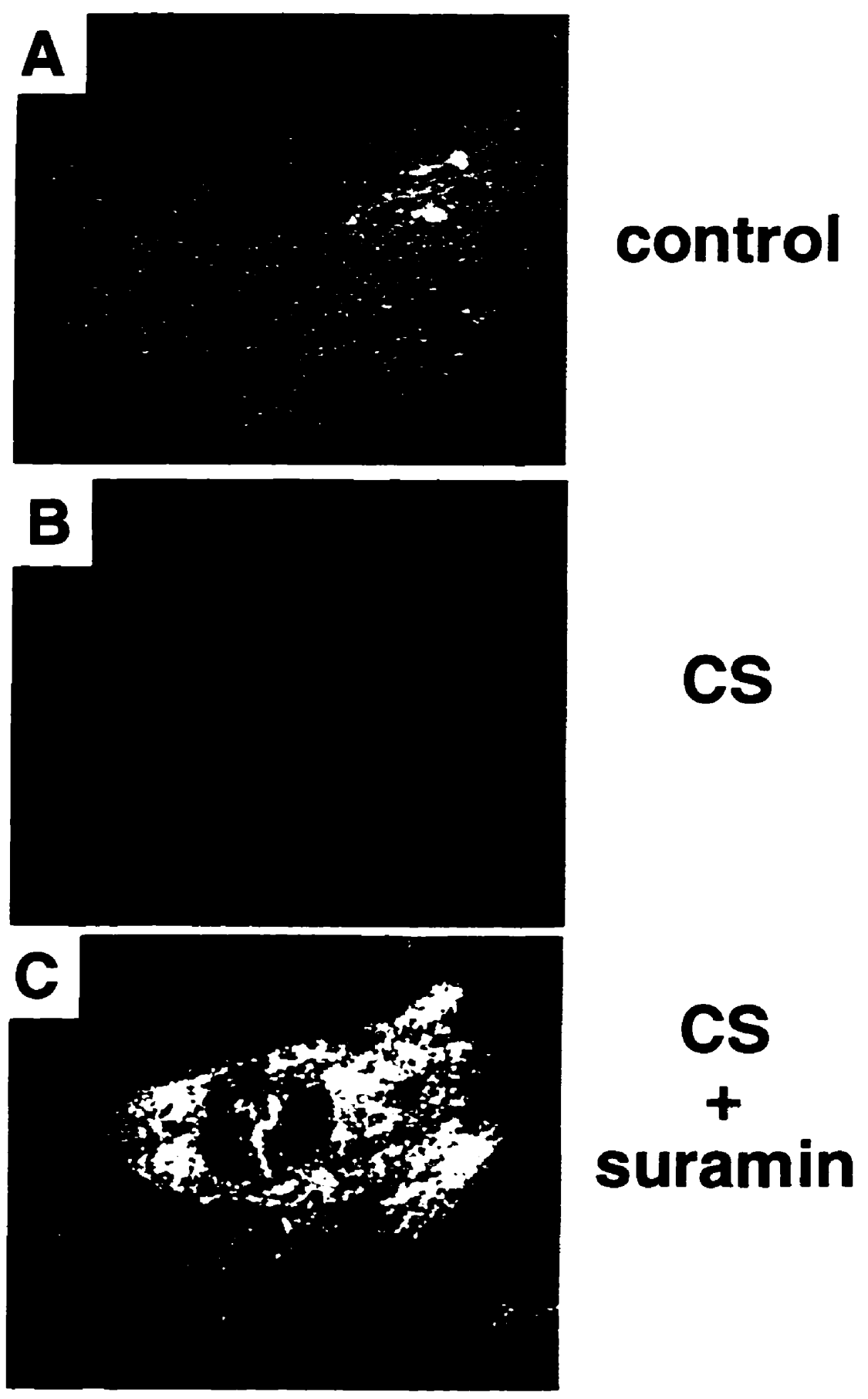


Figure 21. Suramin inhibits CA SMC response to chondroitin sulfate reducing fibronectin deposition. Representative photomicrographs showing immunolocalization of fibronectin in CA SMC cultures incubated for 48 hours in control medium (A), medium with $200 \mu \mathrm{g} / \mathrm{mL}$ CS (B), or medium with $200 \mu \mathrm{g} / \mathrm{mL}$ CS and 100 $\mu \mathrm{M}$ suramin (C). Cultures were stained with a monoclonal antibody to FN and GAMFITC as well as with propidium iodide to distinguish cell nuclei. Magnification x100. 


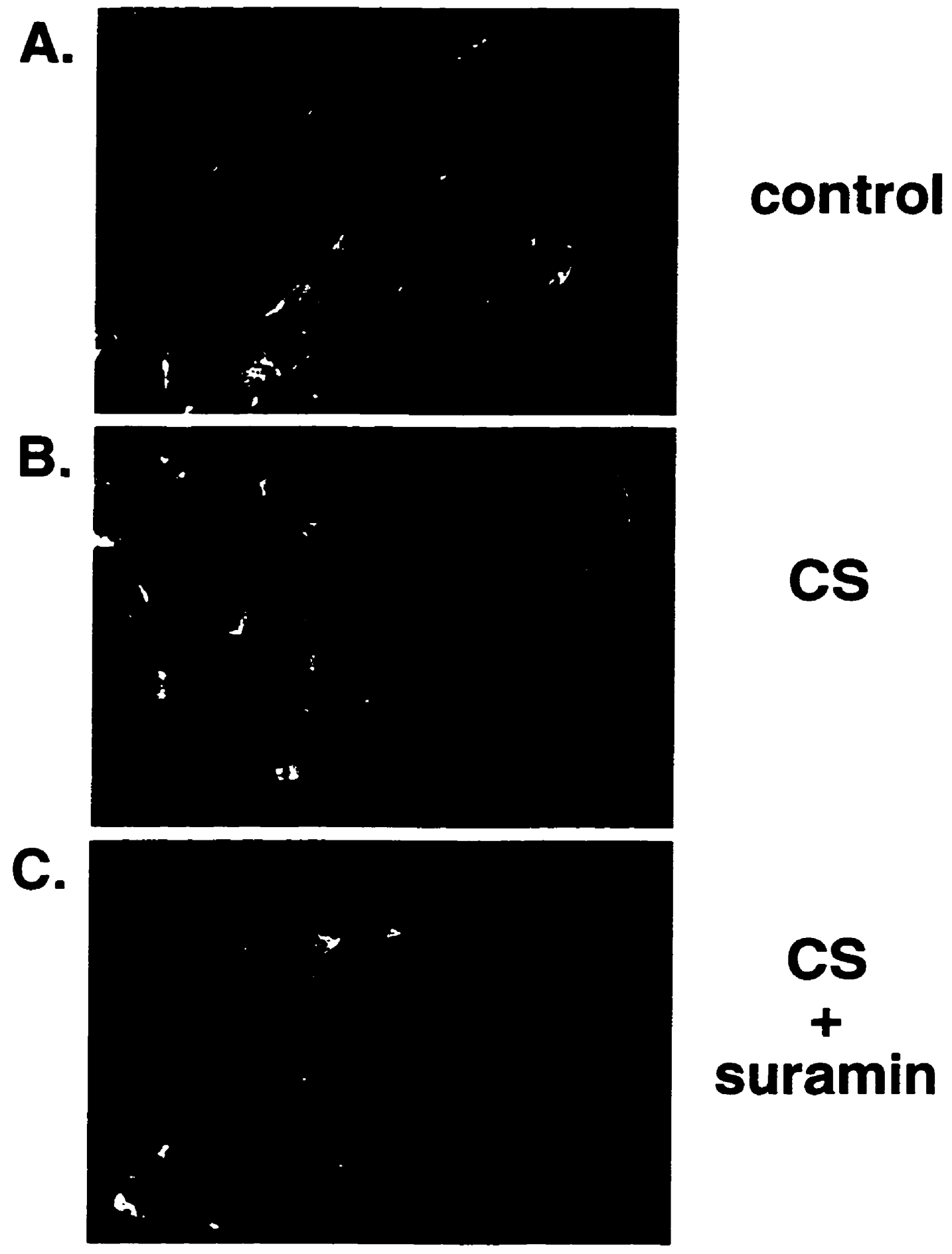




\section{DISCUSSION}

The previously described performance of suramin as an anti-cancer drug capable of interrupting cellular interactions with the major growth factors has already attracted attention of vascular researchers. A previous publication has addressed the possible therapeutic effect of this drug on the development of intimal thickening after mechanical injury of rabbit aorta (220). This study, however, did not detail the mechanism of suramin's action on vascular SMCs. The present study was therefore aimed at 1) evaluation of the suramin potential to inhibit neointimal thickening after a balloon catheter-inflicted injury of a normal and previously injured artery and 2) delineation of cellular mechanisms which might explain a suramin-dependent inhibitory effect on intimal thickening.

While single balloon catheter-inflicted damage to the intima provided a relatively clean model of the vascular response to mechanical injury, the double-injury model used in the pilot study has several features that mimic human coronary restenosis after angioplasty (57). Histologically, injury-induced neointimal lesions in these non-cholesterol-fed rabbit models resemble human fibrous coronary plaques (consisting mainly of SMCs and newly-deposited extracellular matrix) and are distinct from lesions in the cholesterol-fed rabbit model (characterized by a large number of lipid-laden macrophages) and post-transplant coronary artheriopathy which is marked with intensive lymphocyte infiltration $(226,227)$. Results from our pilot study demonstrate that suramin significantly inhibits neointimal formation after primary injury of the rabbit iliac artery (Figure 4). Suramin treatment also reduced neointimal formation in double injured arteries (Figure 5). Specific cellular mechanisms in which this drug may inhibit intimal thickening have not been elucidated yet, however results from these preliminary studies suggest that suramin may directly affect the function of vascular SMCs which are mostly responsible for the development of intimal thickening. We therefore tested whether this drug may affect three basic processes 
responsible for neointimal formation: SMC proliferation, migration and excessive production of ECM components.

At the outset of our in vitro experiments, we assessed cellular viability to confirm that the suramin concentrations used in our experiments were not cytotoxic for CA SMCs. Similarly, morphologic and trypan blue exclusion profiles of control and suramin-treated cultures suggest that cellular effects induced by suramin exposure are not the result of a generalized cytotoxic action (Figure $6 \mathrm{~A}$ ). Continued cellular viability after prolonged suramin exposure (7 days) in subsequent in vitro studies, further support these findings. Reduction in total protein synthesis observed at high concentrations of suramin $(>100 \mu \mathrm{M})$, suggest suramin may induce a general "cytostatic" effect on SMCs, and since cell motility requires protein synthesis this may be a mechanism through which cellular migration is inhibited (Figure $6 \mathrm{~B}$ ).

The known importance of growth factors in SMC proliferation during arterial restenosis and the previously demonstrated ability of suramin to directly bind several growth factors (PDGF, bFGF, EGF, IGF-1, and TGF-B) and inhibit interactions with their respective receptors (206) should be linked and considered as a major part of a suramin-dependent effect. PDGF, released from platelets after vascular injury and later by SMCs, is considered to be a mitogen for SMCs both in the early phase after intimal injury and, along with other growth factors including bFGF, may contribute to chronic SMC proliferation (99). Suramin has been observed to inhibit cellular binding of PDGF to its receptors and limit SMC proliferation stimulated by this growth factor (219). Furthermore, it has been reported that suramin inhibits the binding of bFGF to its receptors in vitro $(228,229)$ and limits SMC proliferation stimulated by All or conditioned media from damaged SMC $(217,218)$. Suramin may function in a similar fashion to heparin which is thought to inhibit intimal thickening by sequestering growth factors and displacing bFGF from the arterial wall at the site of injury (230).

Our in vitro results demonstrated that suramin significantly inhibited DNA synthesis and cellular proliferation at concentrations ranging from $50 \mu \mathrm{M}$ to $100 \mu \mathrm{M}$ 
(Figures $7+8$ ). Further increase of the suramin dose to $200 \mu \mathrm{M}$ did not demonstrate any additional inhibition on DNA synthesis. Although it is not clear to what extent proliferation contributes to intimal thickening after balloon injury, results of these experiments using clinically safe concentrations of this drug indicate that suramin may likely inhibit neointimal formation through an effect on cellular proliferation. Although SMC proliferation appears to play a critical role in the later stages of restenotic lesion development, migration of medial SMC seems to be responsible for the increased cellularity of the early restenotic lesion.

Migration of SMCs from the media to the intima through breaks in the internal elastic lamina is though to be a critical step in the development of intimal thickening (208). In the healthy and non-injured arteries SMCs are compartmentalized in the media, attached one to another and to ECM containing abundant elastic lamellae. After injury, which may include medial stretching or tearing, a sub-population of previously quiescent medial SMCs become stimulated and begin to migrate from the media to the intima. This process obviously begins after SMCs loose their tight contacts with the surrounding ECM. Since histological sections of neointimas formed in the injured arteries of suramin-treated animals contain fewer SMC then the untreated group, one can speculate that suramin may also inhibit their migration.

In the present studies, CA SMC migration was assessed following razor blade wounding injury of confluent cultured cells $(224,225)$. Since the extent of migration from wounded confluent cultures is affected by the rate of proliferation of the studied cells, the dissection of the anti-proliferative and anti-migratory effects of the studied drug is difficult. Our results demonstrate for the first time, that suramin significantly inhibits migration of CA SMCs at concentrations between $25 \mu \mathrm{M}$ and $100 \mu \mathrm{M}$ (Figure 14). Since our assays were performed in the presence of the anti-proliferative agent hydroxyurea (a technique used previously to distinguish anti-migratory from antiproliferative effects of heparin (225)), we concluded that this effect was not be due to 
suppression of SMC proliferation but reflected a suramin-dependent inhibition of cellular migration.

We have established that 24 hour pre-treatment with $5 \mathrm{mM}$ hydroxyurea resulted in near complete inhibition of cell proliferation (Figure 11) which could not be further inhibited by suramin (Figure 12). Previous studies have shown that hydroxyurea does not alter VSMC migration compared to irradiated control cells (225). Additional data demonstrated that more complete inhibition of CA SMC movement into scratch gaps was observed in 2 (Figure $9 \& 10$ ) and 7 day (data not shown) wounding migration assays tested in the absence of a proliferation block. Thus the total suramindependent effect seems to be due to its inhibitory effect on both SMC proliferation and migration.

Although migration into the scratch gap of monolayer culture, with the two dimensional nature of the migratory plane may not fully reflect the three dimensional in vivo movement of SMCs through the vascular wall, this technique allows for direct, continual observation over time and precise quantification of both single cell and population characteristics. This method can be used for both short-term, time lapse analysis - to enable individual cells to be studied- and for long term analysis over days, such as in the case with this study.

Our study also showed that in contrast to the elongated or stelate-shaped migrating control SMCs, the suramin treated cells were more rounded and symmetrical, suggesting that suramin affected organization of their cytoskeleton. SMCs exposed to suramin did not exhibit the extended lamellipodia normally present in actively migrating SMCs and demonstrated a visible increase in number of vinculinpositive focal adhesions distributed uniformly around the cell periphery. These findings were in sharp contrast to the untreated SMCs which displayed few scattered focal adhesions present on their multiple cellular protrusions (Figure 19) .

Remodeling of the ECM in the injured vascular wall, involving partial degradation of existing ECM and accumulation of new ECM components produced by 
activated SMCs, also contributes to the pathogenesis of arterial restenosis (55). The modified ECM, does not simply provide an inert scaffolding that stabilizes the physical structure of newly formed intima, but actively modulates the proliferative and migratory behaviour of arterial SMCs. Specifically the matrix glycoprotein fibronectin has been shown to facilitate and mediate SMC migration in vitro and in vivo $(112-116,119)$. Increased SMC migration may be dependent on increased synthesis and deposition of cell associated fibronectin in several models of neointimal formation including heart transplant coronary arteriopathy, late gestational intimal cushion formation in the ductus arteriosus, and in restenotic lesion formation $(112-115,119,120,123)$. Results from the present study demonstrate that suramin inhibits fibronectin deposition by CA SMCs in vitro (Figure 16). Similar to the migration and proliferation assays, the most profound inhibition on fibronectin production was observed at a suramin concentration of $100 \mu \mathrm{M}$. Northem blot analysis revealed that suramin inhibited steady-state mRNA levels of fibronectin suggesting a potential effect of suramin on transcription and/or stability of fibronectin (Figure 17).

Since fibronectin has been implicated as a critical factor facilitating SMC migration during neointimal formation, we speculated that the suramin-dependent inhibition of CA SMC migration can be directly linked to a decrease in fibronectin deposition. Our experiments showed that while pre-existing exogenous fibronectin (fibronectin covered dishes) stimulates migration of untreated cells, its presence does not reverse the inhibitory effect of suramin on SMC migration (Figure 18). The inability of exogenous fibronectin to overcome suramin's inhibitory effects on CA SMC migration indicates that other mechanisms modulating cellular migration may also be affected by suramin confirming a multi-targeted action of this drug. We hypothesized that one such additional mechanism may concern the strengthening of SMC anchorage to the extracellular matrix through a suramin-dependent modification of cell surface receptors. 
In order to proliferate and migrate, vascular SMCs must detach from the abundant elastic fibers and laminae present in the tunica media of the restenotic arteries. Cellular interactions with these elastic structures in intact arteries, immobilize the SMCs and provide physical barriers for their migration. Previous studies from our laboratory have established that contact between cells and elastic membranes is mediated by a non-integrin cell surface receptor complexes consisting of three protein subunits $(124,125)$. Two of these subunits $(61-k D$ and $55-k D)$ are cell membraneassociated proteins which immobilize the third 67-kD peripheral elastin binding protein (EBP), which is also capable of binding B-galactosugars $(124,125,126)$. Furthermore, Hinek et al $(127,128)$ have shown that there is a functional relationship between deficiency in the expression of cell-surface EBP, detachment from elastin, and capability of SMC to migrate.

Vascular SMCs isolated from intimal cushions of the late gestation ductus arterioles display reduced adherence to elastin covered dishes when compared to medial SMC taken from aorta. Additionally, in contrast to aortic SMCs which display EBP on their cell surface, ductus arteriosus SMCs, which are deficient in EBP, are unable to anchor to insoluble elastin resulting and they migrate freely through scaffolds of elastin membranes (127). Moreover, addition of $\mathrm{N}$-acetyl-galactosamine containing glycosaminoglycans, chondroitin sulfate or dermatan sulfate, (glycosaminoglycans that accumulate in atherosclerotic and injured vessels), causes detachment of normal aortic SMCs from the elastin-coated surfaces and stimulates aortic SMC migration through elastic membranes. This sudden loss of cell-matrix interactions was synchronized with the shedding of EBP from the cell surface due to the chondroitin sulfate-induced dissociation of EBP from the two other components of this cell surface receptor. It has been speculated that detachment from elastic membranes may represent a critical step in the process promoting SMC migration associated with intimal thickenings. Since suramin can cause upregulation of cellsurface expression of several receptors $(204,205)$, we speculate that this drug may 
also induce prolonged expression of EBP on the surface of SMCs which may alter cellular attachment to the ECM.

In the present study we observed that exposure to suramin causes an unusual accumulation of cell surface EBP (detected by immunostaining) and renders it unresponsive to the shedding effects of chondroitin sulfate (Figure 20). This suramininduced accumulation of EBP also coincides with an increased attachment to elastin and an abolition of chondroitin sulfate-induced CA SMC migration through elastin membranes (Figure 15). We speculate therefore, that in addition to other suramindependent mechanisms which inhibit SMC migration, this drug may inhibit EBP endocytosis, the first stage of its normal recycling (125), resulting in its accumulation on the cell surface and increased attachment to elastin matrices.

The unusual accumulation of EBP molecules on the cell surfaces may also be linked to the functional decrease in fibronectin deposition since EBP may functionally block the adjacent IL-1 receptor type 1 of vascular SMC (116). The loss of cell-surface EBP, through shedding or intemalization, has been previously proposed to allow for unrestricted cellular response to IL-1 $\beta$ and upregulation of fibronectin synthesis, which, in turn, facilitates SMC migration (116). In addition to the above mentioned mechanism, suramin may also induce conformational changes in the EBP and prevent its interaction with galactosugars. Results from this study demonstrate that exposure to suramin prevents CS-dependent shedding of the EBP and abolishes the subsequent stimulatory effects on fibronectin production (Figure 21).

In summary, the present study indicates that suramin is not cytotoxic but inhibits crucial features of activated SMC phenotype normally responsible for the development of pathological intimal thickening of injured arteries. We have demonstrated that suramin, at relatively low and clinically safe concentrations $(25-200 \mu \mathrm{M})$, was able to inhibit of CA SMC proliferation and migration in vitro, as well as inhibit the deposition of fibronectin; a glycoprotein which is over-expressed by activated SMC and contributes to intimal thickening by facilitating cell migration. Our data also suggest 
that in addition to the previously described cellular effects of suramin, this drug induces cell-surface aggregation of the 67-kD elastin binding protein which not only immobilizes cells to extracellular matrix containing elastin, laminin and collagen type IV but may also block adjacent IL-1 type 1 receptors and inhibit the CA SMC response to this cytokine.

The fact that suramin has been approved for human clinical use seems to be especially encouraging for any further clinical testing regarding vascular disease. As the most pronounced intimal thickening during restenosis occurs within the first few weeks after balloon angioplasty, perhaps a short-term regime of suramin administration immediately following PTCA might lead to attenuation of the vascular occlusion associated with this common therapeutic procedure with only minimal side effects. Additionally, although undesirable side-effects such as compromised endothelial regeneration may result from such a regime, a dramatic reduction in SMC activation accomplished by suramin after balloon injury might outweigh any such negative complications. Overall results of this study suggest that suramin acts as a multi-target inhibitor of SMC activation, thus it should be considered and further examined as a potential therapeutic agent that may attenuate intimal thickening and restenosis after angioplasty of atherosclerotic arteries. 


\section{REFERENCES}

1. Virmani R., Farb A., Burke A.P. Coronary angioplasty from the perspective of atherosclerotic plaque: morphologic predictors of immediate success and restenosis. Am. Heart. J. 127:163-174, 1994.

2. Ross R. The pathogenesis of atherosclerosis: A perspective for the 1990s. Nature 362:801-809, 1993.

3. Davies M.J., Thomas A.N. Thrombosis and acute coronary artery lesions in sudden cardiac ischemic death. N. Engl. J. Med. 310:1137-1140, 1984.

4. Detre K., Holubkov R., Kelsey S., Cowley M., Kent K., Williams D., Myler R., Faxon D., Holmes D.J., Bourassa M., Block P., Gosselin A., Bentiviglio L., Leatherman L., Dorios G., King S., Galichia J., Al-Bassam M., Leon M., Robertson T., Passomani E. Percutaneous transluminal coronary angioplasty in 1985-1986 and 1977-1981. The National Heart, Lung, and Blood Institute Registry. N. Eng. J. Med. 318:265-270, 1988.

5. Ip J.H., Fuster V., Israel D., Badimon L., Badimon J., Chesebro J.H. The role of platelets, thrombin and hyperplasia in restenosis after coronary angioplasty. J. Am. Coll. Cardiol. 17:77B-88B, 1991.

6. Landzberg B.R., Frishman W.H., Lerrick K. Pathophysiology and pharmacological approaches for prevention of coronary artery restenosis following coronary artery balloon angioplasty and related procedures. Prog. Vasc. Dis. 39:361398, 1997.

7. Gruentzig A.R., Senning A., Siegenthaler W.E. Nonoperative dilation of coronary artery stenosis: percutaneous transluminal angioplasty. N. Engl. J. Med. 301:61-68, 1979.

8. Waller,B.F. "Crackers, breakers, stretchers, drillers, scrapers, shavers, burners, welders, melters"; the future treatment of atherosclerotic coronary artery diseases? A clinical-morphologic assessment. J. Am. Coll. Cardiol. 13:969-87, 1989.

9. Kovach J.A., Mintz G.S., Pichard A.D., Kent K.M., Popma J., Salter L.F., Leon, M.B. Sequential intravascular ultrasound characterization of the mechanisms of rotational atherectomy and adjunct balloon angioplasty. J. Am. Coll. Cardiol. 22:102432, 1993.

10. Abrupt closure: The CAVEAT I experience. J. Am. Coll. Cardiol. 26:1494-1500, 1995.

11. Cowley M.J., Dorros G., Kelsey S.F., VanRaden M., Detre K.M. Acute coronary events associated with percutaneous transluminal coronary angioplasty. Am. J. Cardiol. 53:12C-15C, 1984.

12. Hollman J., Gruentzig A.R., Douglas J.S., King S.B.III, Ischinger T., Meier B. Acute occlusion after percutaneous transluminal coronary angioplasty-A new approach. Circulation 68:725-732, 1983. 
13. Leimgruber P.P., Roubin G.S., Hollman J., Cotsonis G.A., Meier B., Douglas J.S., King S.B.Jr., Gruentzig A.R. Restenosis after successful angioplasty in patients with single-vessel disease. Circulation 73:710-717, 1986.

14. Serruys P.W., Luijten H.E., Beatt K.J., Geuskens R., deFeyter P.J., vanden Brand M., Reiber J.H., tenKaten H.J., CanEs G.A., Hugenholtz P.G. Incidence of restenosis after successful coronary angioplasty: a time related phenomenon. A quantitative angiographic study in 342 consecutive patients at 1,2 , and 3 months. Circulation 77:361-372, 1988.

15. Holmes D.R.J., Vlietstra R.E., Smith H.C., Vetrovec G.W., Kent K.M., Cowley M.J., Faxon D.P., Gruentzig A.R., Kelsey S.F., Detre K.M., Mark J., VanRaden M.A., Mock M.B. Restenosis after percutaneous transluminal coronary angioplasty (PTCA): a report from the PTCA Registry of the National Heart, Lung, and Blood Institute. Am. J. Cardiol. 53:77C-81C, 1984.

16. Reeder G.S., Krishan I., Nobrega F.T., Naessens J., Kelly M., Christianson J.B., McAfee M.K. Is percutaneous coronary angioplasty less expensive than bypass surgery? N. Engl. J. Med. 311:1157-1162, 1984.

17. Lefkovits J., Topol E.J. Pharmacological approaches for the prevention of restenosis after percutaneous coronary intervention. Prog. Cardiovasc. Dis. 40:141-58, 1997.

18. Rubin,E., and Farber,J.L. In: Pathology, Second Edition, J. B. Lippincott Co. (Philadelphia), pp. 457-460, 1994.

19. Forrester J.S., Fishbein M., Helfant R., Fagin J. A paradigm for restenosis based on cell biology: clues for the development of new preventive therapies. J. Am. Coll. Cardiol. 17:758-69, 1991.

20. Gravanis M.B., Roubin G.S. Histopathologic phenomena at the site of percutaneous transluminal coronary angioplasty: the problem of restenosis. Hum. Pathol. 20:477-85, 1989.

21. Garg U.C., Hassid A. Nitric oxide-generating vasodilators and 8-bromo-cyclic guanosine monophosphate inhibit mitogenesis and proliferation of cultured rat vascular smooth muscle cells. J. Clin. Invest. 83:1774-7, 1989.

22. Folts J.D., Stamler J., Keaney J.F.Jr. Coating stenosed intimally damaged dog coronary arteries with nitrosated albumin prevents platelet adhesion-aggregation and thrombus formation. Circulation 90:1-345, 1994.

23. Reidy M.A., Clowes A.W., Schwartz S.M. Endothelial regeneration. V. Inhibition of endothelial regrowth in arteries of rat and rabbit. Lab. Invest. 49:569-75, 1983.

24. Lindner V., Reidy M.A., Fingerle J. Regrowth of arterial endothelium. Denudation with minimal trauma leads to complete endothelial cell regrowth. Lab. Invest. 61:556-63, 1989. 
25. Weidinger F.F., McLenachan J.M., Cybulsky M.I., Gordon J.B., Rennke H.G., Hollenberg N.K., Fallon J.T., Ganz P., Cooke J.P. Persistent dysfunction of regenerated endothelium after balloon angioplasty of rabbit iliac artery. Circulation 81:1667-79, 1990.

26. Haudenschild C.C., Schwartz S.M. Endothelial regeneration. II. Restitution of endothelial continuity. Lab. Invest. 41:407-18, 1979.

27. Reidy M.A., Schwartz S.M. Endothelial regeneration. III. Time course of intimal changes after small defined injury to rat aortic endothelium. Lab. Invest. 44:301-8, 1981.

28. Reidy M.A., Standaert D., Schwartz S.M. Inhibition of endothelial cell regrowth. Cessation of aortic endothelial cell replication after balloon catheter denudation. Arteriosclerosis 2:216-20, 1982.

29. Clowes A.W., Clowes M.M. Kinetics of cellular proliferation after arterial injury. III. Endothelial and smooth muscle growth in chronically denuded vessels. Lab. Invest. 54: 295-303, 1986

30. Fingerle J., Johnson R., Clowes A.W., Majesky M.W., Riedy,M.A. Role of platelets in smooth muscle cell proliferation and migration after vascular injury in rat carotid artery. Proc. Natl. Acad. Sci. USA. 86:8412-8416, 1989.

31. LeBreton H., Plow E.F., Topol E.J. Role of platelets in restenosis after percutaneous coronary revascularization. J. Am. Coll. Cardiol. 28:1643-51, 1996.

32. Oates J.A., FitzGerald G.A., Branch R.A., Jackson E.K., Knapp H.R., Roberts L.J.2. Clinical implications of prostaglandin and thromboxane A2 formation (2). N. Engl. J. Med. 319:761-767, 1988.

33. Ross R., Raines E.W., Bowen-Pope D.F. The biology of platelet-derived growth factor. Cell 46:155-169, 1986.

34. Walz D.A., Anderson G.F., Ciaglowski R.E., Aiken M., Fenton J.W. Thrombinelicited contractile responses of aortic smooth muscle. Proc. Soc. Exp. Biol. Med. 180:518-526, 1985.

35. Badimon L., Badimon J.J. Mechanism of arterial thrombosis in nonparallel streamlines: platelet thrombi grow at the apex of stenotic severely injured vessel wall: experimental study in the pig model. J. Clin. Invest. 84:1134-44, 1989.

36. Fernandez-Ortiz A., Badimon J.J., Flak E., Fuster V., Meyer B., Mailhac A., Weng D., Shah P.K., Badimon L. Characterization of the relative thrombogenicity of atherosclerotic plaque components: Implications for consequences of plaque rupture. J. Am. Coll. Cardiol. 23:1562-1569, 1994.

37. Wilentz J.R., Sanborn T.A., Haudenschild C.C., Valeri C.R, Ryan T.J., Faxon D.P. Platelet accumulation in experimental angioplasty: time course and relation to vascular injury. Circulation 75:636-642, 1987.

38. Friedman R.J., Stemerman M.B., Wenz B., Moore S., Gauldie J., Gent M., Tiell M.L., Spaet H. The effect of thrombocytopenia on experimental arteriosclerotic lesion 
formation in rabbits. Smooth muscle cell proliferation and re-endothelialization. J. Clin. Invest. 60:1191-1201, 1977.

39. Tanaka H., Sukhova G.K., Swanson S.J., Slinton S.K., Ganz P., Cybulsky M.I., Libby P. Sustained activation of vascular cells and leukocytes in the rabbit aorta after balloon injury. Circulation 88:1788-1803, 1993.

40. Fuster V., Falk E., Fallon J.T., Badimon L., Chesebro J.H., Badimon J.J. The three processes leading to post PTCA restenosis: Dependence on the lesion substrate. Thromb. Haemost. 74:552-559, 1995.

41. Guzman L.A., Whitlow P.L., Beall C.J., Kolattakudy P. Monocyte chemotactic protein antibody inhibits restenosis in the rabbit atherosclerotic model. Circulation 88:11$371,1993$.

42. Campbell G.R., Campbell J.H., Manderson J.A., Horrigan S., Rennick R.E. Arterial smooth muscle: a multifunctional mesenchymal cell. Arch. Pathol. Lab. Med. 112:977-86, 1988.

43. Bauters C., de G.P., Adamantidis M., Delcayre C., Hamon M., Lablanche J.M., Bertrand M.E., Dupuis B., Swynghedauw B. Proto-oncogene expression in rabbit aorta after wall injury. First marker of the cellular process leading to restenosis after angioplasty? Eur. Heart J. 13:556-9, 1992.

44. Miano J., Vlasic N., Tota R., Stemerman M. Localization of fos and jun proteins in rat aortic smooth muscle cells after vascular injury. Am. J. Pathol. 142:715-724, 1993.

45. Simons M., Edelman E.R., DeKeyser J.-L., Langer R., Rosenberg R.D. Antisense c-myb oligonucleotides inhibit intimal arterial smooth muscle cell accumulation in vivo. Nature 359:67-70, 1992.

46. Bennett M.R., Anglin S., McEwan J.R., Jagoe R., Newby A.C., Evan G.I. Inhibition of vascular smooth muscle cell proliferation in vitro and in vivo by $c$-myc antisense oligodeoxynucleotides. J. Clin. Invest. 93:820-8, 1994.

47. Pickering J., Weir L., Jekanowski J., Kearney M., Isner J. Proliferative activity in peripheral and coronary atherosclerotic plaque among patients undergoing percutaneous revascularization. J. Clin. Invest. 91:1469-1480, 1993.

48. Webster M.W.I., Chesebro J.H., Heras M., Mruk J.S., Grill D.E., Fuster V. Effect of balloon inflation on smooth muscle cell proliferation in the porcine carotid artery. $\mathrm{J}$. Am. Coll. Cardiol.14:165A, 1990.

49. Nobuyoshi M., Kimura T., Ohishi H., Horiuchi H., Nosaka H., Hamasaki N., Yokoi $\mathrm{H}$., Kim K. Restenosis after percutaneous transluminal coronary angioplasty: pathologic observations in 20 patients. J. Am. Coll. Cardiol. 17:433-9, 1991.

50. O'Brien E.R., Alpers C.E., Stewart D.K., Ferguson M., Tran N., Gordon D., Benditt E.P., Hinohara T., Simpson J.B., Schwartz S.M. Proliferation in primary and restenotic coronary atherectomy tissue. Implications for antiproliferative therapy. Circ. Res. 73:223-231, 1993. 
51. Ohara T., Kodama K., Mishimi M. Ultrastructural findings of proliferating and migrating smooth muscle cells at the site of percutaneous transluminal coronary angioplasty. J. Am. Coll. Cardiol. 11:131A, 1988.

52. Campbell J.H., Campbell G.R. Endothelial cell influences on vascular smooth muscle phenotype. Ann. Rev. Physiol. 48:295-306, 1986.

53. Glagov S. Intimal hyperplasia, vascular modeling and the restenosis problem. Circulation 89:2888-2891, 1994.

54. Jones P.L., Rabinovitch M. Regulation of tenascin-C, a vascular smooth muscle cell survival factor that interacts with the avB3 integrin to promote EGF receptor phosphorylation and growth. J. Cell Biol. 139:279-293, 1997.

55. Nobuyoshi M., Kimura T., Nosaka H., Mioka S., Ueno K., Yokoi H., Hamasaki N., Horiuchi $H$., Ohishi $H$. Restenosis after successful percutaneous transluminal coronary angioplasty: serial angiographic follow-up of 229 patients. J. Am. Coll. Cardiol. 12:616-623, 1988.

56. Boyd C.D., Kniep A.C., Pierce R.A., Deak S.B., Karboski C., Miller D.C., Parker M.I., Mackenzie J.W., Rosenbloom J., Scott G.E. Increased elastin mRNA levels associated with surgically induced intimal injury. Connect. Tissue Res. 18:65-78, 1988.

57. Strauss B.H., Chisholm R.J., Keeley F.W., Gotlieb A.I., Logan R.A., Armstrong P.W. Extracellular matrix remodeling after balloon angioplasty injury in a rabbit model of restenosis. Circ. Res. 75:650-658, 1994.

58. Clowes A.W., Reidy M.A., Clowes M.M. Kinetics of cellular proliferation after arterial injury. I. Smooth muscle growth in the absence of endothelium. Lab. Invest. 49:327-33, 1983.

59. Clowes A.W., Clowes M.M., Kocher O., Ropraz P., Chaponnier C., Gabbiani G. Arterial smooth muscle cells in vivo: relationship between actin isoform expression and mitogenesis and their modulation by heparin. J. Cell Biol. 107:1939-45, 1988.

60. Fingerle J., Au Y.P., Clowes A.W., Reidy M.A. Intimal lesion formation in rat carotid arteries after endothelial denudation in absence of medial injury. Arteriosclerosis 10:1082-7, 1990.

61. Walker L.N., Ramsay M.M., Bowyer D.E. Endothelial healing following defined injury to rabbit aorta. Depth of injury and mode of repair. Atherosclerosis 47:123-30, 1983.

62. Berk B.C., Taubman M.B., Griendling K.K., Cragoe E.J., Fenton J.W., Brock T.A. Thrombin-stimulated events in cultured vascular smooth-muscle cells. Biochem. J. 799805, 1991.

63. Willerson J.T., Eidt J.F., McNatt J., Yao S.K., Golino P., Anderson H.V., Buja L.M. Role of thromboxane and serotonin as mediators in the development of spontaneous alterations in coronary blood flow and neointimal proliferation in canine models with chronic coronary artery stenoses and endothelial injury. J. Am. Coll. Cardiol. 17:101B-110B, 1991. 
64. Schwartz R.S., Holmes D.J., Topol E.J. The restenosis paradigm revisited: an alternative proposal for cellular mechanisms. J. Am. Coll. Cardiol. 20:1284-93, 1992.

65. Thyberg J., Hedin U., Sjolund M., Palmberg L., Bottger B.A. Regulation of differentiated properties and proliferation of arterial smooth muscle cells. Arteriosclerosis 10:966-90, 1990.

66. Assoian R.K., Grotendorst G.R., Miller D.M., Spom M.B. Cellular transformation by coordinated action of three peptide growth factors from human platelets. Nature 309:804-6, 1984.

67. Walker L.N., Bowen-Pope D.F., Ross R., Reidy M.A. Production of plateletderived growth factor-like molecules by cultured arterial smooth muscle cells accompanies proliferation after arterial injury. Proc. Natl. Acad. Sci. USA 83:7311-7315, 1986.

68. Wilcox J.N., Smith K.M., Williams L.T., Schwartz S.M., Gordon D. Plateletderived growth factor mRNA detection in human atherosclerotic plaques by in situ hybridization. J. Clin .Invest. 82:1134-43, 1988.

69. Walker L.N., Bowen-Pope D.F., Ross R., Reidy M.A. Production of plateletderived growth factor-like molecules by cultured arterial smooth muscle cells accompanies proliferation after arterial injury. Proc. Natl. Acad. Sci. USA 83:7311-7315, 1986.

70. Assoian R.K., Groten G.R., Miller D.M., Sporm M.B. Cellular transformation by coordinate action by three peptide growth factors from human platelets. Nature 309:804$6,1984$.

71. Wilcox J.N., Scott N., Lumsden A.B., Subramanian R.R., Rodriguez J.C., Kelly A. Onset of cell proliferation and growth factor expression after clinical angioplasty of primate vascular injury. Circulation 88:I-469, 1993.

72. Ferns G.A.A., Raines E.W., Sprugel K.H., Montani A.S., Riedy M.A., Ross R. Inhibition of neointimal smooth muscle cell accumulation after angioplasty by an antibody to PDGF. Science 253:1129-1132, 1991.

73. Lindner V., Reidy M.A. Expression of basic fibroblast growth factor and its receptor by smooth muscle cells and endothelium in injured rat arteries. An en face study. Circ. Res. 73:589-95, 1993.

74. Thompson K., Rabinovitch M. Exogenous leukocyte and endogenous elastases can mediate mitogenic activity in pulmonary artery smooth muscle cells by release of extracellular matrix-bound basic fibroblast growth factor. J. Cell. Physiol. 166:495-505, 1995.

75. Lindner V., Majack R.A., Reidy M.A. Basic fibroblast growth factor stimulates endothelial regrowth and proliferation in denuded arteries. J. Clin. Invest. 85:2004-8, 1990. 
76. Meurice T., Bauters C., Auffray J.L., Vallet B., Hamon M., Valero F., Van B.E., Lablanche J.M., Bertrand M.E. Basic fibroblast growth factor restores endotheliumdependent responses after balloon injury of rabbit arteries. Circulation 93:18-22, 1996.

77. Lindner V., Reidy M.A. Proliferation of smooth muscle cells after vascular injury is inhibited by an antibody against basic fibroblast growth factor. Proc. Natl. Acad. Sci. U S A 88:3739-43, 1991.

78. Border W.A., Ruoslahti E. Transforming growth factor-beta in disease: the dark side of tissue repair. J. Clin. Invest. 90:1-7, 1992.

79. Sporn M.B., Roberts A.B., Wakefield L.M., de Crombrugghe B. Some recent advances in the chemistry and biology of transfroming growth factor-beta. J. Cell Biol. 105:1039-1045, 1987.

80. Roberts A.B., Spom M.B., Assoian R.K., Smith J.M., Roche N.S., Wakefield L.M., Heine U.I., Liotta L.A., Falanga V., Kehrl J.H. Transforming growth factor type beta: rapid induction of fibrosis and angiogenesis in vivo and stimulation of collagen formation in vitro. Proc. Natl. Acad. Sci. U S A. 83:4167-71, 1986.

81. Bassols A., Massague J. Transforming growth factor beta regulates the expression and structure of extracellular matrix chondroitin/dermatan sulfate proteoglycans. J. Biol. Chem. 263:3039-45, 1988.

82. Nikol S., Isner J.M., Pickering J.G., Keamey M., Leclerc G., Weir L. Expression of transforming growth factor-beta 1 is increased in human vascular restenosis lesions. $J$. Clin. Invest. 90:1582-92, 1992.

83. Roberts A.B., Spom M.B. Pathophysiological actions and clinical applications of TGF-B. Am. J. Physiol. 264:G179-G186, 1993.

84. Nabel E.G., Shum L., Pompili V.J., Yang Z.Y., San H., Shu H.B., Liptay S., Gold L., Gordon D., Derynck R. Direct transfer of transforming growth factor beta 1 gene into arteries stimulates fibrocellular hyperplasiz. Proc. Natl. Acad. Sci. USA 90:10759-10763, 1993.

85. Cercek B., Fishbein M.C., Forrester J.S., Helfant R.H., Fagin J.A. Induction of insulin-like growth factor I messenger RNA in rat aorta after balloon denudation. Circ. Res. 66:1755-60, 1990.

86. Tanaka H., Schwartz D., Sukhova G., Libby P. Expression of tumor necrosis factor-alpha by proliferating smooth muscle cells in the balloon injured rabbit aorta. Circulation 88:1-468, 1993.

87. Turla M.B., Thompson M.M., Corjay M.H., Owens G.K. Mechanisms of angiotensin II- and arginine vasopressin-induced increases in protein synthesis and content in cultured rat aortic smooth muscle cells. Evidence for selective increases in smooth muscle isoactin expression. Circ. Res. 68:288-99, 1991.

88. Rakugi H., Kim D., Krieger J.E., Wang D.S., Dzau V.J., Pratt R.E. Induction of angiotensin converting enzyme in the neointima after vascular injury. J. Clin. Invest. 93:339-346, 1994. 
89 Daemen M.J., Lombardi D.M., Bosman F.T., Schwartz S.M. Angiotensin II induces smooth muscle cell proliferation in the normal and injured rat arterial wall. Circ. Res. 68:450-6, 1991.

90. Powell J.S., Clozel J.P., Muller R.K., Kuhn H., Hefti F., Hosang M., Baumgartner H.R. Inhibitors of angiotensin-converting enzyme prevent myointimal proliferation after vascular injury. Science 245:186-8, 1989.

91. Itoh H., Pratt R.E., Gibbons G., Dzau V.J. Multiple autocrine growth factors modulate vascular smooth muscle cell growth response to angiotensin II. J. Clin. Invest. 91:2268-2274, 1993.

92. Vanhoutte P.M., Houston D.S. Platelets, endothelium, and vasospasm. Circulation 72:728-34, 1985.

93. Iwaki K., Sukhatme V.P., Shubeita H.E., Chien K.R. Alpha- and beta-adrenergic stimulation induces distinct patterns of immediate early gene expression in neonatal rat myocardial cells. fos/jun expression is associated with sarcomere assembly; Egr-1 induction is primarily an alpha 1-mediated response. J. Biol. Chem. 265:13809-17, 1990.

94. Hirata Y., Takagi Y., Fukuda Y., Marumo F. Endothelin is a potent mitogen for rat vascular smooth muscle cells. Atherosclerosis. 78:225-8, 1989.

95. Douglas S.A., Louden C., Vickery C.L., Storer B.L., Hart T., Feuerstein G.Z., Elliott J.D., Ohlstein E.H. A role for endogenous endothelin-1 in neointimal formation after rat carotid artery balloon angioplasty. Protective effects of the novel nonpeptide endothelin receptor antagonist SB 209670. Circ. Res. 75:190-7, 1994.

96. Bendeck M.P., Zempo N., Clowes A.W., Galardy R.E., Reidy M.A. Smooth muscle cell migration and matrix metalloproteinase expression after arterial injury in the rat. Circ. Res. 75:539-45, 1994.

97. Schwartz S.M., Reidy M.A., O'Brien E.R. Assessment of factors important in atherosclerotic occlusion and restenosis. Thromb. Haemost. 74:541-51, 1995.

98. Southgate K.M., Fisher M., Banning A.P., Thurston V.J., Baker A.H., Fabunmi R.P., Groves P.H., Davies M., Newby A.C. Upregulation of basement membranedegrading metalloproteinase secretion after balloon injury of pig carotid arteries. Circ. Res. 79:1177-1187, 1996.

99. Matrisian L.M. The matrix-degrading metalloproteinases. Bioessays $14: 455-463$, 1992.

100. Clowes A.W., Clowes M.M., Kirkman T.R., Jackson C.L., Au Y.P., Kenagy R. Heparin inhibits the expression of tissue-type plasminogen activator by smooth muscle cells in injured rat carotid artery. Circ. Res. 70:1128-36, 1992.

101. Bendeck M.P., Irvin C., Reidy M.A. Inhibition of matrix metalloproteinase activity inhibits smooth muscle cell migration but not neointimal thickening after arterial injury. Circ. Res. 78:38-43, 1996. 
102. Hornebeck W., Brechemier D., Soleilhac J.M., Bourdillon M.C., Robert L. Studies on rat aorta smooth muscle cells' elastase activity. In Reddi AH (eds) Extracellular Matrix: Structure and Function. New York, Alan R. Liss, 1985, 269-282.

103. Rabinovitch $M$. Elastase and cell extracellular matrix interactions in the pathogenesis of intimal proliferation. In Atherosclerosis, Woodford,E.P. Davignon,J., Sniderman, A. eds. New York: Elsevier, pp. 338-349.

104. Ye C., Rabinovitch M. Inhibition of elastolysis by SC-37698 reduces development and progression of monocrotaline pulmonary hypertension. Am. J. Physiol. 261:H1255-H1267, 1991.

105. Cowan B., Baron O., Crack J., Coulber C., Wilson G.J., Rabinovitch M. Elafin, a serine elastase inhibitor, attenuates post-cardiac transplant coronary arteriopathy and reduces myocardial necrosis in rabbits following heterotopic cardiac transplantation. J. Clin. Invest. 97:2452-2468, 1996.

106. Glagov S., Weisenberg E., Zarins C.K., Stankunavicius R., Kolettis G.J. Compensatory enlargement of human atherosclerotic coronary arteries. N. Engl. J. Med. 316:1371-5, 1987.

107. Post M.J., Borst C., Kuntz R.E. The relative importance of arterial remodeling compared with intimal hyperplasia in lumen renarrowing after balloon angioplasty. A study in the normal rabbit and the hypercholesterolemic Yucatan micropig [see comments]. Circulation 89:2816-21, 1994.

108. Kakuta T., Currier J.W., Haudenschild C.C., Ryan T.J., Faxon D.P. Differences in compensatory vessel enlargement, not intimal formation, account for restenosis after angioplasty in the hypercholesterolemic rabbit model. Circulation 89:2809-15, 1994.

109. Lafont A., Guzman L.A., Whitlow P.L., Goormastic M., Cornhill J.F., Chisolm G.M. Restenosis after experimental angioplasty. Intimal, medial, and adventitial changes associated with constrictive remodeling. Circ. Res. 76:996-1002, 1995.

110. Leverque M.J., Nerem R.M. The proliferation of subconfluent endothelial cell monolayers exposed to shear stress. FASEB J. 2:419A, 1988.

111. Farhadian F., Contard F., Sabri A., Samuel J.L., Rappaport L. Fibronectin and basement membrane in cardiovascular organogenesis and disease pathogenesis. Cardiovasc. Res. 32:433-42, 1996.

112. Molossi S., Clausell N., Rabinovitch M. Coronary artery endothelial interleukin$1 B$ mediates enhanced fibronectin production related to post-cardiac transplant arteriopathy in piglets. Circulation 88:248-256, 1993.

113. Molossi S., Clausell N., Rabinovitch M. Reciprocal induction of tumor necrosis factor-a and interleukin-1B activity mediates fibronectin synthesis in coronary artery smooth muscle cells. J. Cell. Physiol. 163:19-29, 1995. 
114. Clausell N., Rabinovitch $M$. Increased smooth muscle cell fibronectin mRNA transcription and protein synthesis associated with post-cardiac transplant coronary arteriopathy is regulated by increased IL-1B receptors. Circulation 86:769, 1992.

115. Clausell N., Rabinovitch M. Upregulation of fibronectin synthesis by interleukin$1 B$ in coronary artery smooth muscle cells is associated with the development of the post-cardiac transplant arteriopathy in piglets. J. Clin. Invest. 92:1850-1858, 1992.

116. Hinek A., Molossi S., Rabinovitch M. Functional interplay between interleukin-1 receptor and elastin binding protein controls fibronectin synthesis in coronary artery smooth muscle cells. Exp. Cell Res. 225:122-131, 1996.

117. Weintraub A.S., Giachelli C.M., Krauss R.S., Almeida M., Taubman M.B. Autocrine secretion of osteopontin by vascular smooth muscle cells regulates their adhesion to collagen gels. Am. J. Pathol. 149:259-72, 1996.

118. Clark R.A., Tonnesen M.G., Gailit J., Cheresh D.A. Transient functional expression of alphaVbeta 3 on vascular cells during wound repair. Am. J. Pathol. 148:1407-21, 1996.

119. Boudreau N., Turley E., Rabinovitch M. Fibronectin, hyaluronan and a hyaluronan binding protein contribute to increased ductus arteriosus smooth muscle cell migration. Dev. Biol. 143:235-247, 1991.

120. Boudreau N., Rabinovitch $M$. Developmentally regulated changes in extracellular matrix in endothelial and smooth muscle cells in the ductus arteriosus may be related to intimal proliferation. Lab. Invest. 64:187-199, 1991.

121. Shekhonin B.V., Domogatsky S.P., Idelson G.L., Koteliansky V.E., Rukosuev V.S. Relative distribution of fibronectin and type I, III, IV, V collagens in normal and atherosclerotic intima of human arteries. Atherosclerosis 67:9-16, 1987.

122. Bauters C., Marotte F., Hamon M., Oliviéro P., Farhadian F., Robert V., Samuel J.L., Rappaport L. Accumulation of fetal fibronectin mRNAs after balloon denudation of rabbit arteries. Circulation 92:904-911, 1995.

123. Clausell N., Correa de Lima V., Molossi S., Liu P., Turley E.A., Gotlieb A.I., Adelman A.G., Rabinovitch M. Expression of tumor necrosis factor alpha and accumulation of fibronectin in coronary artery restenotic lesions retrieved by atherectomy. Br. Heart J. 73:534-549, 1995.

124. Hinek A., Rabinovitch M., Keeley F., Okamura-Oho Y., Callahan J. The 67-kD elastin/laminin-binding protein is related to an enzymatically inactive, alternatively spliced from of B-galactosidase. J. Clin. Invest. 91:1198-1205, 1993.

125. Hinek A. Nature and the multiple functions of the 67-kD elastin/laminin binding protein. Cell Adhes. Commun. 2:185-193, 1994.

126. Hinek A., Wrenn D.S., Mecham R.S., Barondes S.H. The elastin receptor: a galactoside-binding protein. Science 239:1539-1541, 1988. 
127. Hinek A., Boyle J., Rabinovitch M. Vascular smooth muscle cell detachment from elastin and migration through elastic laminae is promoted by chondroitin sulfateinduced "shedding" of the 67-kDa cell surface elastin binding protein. Exp. Cell Res. 203:344-353, 1992.

128. Hinek A., Mecham R.P., Keeley F., Rabinovitch M. Impaired elastin fiber assembly related to reduced 67-kD elastin-binding protein in fetal lamb ductus arteriosus and cultured aortic smooth muscle cells treated with chondroitin sulfate. $\mathrm{J}$. Clin. Invest. 88:2083-2094, 1991.

129. Privetera S., Prody C.A., Callahan C.A., Hinek A. The 67-kDa enzymatically inactive alternatively spliced variant of b-galactosidase is identical to the elastin/lamininbinding protein. (Manuscript submitted to J. Cell Biol. Nov. 1997).

130. Ciabattoni G., Ujang S., Sritara P., Andreotti F., Davies G., Simonetti B.M., Patrono C., Maseri A. Aspirin, but not heparin, suppresses the transient increase in thromboxane biosynthesis associated with cardiac catheterization or coronary angioplasty. J. Am. Coll. Cardiol. 21:1377-81, 1993.

131. Barnathan E.S., Schwartz J.S., Taylor L., Laskey W.K., Kleaveland J.P., Kussmaul W.G., Hirshfeld J.J. Aspirin and dipyridamole in the prevention of acute coronary thrombosis complicating coronary angioplasty. Circulation 76:125-34, 1987.

132. Faxon D.P., Sanborn T.A., Haudenschild C.C., Ryan T.J. Effect of antiplatelet therapy on restenosis after experimental angioplasty. Am. J. Cardiol. 53:72C-76C, 1984.

133. Schwartz L., Bourassa M.G., Lesperance J., Aldridge H.E., Kazim F., Salvatori V.A., Henderson M., Bonan R., David P.R. Aspirin and dipyridamole in the prevention of restenosis after percutaneous transluminal coronary angioplasty. N. Engl. J. Med. 318:1714-9, 1988.

134. Savage M.P., Goldberg S., Bove A.A., Deutsch E., Vetrovec G., Macdonald R.G., Bass T., Margolis J.R., Whitworth H.B., Taussig A. Effect of thromboxane A2 blockade on clinical outcome and restenosis after successful coronary angioplasty. Multi-Hospital Eastem Atlantic Restenosis Trial (M-HEART II). Circulation 92:3194-200, 1995.

135. Serruys P.W., Rutsch W., Heyndrickx G.R., Danchin N., Mast E.G., Wijns W., Rensing B.J., Vos J., Stibbe J. Prevention of restenosis after percutaneous transluminal coronary angioplasty with thromboxane A2-receptor blockade. A randomized, doubleblind, placebo-controlled trial. Coronary Artery Restenosis Prevention on Repeated Thromboxane-Antagonism Study (CARPORT). Circulation 84:1568-80, 1991.

136. Yabe Y., Nakano H., Muramatsu T., Wagatsuma T. Could a novel TXA2 receptor antagonist (S-1452) reduce restenosis after PTCA in patients with post infarction angina. Circulation 90:I-651, 1994.

137. Yabe Y., Okamoto K., Oosawa H., Miyairi M., Noike H., Aihara M., Muramatu T. Does a thromboxane A2 synthetase inhibitor prevent restenosis after PTCA?. Circulation 80:II-260, 1989. 
138. Jacobs A.K., Weiner B.H., Raizner A. the impact of fish oil on restenosis following coronary angioplasty: The Fish Oil Restenosis Trial (FORT). J. Am. Coll. Cardiol. 23:I$19,1994$.

139. Caims J.A., Gill J.B., Morton,B. Enoxaparine and maxepa for the prevention of angioplasty restenosis (EMPAR). Circulation 90:I-651, 1994.

140. Swanson K.T., Vlietstra R.E., Holmes D.J., Smith H.C., Reeder G.S., Bresnahan J.F., Bove A.A. Efficacy of adjunctive dextran during percutaneous transluminal coronary angioplasty. Am. J. Cardiol. 54:447-8, 1984.

141. Bertrand M.E., Allain H., Lablanche J.M. Results of a randomized trial of ticlopidine versus placebo for prevention of acute closure and restenosis after coronary angioplasty. Circulation 82:III-190, 1990.

142. Clowes A.W., Karnowsky M.J. Supression by heparin of smooth muscle cell proliferation in injured arteries. Nature 265:625-626, 1977.

143. Brack M.J., Ray S., Chauhan A., Fox J., Hubner P.J., Schofield P., Harley A., Gershlick A.H. The Subcutaneous Heparin and Angioplasty Restenosis Prevention (SHARP) trial. Results of a multicenter randomized trial investigating the effects of high dose unfractionated heparin on angiographic restenosis and clinical outcome. J. Am. Coll. Cardiol. 26:947-54, 1995.

144. Currier J.W., Pow T.K., Haudenschild C.C., Minihan A.C., Faxon D.P. Low molecular weight heparin (enoxaparin) reduces restenosis after iliac angioplasty in the hypercholesterolemic rabbit. J. Am. Coll. Cardiol. 118B-125B, 1991.

145. Buchwald A.B., Unterberg C., Nebendahl K., Grone H.J., Wiegand V. Lowmolecular-weight heparin reduces neointimal proliferation after coronary stent implantation in hypercholesterolemic minipigs. Circulation 86:531-7, 1992.

146. Faxon D.P., Spiro T.E., Minor S., Cote G., Douglas J., Gottlieb R., Califf R., Dorosti K., Topol E., Gordon J.B., et a.I. Low molecular weight heparin in prevention of restenosis after angioplasty. Results of Enoxaparin Restenosis (ERA) Trial. Circulation 90:908-14, 1994.

147. Heras M., Chesebro J.H., Penny W.J., Bailey K.R., Badimon L., Fuster V. Effects of thrombin inhibition on the development of acute platelet- thrombus deposition during angioplasty in pigs. Heparin versus recombinant hirudin, a specific thrombin inhibitor. Circulation 79:657-65, 1989.

148. Buchwald A.B., Hammerschmidt S., Stevens J., Goring J., Nebendahl K., Unterberg C. Inhibition of neointimal proliferation after coronary angioplasty by lowmolecular-weight heparin (clivarine) and polyethyleneglycol-hirudin. J. Cardiovasc. Pharmacol. 28:481-7, 1996.

149. Serruys P.W., Herman J.P., Simon R., Rutsch W., Bode C., Laarman G.J., van D.R., vanden Bos A., Umans V.A., Fox K.A. A comparison of hirudin with heparin in the prevention of restenosis after coronary angioplasty. Helvetica Investigators. N. Engl. J. Med. 333:757-63, 1995. 
150. Kanaka S., Takenouchi S., Tajima,T., Dohi Y., Kyo S., Yokote Y., Omoto R. Increased platelet derived growth factor and reduced prostacyclin production in patients with restenosis after percutaneous transluminal coronary angioplasty. Circulation 78:III$290,1988$.

151. Gershlick A.H., Spriggins D., Davies S.W., Syndercombe C.Y., Timmins J., Timmis A.D., Rothman M.T., Layton C., Balcon R. Failure of epoprostenol (prostacyclin, PGI2) to inhibit platelet aggregation and to prevent restenosis after coronary angioplasty: results of a randomised placebo controlled trial. Br. Heart J. 71:7-15, 1994.

152. Bates E.R., McGillem M.J., Mickelson J.K., Pitt B., Mancini G.B. A monoclonal antibody against the platelet glycoprotein $\mathrm{Ilb} / \mathrm{llla}$ receptor complex prevents platelet aggregation and thrombosis in a canine model of coronary angioplasty. Circulation 84:2463-9, 1991.

153. Topol E.J., Califf R.M., Weisman H.F., Ellis S.G., Tcheng J.E., Worley S., Ivanhoe R., George B.S., Fintel D., Weston M., Sigmon K., Anderson K.M., Lee K.L., Willerson J.T. Randomised trial of coronary intervention with antibody against platelet Ilb/llla integrin for reduction of clinical restenosis: results at six months. The EPIC Investigators. Lancet 343:881-6, 1994.

154. Slepian M.J., Massia S.P. Local delivery of a cyclic RGD peptide inhibits neointimal hyperplasia following balloon injury. Circulation 88:I-372, 1994.

155. Raizner A., Hollman J., Demke D., Wakefield L. Beneficial effects of ciprostene in PTCA: A multicentre, randomized, controlled trial. Circulation 78:III-290, 1988.

156. Liu M.W., Roubin G.S., Robinson K.A., Black A.J., Hearn J.A., Siegel R.J., King S.3. Trapidil in preventing restenosis after balloon angioplasty in the atherosclerotic rabbit. Circulation 81:1089-93, 1990.

157. Okamoto S., Inden M., Setsuda M., Konishi T., Nakano T. Effects of trapidil (triazolopyrimidine), a platelet-derived growth factor antagonist, in preventing restenosis after percutaneous transluminal coronary angioplasty. Am. Heart J. 123:1439-44, 1992.

158. Maresta A., Balducelli M., Cantini L., Casari A., Chioin R., Fabbri M., Fontanelli A., Monici P.P., Repetto S., DeServi S., Varni M.D. Trapidil (triazolopyrimidine), a platelet-derived growth factor antagonist, reduces restenosis after percutaneous transluminal coronary angioplasty. Results of the randomized, double-blind STARC study. Studio Trapidil versus Aspirin nella Restenosis Coronarica. Circulation 90:2710-5, 1994.

159. Serruys P.W., Klein W., Tijssen J.P., Rutsch W., Heyndrickx G.R., Emanuelsson H., Ball S.G., Decoster O., Schroeder E., Liberman H. Evaluation of ketanserin in the prevention of restenosis after percutaneous transluminal coronary angioplasty. A multicenter randomized double-blind placebo-controlled trial. Circulation 1588-601, 1993.

160. ACCORD Study Investigators. Nitric oxide donors reduce restenosis after coronary angioplasty: The ACCORD study. J. Am. Coll. Cardiol. 23:I-59A, 1994. 
161. Fraser S.E., Rosete J.D., Schatzman R.C. Suppression by mycophenolate mofetil of the neointimal thickening caused by vascular injury in a rat arterial stenosis model. J. Pharmacol. Exp. Ther. 275:1204-8, 1995.

162. Muller D.W., Ellis S.G., Topol E.J. Colchicine and antineoplastic therapy for the prevention of restenosis after percutaneous coronary interventions. J. Am. Coll. Cardiol. 126B-131B, 1991.

163. Currier J.W., Pow T,K., Haudenschild C.C., Faxon D.P., Ryan T.J. Colchicine inhibits restenosis after iliac angioplasty in the atherosclerotic rabbit. Circulation 80:III$66,1989$.

164. O'Keefe J.J., McCallister B.D., Bateman T.M., Kuhnlein D.L., Ligon R.W., Hartzler G.O. Ineffectiveness of colchicine for the prevention of restenosis after coronary angioplasty. J. Am. Coll. Cardiol. 19:1597-600, 1992.

165. Barath B, Arakawa K., Cao J. Low dose of antitumor agents prevents smooth muscle cell proliferation after endothelial injury. J. Am. Coll. Cardiol.13:252A, 1989.

166. McKenny P.A., Currier J.W., Haudeisschild C.C. Cyclosporin A does not inhibit restenosis in experimental angioplasty. Circulation 85:II-70, 1991.

167. Murphy J.G., Schwartz R.S., Edwards W.D., Cumrud A.R., Ko J., Kennedy K.D., Vliestra R.E. Methotrexate and azathioprine fail to inhibit porcine coronary restenosis. Circulation 82:III-429, 1990.

168. Clowes A.W., Clowes M.M. Kinetics of cellular proliferation after arterial injury. IV. Heparin inhibits rat smooth muscle mitogenesis and migration. Circ. Res. 58:839-845, 1986.

169. Rakugi H., Kim D.K., Krieger J.E., Wang D.S., Dzau V.J., Pratt R.E. Induction of angiotensin converting enzyme in the neointima after vascular injury. Possible role in restenosis. J. Clin. Invest. 93:339-46, 1994.

170. Rakugi H., Wang D.S., Dzau V.J., Pratt R.E. Potential importance of tissue angiotensin-converting enzyme inhibition in preventing neointima formation. Circulation 90:449-55, 1994.

171. Powell J.S., Clozel J.P., Muller R.K., Kuhn H., Hefti F., Hosang M., Baumgartner H.R. Inhibitors of angiotensin-converting enzyme prevent myointimal proliferation after vascular injury. Science 245:186-8, 1989.

172. Lehmann K., Powell J.S. Effect of cilazapril on the proliferative response after vascular damage. J. Cardiovasc. Pharmacol. S19-24, 1993.

173. Lam J.Y.T., Bourassa M.G., Lacoste L., Lachapelle C. Can cilazapril reduce the development of atherosclerotic changes in balloon injured porcine coronary arteries? Circulation 82:III-429, 1990.

174. Multicenter European Research Trial with Cilazapril after Angioplasty to Prevent Transluminal Coronary Obstruction and Restenosis (MERCATOR) Study Group [comment]. Does the new angiotensin converting enzyme inhibitor cilazapril prevent 
restenosis after percutaneous transluminal coronary angioplasty? Results of the MERCATOR study: a multicenter, randomized, double-blind placebo-controlled trial. Circulation 86:100-10, 1992.

175. Desmet W., Vrolix M., De S.I., Van L.J., Willems J.L., Piessens J. Angiotensinconverting enzyme inhibition with fosinopril sodium in the prevention of restenosis after coronary angioplasty. Circulation 89:385-92, 1994.

176. Hoberg E., Kubler W. Calcium-antagonists in preventing restenosis following coronary angioplasty. Cardiologia 225-7, 1991.

177. Corcos T., David P.R., Val P.G., Renkin J., Dangoisse V., Rapold H.G., Bourassa M.G. Failure of diltiazem to prevent restenosis after percutaneous transluminal coronary angioplasty. Am. Heart J. 926-31, 1985.

178. Whitworth H.B., Roubin G.S., Hollman J., Meier B., Leimgruber P.P., Douglas J.J., King S.3., Gruentzig A.R. Effect of nifedipine on recurrent stenosis after percutaneous transluminal coronary angioplasty. J. Am. Coll. Cardiol. 8:1271-6, 1986.

179. Berk B.C., Gordon J.B., Alexander R.W. Pharmacologic roles of heparin and glucocorticoids to prevent restenosis after coronary angioplasty. J. Am. Coll. Cardiol. 111B-117B, 1991.

180. Faxon D.P., Sanborn T.A., Haudenschild C.C., Ryan T.J. Effect of antiplatelet therapy on restenosis after experimental angioplasty. Am. J. Cardiol. 53:72C-76C, 1984.

181. Jonasson L., Holm J., Hansson G.K. Cyclosporin A inhibits smooth muscle proliferation in the vascular response to injury. Proc. Natl. Acad. Sci. U S A 85:2303-6, 1988.

182. Golino P., Ambrosio G., Ragni M., Cirillo R., Willerson J.T., Chiariello M., Rothlein R., Buja L.M. Inhibition of neutrophil adhesion proteins reduces neointimal hyperplasia following artery injury in rabbit carotid arteries. Circulation 90:1-85, 1994.

183. Guzman L.A., Villa A.E., Forudi F. Effect of anti-CD18 adhesion glycoprotein monoclonal antibody on restenosis following balloon angioplasty in the rabbit atherosclerotic model. J. Am. Coll .Cardiol. 23:I-20A, 1994.

184. Hirayama A., Nanto S., Ohara T. Preventative effect on restenosis after PTCA by ebselen: A newly synthesized antiinflammatory agent. J. Am. Coll. Cardiol. 19:259A, 1992.

185. The TREAT Study Investigators. The impact of tranilast on restenosis following coronary angioplasty: The Tranilast Restenosis Following Angioplasty Trial (TREAT). Circulation 90:I-652, 1994.

186. Speedy T.J., March K.L, Wilensky R.L., Aita M., Gradus-Pizlo I., Hathaway D.R. The combination of 8-methoxypsoralen and ultraviolet $A$ light in vivo inhibits smooth muscle cell proliferation after angioplasty. Circulation 88:II-81, 1993. 
187. Epstein S.E., Siegall C.B., Biro S., Fu Y.M., FitzGerald D., Pastan I. Cytotoxic effects of a recombinant chimeric toxin on rapidly proliferating vascular smooth muscle cells. Circulation 84:778-87, 1991.

188. Casscells W., Lappi D.A., Olwin B.B., Wai C., Siegman M., Speir E.H., Sasse J., Baird A. Elimination of smooth muscle cells in experimental restenosis: targeting of fibroblast growth factor receptors. Proc. Natl. Acad. Sci. U S A 89:7159-63, 1992.

189. Pastore C.,Bacha P.A., Pickering .G., Riessen R., Takeshita S., Isner J.M. Local and systemic delivery of DAB 389EGF fusion toxin inhibits neointimal thickening in balloon injured rat carotid arteries. Circulation 88:II-310, 1993.

190. Simons M., Edelman E.R., Rosenberg R.D. Inhibition of neointimal formation by anti-PCNA oligonucleotides in a rat model of arterial injury. Circulation 88:II-368, 1993.

191. Azrin M.A., Mitchel J.F., Pedersen C. Inhibition of smooth muscle cell proliferation in vivo following local delivery of antisense oligonucleotides to c-myc during angioplasty. J. Am. Coll. Cardiol. 23:I-396A, 1994.

192. Shi Y., Galeo A.J., Fard A., Vermani P., Zalewski A. Safety and efficacy of transcatheter delivery of c-myc antisense oligomers in the coronary vasculature. Circulation 90:II-393, 1994.

193. Nagler A., Miao H.Q., Aingom H., Pines M., Genina O., Vlodavsky I. Inhibition of collagen synthesis, smooth muscle cell proliferation, and injury-induced intimal hyperplasia by halofuginone. Arterioscier. Thromb. Vasc. Biol. 17:194-202, 1997.

194. Hawking F. Suramin: with special reference to onchocerciasis. Adv. Pharmacol. Chemother. 15:289-322, 1978.

195. Mitsuya H., Looney D.J., Kuno S., Ueno R., Wong S.F., Broder S. Dextran sulfate suppression of viruses in the HIV family: inhibition of virion binding to CD4+cells. Science 240:646-9, 1988.

196. Broder S., Yarchoan R., Collins J.M., Lane H.C., Markham P.D., Klecker R.W., Redfield R.R., Mitsuya H., Hoth D.F., Gelmann E. Effects of suramin on HTLV-III/LAV infection presenting as Kaposi's sarcoma or AIDS-related complex: clinical pharmacology and suppression of virus replication in vivo. Lancet 2:627-30, 1985.

197. La R.R., Stein C.A., Danesi R., Myers C.E. Suramin, a novel antitumor compound. J. Steroid Biochem. Mol. Biol. 37:893-8, 1990.

198. La R.R., Stein C.A., Myers C.E. Suramin: prototype of a new generation of antitumor compounds. Cancer Cells 2:106-15, 1990.

199. Stein C.A. Suramin: a novel antineoplastic agent with multiple potential mechanisms of action. Cancer Res. 2239-48, 1993.

200. Voogd T.E., Vansterkenburg E.L., Wilting J., Janssen L.H. Recent research on the biological activity of suramin. Pharmacol. Rev. 45:177-203, 1993. 
201. Middaugh C.R., Mach H., Burke C.J., Volkin D.B., Dabora J.M., Tsai P.K., Bruner M.W., Ryan J.A., Marfia K.E. Nature of the interaction of growth factors with suramin. Biochemistry 31:9016-24, 1992.

202. Hosang $M$. Suramin binds to platelet-derived growth factor and inhibits its biological activity. J. Cell. Biochem. 29:265-73, 1985.

203. Strassmann G., D'Alessandro F., Fong M., Nordan R.P., Nickel P., Chizzonite R. Suramin blocks the binding of interleukin-1 to its receptor and neutralizes IL-1 biological activities. Int. J. Immunopharmacol. 16:931-9, 1994.

204. Huang S.S., Huang J.S. Rapid turnover of the platelet-derived growth factor receptor in sis- transformed cells and reversal by suramin. Implications for the mechanism of autocrine transformation. J. Biol. Chem. 263:12608-18, 1988.

205. Moscatelli D., Quarto N. Transformation of NIH 3T3 cells with basic fibroblast growth factor or the hst/K-fgf oncogene causes downregulation of the fibroblast growth factor receptor: reversal of morphological transformation and restoration of receptor number by suramin. J. Cell Biol. 109:2519-27, 1989.

206. Larsen A.K. Suramin: an anticancer drug with unique biological effects. Cancer Chemother. Pharmacol. 32:96-8, 1993.

207. Cooper M.R., Danesi R., LaRocca R., Home M., Myers C.E. Suramin induces the production of antiproliferative heparan sulfate in patients with malignancies. Proc. Am. Assoc. Cancer. Res. 31:200, 1990.

208. Garrido T., Riese H.H., Aracil M., Perez A.A. Endothelial cell differentiation into capillary-like structures in response to tumour cell conditioned medium: a modified chemotaxis chamber assay. Br. J. Cancer. 71:770-5, 1995.

209. Coomber B.L. Centrosome reorientation in regenerating endothelial monolayers requires bFGF. J. Cell. Biochem. 52:289-96, 1993.

210. Kondo H., Matsuda R., Yonezawa Y. Autonomous migration of human fetal skin fibroblasts into a denuded area in a cell monolayer is mediated by basic fibroblast growth factor and collagen. In Vitro Cell. Dev. Biol. Anim. 929-35, 1993.

211. Tonge D.A., Aaronson O.S., Golding J.P., Jaggers D. Cellular migration and axonal outgrowth from adult mammalian peripheral nerves in vitro. J. Neurobiol. 29:15164, 1996.

212. Takano S., Gately S., Neville M.E., Herblin W.F., Gross J.L., Engelhard H., Perricone M., Eidsvoog K., Brem S. Suramin, an anticancer and angiosuppressive agent, inhibits endothelial cell binding of basic fibroblast growth factor, migration, proliferation, and induction of urokinase-type plasminogen activator. Cancer Res. 54:2654-60, 1994.

213. Pepper M.S., Vassalli J.D., Wilks J.W., Schweigerer L., Orci L., Montesano R. Modulation of bovine microvascular endothelial cell proteolytic properties by inhibitors of angiogenesis. J. Cell. Biochem. 55:419-34, 1994. 
214. Nakajima M., DeChavigny A., Johnson C.E., Hamada J., Stein C.A., Nicolson G.L. Suramin. A potent inhibitor of melanoma heparanase and invasion. J. Biol. Chem. 266:9661-6, 1991.

215. Lokshin A., Levitt M.L. Effect of suramin on squamous differentiation and apoptosis in three human non-small-cell lung cancer cell lines. J. Cell. Biochem. Suppl. 24:186-97, 1996.

216. Tu S.M., McConnell K., Marin M.C., Campbell M.L., Fernandez A., von E.A., McDonnell T.J. Combination adriamycin and suramin induces apoptosis in bcl-2 expressing prostate carcinoma cells. Cancer Lett. 93:147-55, 1995.

217. Crowley S.T., Ray C.J., Nawaz D., Majack R.A., Horwitz L.D. Multiple growth factors are released from mechanically injured vascular smooth muscle cells. Am. J. Physiol. H1641-7, 1995.

218. Weber H., Taylor D.S., Molloy C.J. Angiotensin II induces delayed mitogenesis and cellular proliferation in rat aortic smooth muscle cells. Correlation with the expression of specific endogenous growth factors and reversal by suramin. J. Clin. Invest. 93:788-98, 1994.

219. Sjolund M., Thyberg J. Suramin inhibits binding and degradation of plateletderived growth factor in arterial smooth muscle cells but does not interfere with autocrine stimulation of DNA synthesis. Cell Tissue Res. 256:35-43, 1989.

220. Asada Y., Tsuneyoshi A., Marutsuka K., Sumiyoshi A. Suramin inhibits intimal thickening following intimal injury in the rabbit aorta in vivo. Cardiovasc. Res. 28:1166-9, 1994.

221. Strauss B.H., Robinson R., Batchelor W.B., Chisholm R.J., Ravi G., Natarajan M.K., Logan R.A., Mehta S.R., Levy D.E., Ezrin A.M., Keeley F.W. In vivo collagen turnover following experimental balloon angioplasty injury and the role of matrix metalloproteinases. Circ. Res. 79:541-50, 1996.

222. Ross R. The smooth muscle cell II: Growth of smooth muscle in culture and formation of elastic fibres. J. Cell Biol. 50:172-179, 1971.

223. Durante W., Liao L., Iftikhar I., Cheng K., Schafer A.I. Platelet-derived growth factor regulates vascular smooth muscle cell proliferation by inducing cationic amino acid transporter gene expression. J. Biol. Chem. 271:11838-43, 1996.

224. Sarkar R., Meinberg E.G., Stanley J.C., Gordon D., Webb R.C. Nitric oxide reversibly inhibits the migration of cultured vascular smooth muscle cells. Circ. Res. 78:225-30, 1996.

225. Majack R.A., Clowes A.W. Inhibition of vascular smooth muscle cell migration by heparin-like glycosaminoglycans. J. Cell. Physiol. 118:253-6, 1984.

226. Stadius M.L., Rowan R., Fleischhauer J.F., Kemoff R., Billingham M., Gown A.M. Time course and cellular characteristics of the iliac artery response to acute balloon injury. An angiographic, morphometric, and immunocytochemical analysis in the cholesterol-fed New Zealand white rabbit. Arterioscler. Thromb. 12:1267-73, 1992. 
227. Libby P., Salomon R., Payne D., Schoen F., Pober J. Functions of vascular wall cells related to development of transplantation-associated coronary arteriosclerosis. Transplant. Proc. 21:3677-3684, 1989.

228. Sato Y., Rifkin D.B. Autocrine activities of basic fibroblast growth factor: regulation of endothelial cell movement, plasminogen activator synthesis, and DNA synthesis. J. Cell Biol. 107:1199-205, 1988.

229. Presta M., Tiberio L., Rusnati M., Dell'Era P., Ragnotti G. Basic fibroblast growth factor requires a long-lasting activation of protein kinase $\mathrm{C}$ to induce cell proliferation in transformed fetal bovine aortic endothelial cells. Cell. Regul. 2:719-26, 1991.

230. Lindner V., Olson N.E., Clowes A.W., Reidy M.A. Inhibition of smooth muscle cell proliferation in injured rat arteries. Interaction of heparin with basic fibroblast growth factor. J. Clin. Invest. 90:2044-2049, 1992. 


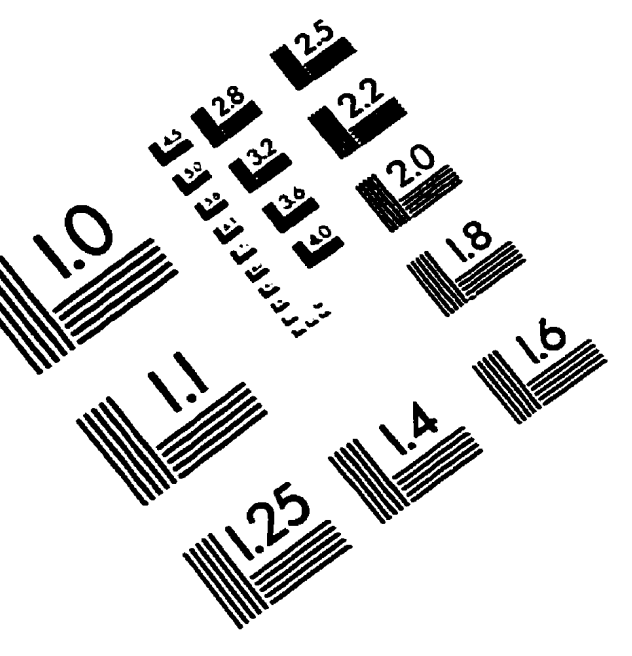

\section{IMAGE EVALUATION \\ TEST TARGET (QA-3)}
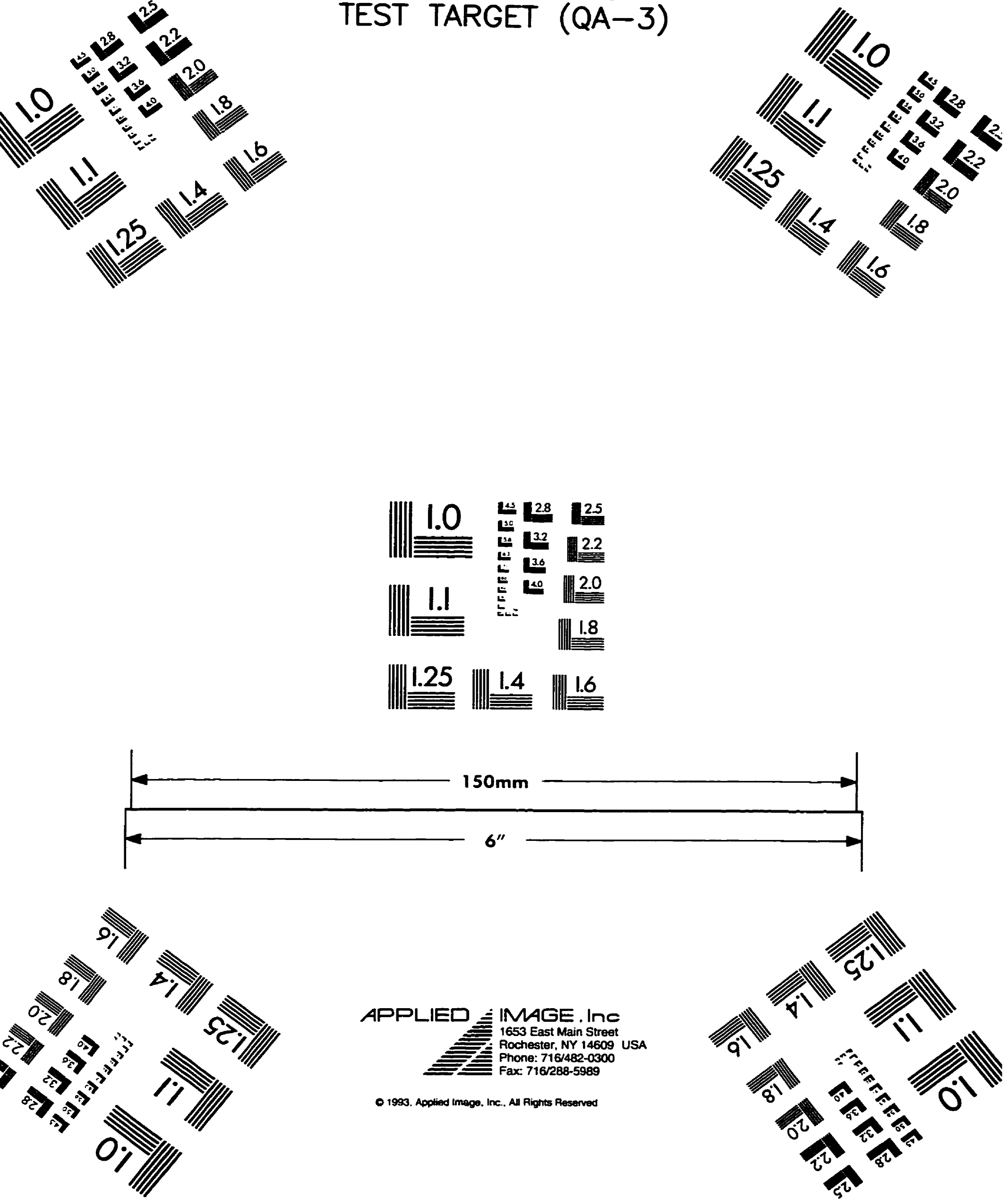

APPLIED 三 IMAGE. InC

1653 East Main Street

Rochester, NY 14609 USA

Phone: 716/482-0300

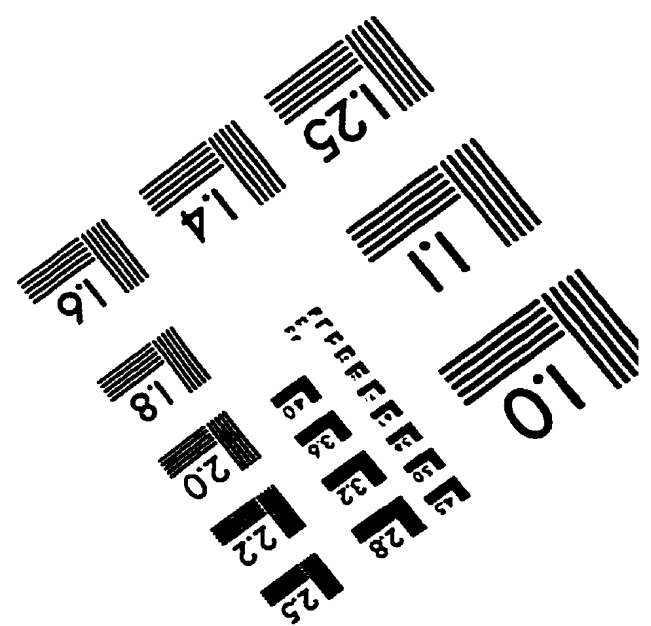

- 1993. Applied tmage. Inc. All Rights Reserved 